San Jose State University

SJSU ScholarWorks

Master's Theses

Master's Theses and Graduate Research

1989

\title{
Effect of particle size and concentration on the mixing time of ammonium sulfate and polybutadiene
}

Winston Teddy Mah

San Jose State University

Follow this and additional works at: https://scholarworks.sjsu.edu/etd_theses

\section{Recommended Citation}

Mah, Winston Teddy, "Effect of particle size and concentration on the mixing time of ammonium sulfate and polybutadiene" (1989). Master's Theses. 3156.

DOI: https://doi.org/10.31979/etd.unub-3a2v

https://scholarworks.sjsu.edu/etd_theses/3156

This Thesis is brought to you for free and open access by the Master's Theses and Graduate Research at SJSU ScholarWorks. It has been accepted for inclusion in Master's Theses by an authorized administrator of SJSU ScholarWorks. For more information, please contact scholarworks@sjsu.edu. 


\section{INFORMATION TO USERS}

The most advanced technology has been used to photograph and reproduce this manuscript from the microfilm master. UMI films the text directly from the original or copy submitted. Thus, some thesis and dissertation copies are in typewriter face, while others may be from any type of computer printer.

The quality of this reproduction is dependent upon the quality of the copy submitted. Broken or indistinct print, colored or poor quality illustrations and photographs, print bleedthrough, substandard margins, and improper alignment can adversely affect reproduction.

In the unlikely event that the author did not send UMI a complete manuscript and there are missing pages, these will be noted. Also, if unauthorized copyright material had to be removed, a note will indicate the deletion.

Oversize materials (e.g., maps, drawings, charts) are reproduced by sectioning the original, beginning at the upper left-hand corner and continuing from left to right in equal sections with small overlaps. Each original is also photographed in one exposure and is included in reduced form at the back of the book. These are also available as one exposure on a standard $35 \mathrm{~mm}$ slide or as a $17^{\prime \prime} \times 23^{\prime \prime}$ black and white photographic print for an additional charge.

Photographs included in the original manuscript have been reproduced xerographically in this copy. Higher quality $6^{\prime \prime} \times 9^{\prime \prime}$ black and white photographic prints are available for any photographs or illustrations appearing in this copy for an additional charge. Contact UMI directly to order.

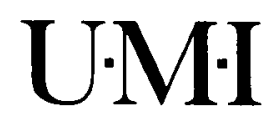

University Microfilms International

A Bell \& Howell Information Company

300 North Zeeb Road, Ann Arbor, MI 48106-1346 USA

$313 / 761-4700 \quad 800 / 521-0600$ 

Effect of particle size and concentration on the mixing time of ammonium sulfate and polybutadiene

Mah, Winston Teddy, M.S.

San Jose State University, 1989 



\title{
EFFECT OF PARTICLE SIZE AND CONCENTRATION \\ ON THE MIXING TIME OF \\ AMMONIUM SULFATE AND POLYBUTADIENE
}

\author{
A Thesis \\ Presented to \\ The Faculty of the Department of Chemical Engineering \\ San Jose State University \\ In Partial Fulfillment \\ of the Requirements for the Degree \\ Master of Science
}

By

Winston Teddy Mah

August, 1989 
APPROVED FOR THE DEPARTMENT OF CHEMICAL ENGINEERING
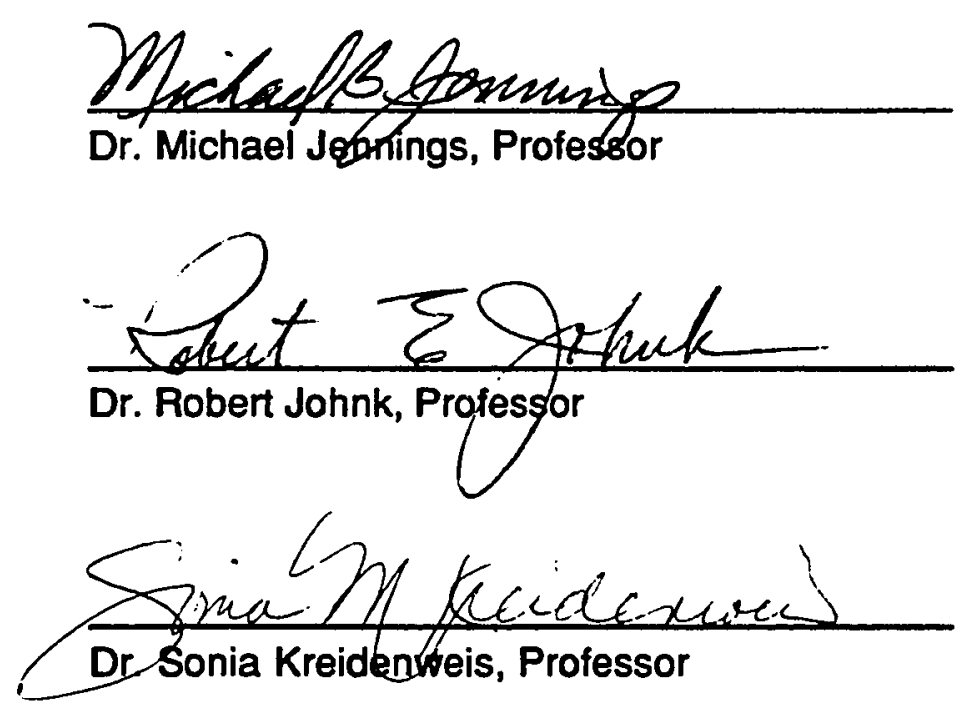

APPROVED FOR THE UNIVERSITY

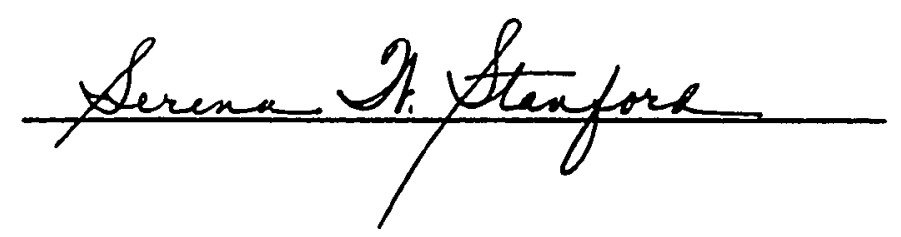




\section{ABSTRACT}

A semi-empirical model is proposed for the mixing time of ammonium sulfate in polybutadiene as a function of agitation rate, fluid viscosity, and size and concentration of the solid particles. Batch mixing was performed in a one-gallon mixer. The current study was focused on the effect of particle size and concentration on the mixing time, while maintaining constant agitation rate and initial fluid viscosity. Three particle sizes were analyzed: 0-75 microns, 75 microns- 150 microns, and 180 microns-250 microns. Concentration data were ascertained by sampling the suspension and analyzing the samples for solids content.

Minimum time required for homogeneity was found to be shorter with the larger-sized particles. For a given particle size, minimum tịme for homogeneity decreased with increasing concentration. 


\section{ACKNOWLEDGEMENTS}

I wish to acknowledge the many persons who have contributed either directly or indirectly with this work:

Douglas Kercher, Stuart MacPherson, David Kinghorn, Peter Wang, and Maurino Flora for their assistance with data collection.

Dr. Michael Jennings for his advice, helpful discussions, and enthusiasm in this work.

Dr. Robert Johnk and Dr. Sonia Kreidenweis for their assistance during the revision of the manuscript.

Dr. R. Richard Miller, Mr. Ed Lee, Mr. Peter Aiello, and Mr. John Denham, of United Technologies Chemical Systems, and Dr. Clayton Henderson for their comments and assistance with the rheological analyses.

My grandparents, Mr. and Mrs. Teddy G. Mah, my parents, Mr. and Mrs. Eddy Mah, and my brother and sisters for their love and support. 
TABLE OF CONTENTS

\section{PAGE}

INTRODUCTION

1

THEORY

PREVIOUS LIQUID-LIQUID

MIXING MODELS

4

DEVELOPMENT OF THE

SEMI-EMPIRICAL

SLURRY-MIXING MODEL

EXPERIMENTAL PROCEDURE

RESULTS

ANALYSIS

CONCLUSIONS

APPENDICES

NOMENCLATURE

71

REFERENCES

73

EXPERIMENTAL DETAILS

75

EXPERIMENTAL DATA 


\section{LIST OF TABLES}

NUMBER

PAGE

1 Equation 21 Correlated from Experimental Data

2 Characteristic Times and Damping Factors

3 Damping Factors for Constant Characteristic Time

4 Experimentally Determined Mixing Times

5 Values for $E$ and $V_{0}$ in the

Hildebrand/Batschinski Equation

6 Experimental and Hildebrand/Batschinski

Determined Viscosities for Particles Sized $<75 \mu$

7 Experimental and Hildebrand/Batschinski Determined Viscosities for Particles Sized $75 \mu-150 \mu$

8 Experimental and Hildebrand/Batschinski

Determined Viscosities for Particles Sized $180 \mu-250 \mu$

$9 \quad$ Values for $E$ and $m$ in the Modified Hildebrand/Batschinski Equation

10 Experimental and Modified

Hildebrand/Batschinski Determined

Viscosities for Particles Sized $<75 \mu$ 


\section{LIST OF TABLES}

NUMBER

PAGE

11 Experimental and Modified

Hildebrand/Batschinski Determined

Viscosities for Particles Sized $75 \mu-150 \mu$

57

12 Experimental and Modified

Hildebrand/Batschinski Determined

Viscosities for Particles Sized 180 $\mu-250 \mu$

59

13 Viscosities of Mixtures of Polybutadiene and Ammonium Sulfate (Size $<75 \mu$ )

94

14 Viscosities of Mixtures of Polybutadiene and Ammonium Sulfate $(75 \mu-150 \mu)$

95

15 Viscosities of Mixtures of Polybutadiene and Ammonium Sulfate $(180 \mu-250 \mu)$

96

16 Concentrations and Pressures for

Viscoelasticity

97 


\section{LIST OF FIGURES}

NUMBER

PAGE

1 Viscosity Behavior for Polybutadiene 7

2 Schematic of Mixing Time Data

3 Damped Vibrator

13

4 Experimental Apparatus $\quad 24$

5 Experimental Data, Batch Mixing 30

6 Equation 21 Correlated to Experimental Data

7 Displacement Representation of Experimental Data

8 Graphical Representation of Correlation 36

9 Viscosity of Ammonium Sulfate/Polybutadiene Slurries: Solids Size $<75 \mu$

10 Viscosity of Ammonium Sulfate/Polybutadiene Slurries: Solids Size $75 \mu-150 \mu$

11 Viscosity of Ammonium Sulfate/Polybutadiene Slurries: Solids Size $180 \mu-250 \mu$

12 Viscosity Analysis Using

Hildebrand/Batschinski Equation 


\section{LIST OF FIGURES}

\section{NUMBER}

PAGE

13 System Pressure for Initial Viscoelastic

Behavior in Ammonium Sulfate/Polybutadiene

Slury as a Function of Concentration:

Solids Addition

62

14 System Pressure for Initial Viscoelastic

Behavior in Ammonium Sulfate/Polybutadiene

Slurry as a Function of Concentration:

Polymer Addition

63

15 June 6, 1988: Experimental Data 79

16 June 11, 1988: Experimental Data 80

17 June 25, 1988: Experimental Data 81

18 July 22, 1988: Experimental Data 82

19 December 16, 1987: Experimental Data 83

20 January 1, 1988: Experimental Data 84

21 January 8, 1988: Experimental Data 85

22 January 12, 1988: Experimental Data 86

23 January 22, 1988: Experimental Data 87

24 February 16, 1988: Experimental Data 88

25 February 19, 1988: Experimental Data 89 


\section{LIST OF FIGURES}

NUMBER

PAGE

26 February 27, 1988: Experimental Data

90

27 March 6, 1988: Experimental Data

91

28 March 13, 1988: Experimental Data

92

29 March 18, 1988: Experimental Data

93 


\section{INTRODUCTION}

A propellant is a material which when burned generates gaseous molecules at high temperature [1]. The propellant must contain both oxidizers and fuel since the combustion must be self sustaining in the absence of ambient oxidizer.

Propellants can be classified by their physical state, as a liquid or solid propellant. Solid propellants are further classified as homogeneous, heterogeneous, or composite. A homogeneous solid propellant contains oxidizer and fuel that are chemically linked in the propellant structural matrix. An example of a homogeneous solid propellant is the double-base propellant prepared from nitroglycerin and nitrocellulose [2]. The oxidizing and reducing agents are contained within the same structure and the nitroglycerin plasticizes the high molecular weight nitrocellulose to give a rubbery mass. When the oxidizer and fuel are physically mixed in the propellant structure the solid propellant is called heterogeneous. This type of propellant consists of three basic components: an organic polymer which serves as both binder and fuel, a solid oxidizer, and a combustible metal additive which provides the primary source of thermal energy. The solid propellant is a composite when both homogeneous and heterogeneous components are present in some combination. This research examines the mixing behavior for heterogeneous solid propellant.

The heterogeneous solid propellant goes through different phases 
while in production. Incremental amounts of solids are mixed into the mixture of liquid binder and solids. With the addition of solids the mixture is transformed from a liquid state to that of a slurry, the solids content attaining a value as high as $94 \%$ by weight [3]. The final production step is the addition of a curing agent into the slurry prior to casting of the propellant. This addition causes the slurry to become a polymerized solid in the shape of the cast model.

In the production of solid propellant, the primary objective of mixing is to produce a mix that has reliable and reproducible ballistic properties. This objective may be achieved if all components in the mix are thoroughly dispersed. Mixing is a process by which local differences in concentration of a tracer or in a quantitatively measurable physical property, such as temperature, between the local and bulk are minimized. This objective may be achieved if the mixture has been agitated for sufficient time. Mixing time, which may be defined as the time necessary to achieve the required uniformity in all parts of the mixing volume, is an important parameter in comparing the effectiveness of different agitation systems. It provides a simple numerical measure of results of mixing in a complex three dimensional flow field in a vessel. Parameters that affect the mixing time include agitator speed, volume of material, particular mixer geometry, and component characteristics.

Numerous semi-empirical models have been developed for liquid/liquid mixing processes. These liquid mixing models have limited 
application to mixing of solids in fluids. The liquid models do not allow for particle size to be included as a variable and they consider molecular diffusion to be significant relative to convective diffusion. Particles are present in slurries and molecular diffusion is not a significant consideration in these systems. Slurries typically have higher effective viscosities than materials considered for the liquid models, especially at higher solids concentrations. Another factor in slurry mixing is the presence of gases in the mixture. Gases may be either in solution or entrained in the slurry during the mixing process, so the actual system contains three phases.

The ultimate objective of this research program at San Jose State University is the development of a comprehensive slurry mixing model that includes the effects not present in liquid-mixing models and that can predict the minimum mixing time required to achieve homogeneity in a concentrated slurry after a batch addition. This mixing model contains parameters which are to be related to agitation rate, fluid viscosity, and particle size and concentration. This thesis project examines the effect of particle size and concentration on the mixing time required to achieve homogeneity. 


\section{IHEORY}

This section is presented in two subsections. The first subsection describes some of the previous mixing models proposed. The second presents the development of the semi-empirical slurry-mixing model.

Previous Liquid-Liquid Mixing Models.

A survey of the literature on mixing concluded that the vast majority of the systems studied were liquid-liquid systems. These studies on the mixing of liquids have generally led to models of a semi-empirical nature. An early study on mixing time was performed by Hoogendoorn and den Hartog [4]. They proposed that the relation between homogeneity and mixing time could be represented by

$$
\frac{p}{100}=1-\exp \left(-c_{H} \theta_{p}\right)
$$

where $p$ denotes the degree of homogeneity and $\theta_{p}$ represents the batch mixing time. The variable $C_{H}$ is an experimentally determined constant. Their study was restricted to batch mixing of water and glycerine and water and molasses mixtures.

Nagata, et. al. [5] were able to correlate their mixing data for viscous carboxymethylcellulose solutions with the equation that stated the product of stirring rate and mixing time is a constant. 


$$
\text { n } \boldsymbol{\theta}=\text { constant. }
$$

Reasoning that macro-mixing, caused by turbulent motion, and micromixing, caused by molecular diffusion, gave mixing times that were additive, Brennan and Lehrer [6] developed relations representing these two times.

$$
\theta_{T}=\frac{-z^{2}}{\Psi N d(\phi H(D-d) d)^{\frac{1}{3}}}\left(\frac{D}{d}\right)^{2} \log (1-\hat{c})
$$

and

$$
\theta_{M}=\frac{-v^{\frac{3}{2}}\left(v d^{2} w \frac{\pi}{4}\right)^{\frac{1}{4}}}{24\left(\phi N^{3} d^{5}\right)^{\frac{1}{2}} D_{A B M}} \log (1-\hat{c})
$$

The dimensions of the impeller are represented by $d$, the diameter, and $w$, the blade width. The blade rotates at a impeller speed $\mathrm{N}$. H is the depth of the liquid and $V$ is the volume of the liquid in a vessel of diameter $D$. Diffusion of one liquid into the second occurs over a distance $z$ and the diffusivity is denoted by $D_{A B M}$. The kinematic viscosity is present in Equation 4 as $v . \phi, \Psi$, and $\hat{C}$ are dimensionless numbers. The mixing medium employed was water with liquid tracer material.

Moo-Young, et. al. [7] obtained data which were correlated by

$$
N t_{p}=A^{\prime} R e^{a^{\prime}}
$$

Equation 5 is similar to the equation proposed by Nagata, et al., but differs in that Moo-Young et. al. defines the constant to be a function of the Reynolds number. $A^{\prime}$ and $a^{\prime}$ are empirical constants for a given geometry. The 
Reynolds number was given as:

$$
R e=\frac{D N^{2-f} \rho B^{1-f}}{J}\left(\frac{4 f}{3 f+1}\right)^{f}
$$

The systems analyzed were aqueous solutions of sodium carboxymethylcellulose and water with aqueous solutions of commercial sugar and glucose. Moo-Young, et. al. developed their equation from an expression developed by van de Vusse [8]. Van de Vusse found that the product of impeller rotational speed and mixing time was independent of Reynolds number for the mixing of water and solutions of acetic acid and of water and solutions of glycerol.

Development of the Semi-Empirical Slurry-Mixing Model.

Although models have been presented for mixing of liquids there is not a generally accepted model for mixing in a slurry system. In the present work the system studied was ammonium sulfate and aerated polybutadiene, which simulates the solid/liquid system actually used for propellants. The ammonium sulfate as salt crystals was mixed into the polymer, a Bingham plastic. A Bingham plastic is a plastic that does not flow until the external stress exceeds a critical threshold value. When the threshold value has been exceeded, the plastic exhibits Newtonian flow. Ed Lee of United Technologies Chemical Systems tested the polymer for viscosity and the results are shown on Figure 1. Addition of ammonium sulfate to 


\section{FIGURE 1}

\section{VISCOSITY BEHAVIOR FOR POLYBUTADIENE}

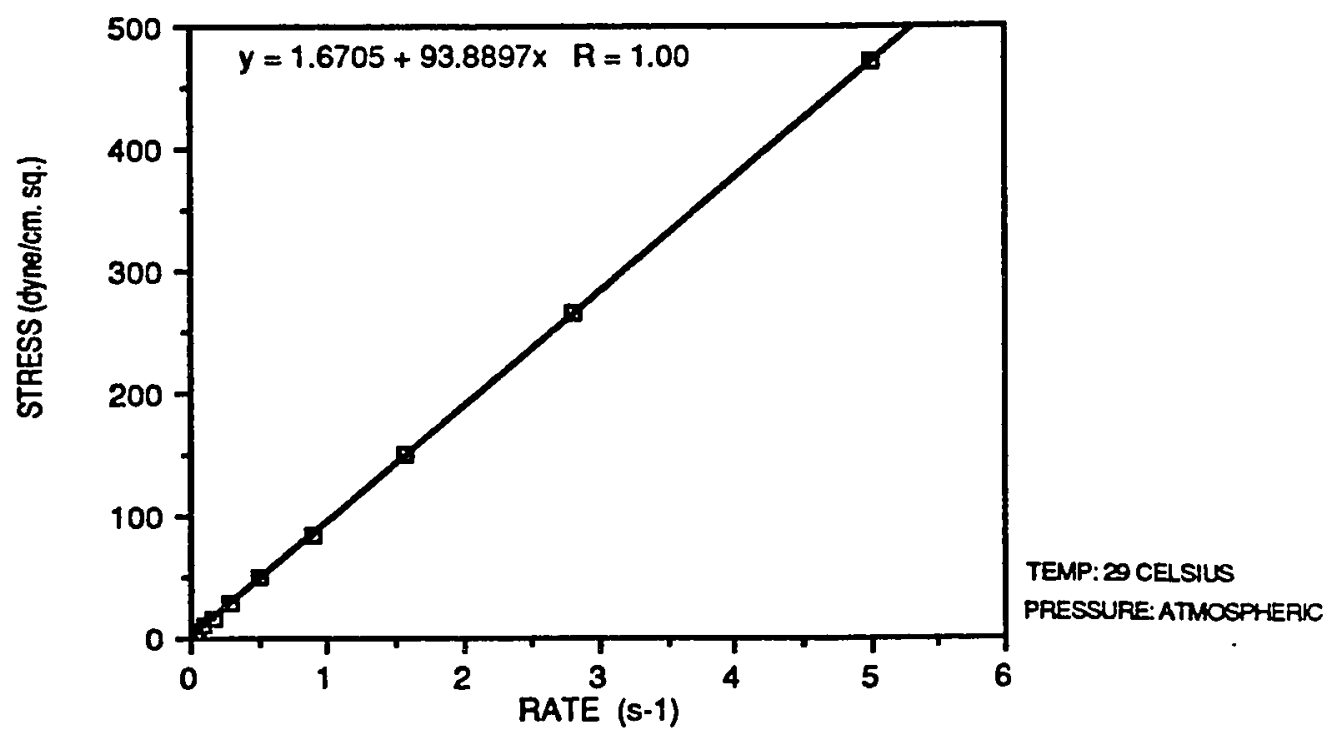


polybutadiene resulted in a mixture which deviated from the Bingham fluid behavior.

In liquid mixing the two primary routes to mixture homogeneity are molecular diffusion and convection. In the system of ammonium sulfate and polybutadiene molecular diffusion is assumed not to occur for two reasons. The first reason is that the ammonium sulfate is insoluble in polybutadiene. The other reason is that the system does not entirely consist of molecules but particles of the ammonium sulfate, which are larger than the polymer molecule. The bulk of the ammonium sulfate used was sized between 35 microns and 250 microns. Polymer chains are rarely extended to their full length; however, if the chain could be stretched, a chain of molecular weight 100,000 would stretch 0.9 microns and a chain of 500,000 in molecular weight would extend 4.5 microns. Other forces that may contribute to mixing include settling (gravitational acceleration), Brownian motion (though certainly limited for a system with large particles and polymer as the fluid), and agglomeration (interparticle forces).

Mixing in the present system was assumed to occur due to convective motion, a conclusion that was verified by initial studies of the process. These initial studies were conducted to characterize the flow patterns in the mixing process and to provide the basis for the mixing model. One such study was the mixing of two superimposed layers of different colors. The clear polybutadiene was combined with ammonium sulfate to form a white colored material. A black colored material was obtained by combining 
polybutadiene with carbon black. The white material, having a greater density than the black material, was charged into the clear mixing vessel prior to the black material, forming a two-layer initial system. Observations of the mixing revealed that the blades pushed the black material into the white material in a helical manner. Also noted was the absence of diffusion, that is, the black material did not penetrate into the white material. This observation was further clarified by mixing black $A B S$ plastic particles into the clear polybutadiene. ABS plastic was chosen because its density was similar to the density of the polybutadiene. The plastic particles were initially spread evenly over the surface of the polymer. It was observed that the particles moved due to the fluid flow created by the blades. The particles spiraled in the vertical direction and upon reaching the top and bottom interfaces of the mixing volume, the particles spiraled in the opposite direction.

These observations led to a definition of the mixing flow patterns. On a microscale, solids gain momentum as the blades move through a local region. The velocity is dissipated by the highly viscous material almost immediately after the blade passes. The flow pattern around the blade results in a net vertical and radial displacement for each solid particle. There is no bulk mixing occurring outside of the region occupied by the blade. The net effect is that micromixing phenomena do not form a unique subsystem of the macromixing, so modeling is not useful on a micromixing scale, with respect to project objectives. 
On a macroscale, material in the mixing process moves in a helical pattern from top to bottom, with reflections at the top and bottom interfaces. While a vertical concentration gradient exists in the system, it tends to be in the form of a skewed distribution around a maximum value. The magnitude of this maximum, relative to the average value for the system, decreases with additional mixing. The distribution band also grows wider with additional mixing. The maximum moves down and then up through the mixing volume, with reflections at the top and bottom (and possibly side and center) surfaces.

This observation implies that at any point in the mixing volume, the concentration of solid will fluctuate. The concentration of solids will be greatest when the concentration maximum passes through the point. The difference between the maximum and minimum concentrations decreases as solids are dispersed from the maximum. When the difference is not detectable within experimental error, the concentration at the point maintains a constant value, and the system is said to be homogeneous. This reasoning may also be applied to other points in the mixing vessel. When the concentration at the point is plotted as a function of time, the result is a curve which converges to the homogeneous value with a periodicity related to system variables (Figure 2).

A similar curve has been seen in process control theory as the response of a second order control system to a step input, a decaying sinusoidal curve [9]. A second order system may be represented as a 
FIGURE 2

SCHEMATIC OF MIXING TIME DATA

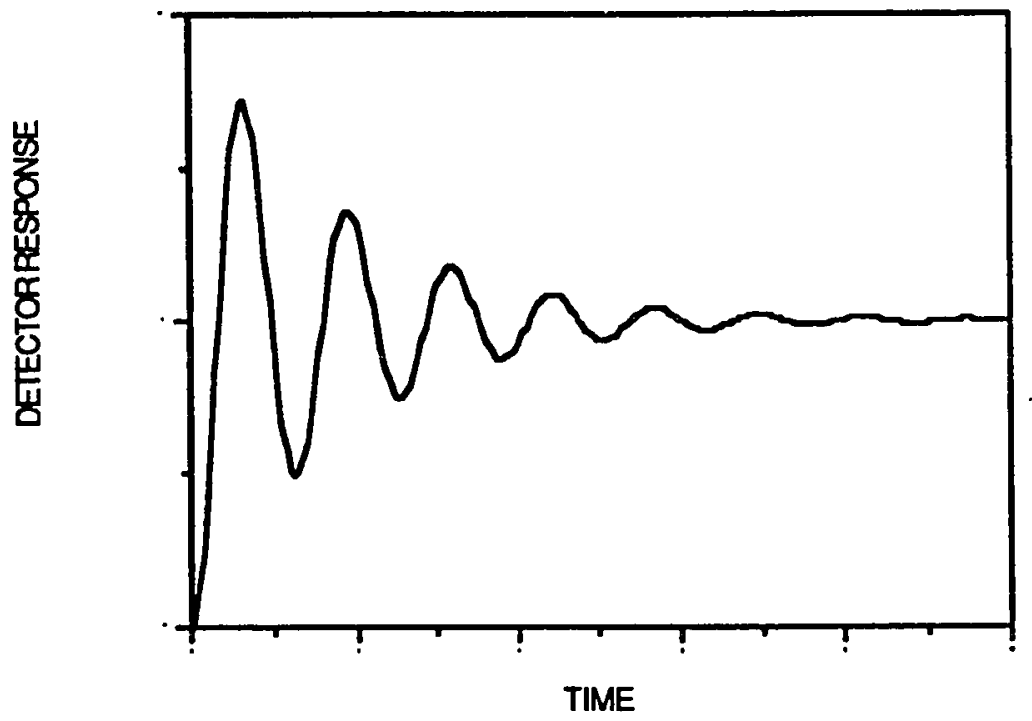


damped vibrator (Figure 3). A weight $W$ is attached to a linear spring and to a viscous dash pot. The weight is free to move under the influence of force F. Movement occurs on a frictionless surface. The origin of the coordinate system is taken to be the right edge of the weight when the spring is unstretched. At time zero, the weight is assumed to be at rest at the origin. Positive directions for force and displacement are indicated by the arrows.

A force balance on the weight results in Equation 7.

$$
\left(\frac{W}{g}\right)\left(\frac{d^{2} c}{d t^{2}}\right)+p\left(\frac{d c}{d t}\right)+k c=F
$$

Applying a Laplace transformation to the above equation yields

$$
K G(s)=\frac{K}{T_{c}^{2} s^{2}+2 \zeta T_{c} s+1} .
$$

Solving for $\mathrm{G}(\mathrm{s})$ in real time gives a local concentration equation:

$$
c(t)=K\left\{1-\frac{\exp \left(\frac{-\zeta t}{T_{c}}\right)}{\sqrt{1-\zeta^{2}}} \sin \left(\sqrt{1-\zeta^{2}} \frac{t}{T_{c}}+\cos ^{-1}(\zeta)\right)\right\}
$$

where $c$ is the displacement from equilibrium, $\zeta$ is the damping factor, $T_{c}$ is the characteristic time, and $\mathrm{K}$ is the system gain.

It is proposed that the equation describing the second order control system may also be used to describe the batch mixing process. This analogy is valid in the sense that in the mixing process, a step change occurs when solids are added to the surface of the mixture. The cyclical pattern of mixing can be modeled as a sinusoidal concentration function 
FIGURE 3

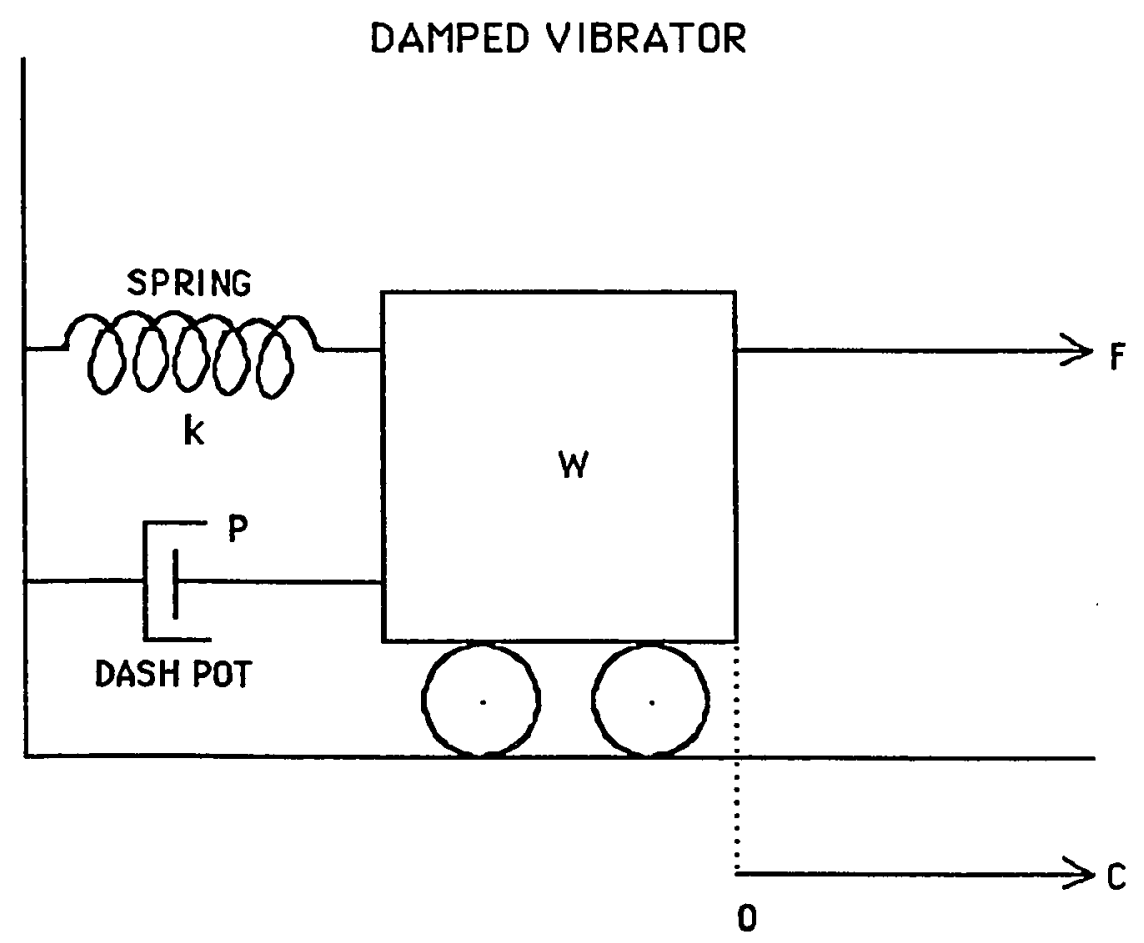


and the decay function represents the tendency of the system towards homogeneity. The damping function represents the resistance to dispersion of the solids and the capacitance function is related to the transport time through the system.

A physical interpretation may also give evidence for the similarity between the second order control system and batch mixing. The weight is acted upon by four forces: a spring-displacement force, a velocity-dependent damping force, an acceleration-dependent inertial force, and an applied force. The result of these four forces is the displacement $c$. In the mixing process, the particle is set into motion by the fluid flow as the blade moves by and it continues to move until it is no longer accelerated by the blade and the viscous forces of the fluid dissipate the momentum. As a result of the imposition of forces by the blade, the particle has relocated to another equilibrium position in the mixing volume. All particles will not receive equal acceleration due to their position relative to the moving blade, so there will be a distribution of particle relocations. This unequal distribution results in dispersion of particles throughout the mixing volume.

The mixing model contains three functions: the gain, the resistance, and the capacitance. The gain function is inherently unity for a batch mixing, that is, the system tries to reach the state of equilibrium. The resistance function is hypothesized to be dependent upon the particle size and concentration. It has been shown that the drag force on a spherical particle in laminar flow, expressed as $C_{D}$, is a linear function of the particle diameter [10]. The larger diameter particle has a larger drag force than a smalier 
diameter particle. Background solids concentration also provides resistance to dispersion. Solids addition to a low concentration mixture encounters less resistance in the form of particle-to-particle collisions compared to an addition to a highly concentrated mixture. Particles that constitute the background concentration effectively act as a barrier to the movement of particles added. The capacitance function is related to the transport time through the system. The transport time is dependent upon the pumping ability of the blades. Mixing time decreases when the circulation of the mixing medium is increased. The circulation rate is assumed to be a function of the agitation rate and volume. Thus, for a given mixture volume, it is hypothesized that the characteristic time variable in the mixing model is dependent upon the agitation rate, a process variable that can be easily determined.

The equation describing the second order control system expresses a displacement as a function of three parameters. The proposed mixing model is concerned with the displacement of the local solids concentration from the steady state concentration. Displacement for the mixing model has the form:

$$
\text { displacement }=1+\left(\frac{c(t)}{c(\infty)}-1\right)\left(\frac{c(\infty)}{c(10 \%)}\right) .
$$

The terms $c(t)$ and $c(\infty)$ represent respectively the concentration at time $t$ and the concentration at time $t=\infty$. The term $c(10 \%)$ is the equilibrium concentration of a $10 \%$ by weight mixture. The ideal value for displacement 
is one, implying the concentration at time $t$ and the equilibrium concentration are equal.

The definition of concentration displacement, Equation 10, was the result of a development for a dimensionless concentration parameter. One form of a dimensionless concentration parameter initially proposed was the ratio of the concentration at time $t$ to the equilibrium concentration.

$$
\text { displacement }=\frac{c(t)}{c(\infty)}
$$

The disadvantage of this form was the inability to compare results deduced from data collected at different mixture concentrations. The next form examined was called "error".

$$
\text { "error" }=\left(\frac{c(t)}{c(\infty)}-1\right)
$$

This form indicated that at large value of $t$, when the concentration of the mixture approaches the equilibrium value, the "error" approaches zero. Comparison between different sets of data was possible if the background mass of the different mixtures was included in the definition of the mixing parameter. This was achieved by multiplying the "error" by the ratio of equilibrium concentration to a base concentration.

$$
\left(\frac{c(t)}{c(\infty)}-1\right)\left(\frac{c(\infty)}{c(\text { base })}\right)
$$

The base concentration was assigned to be the equilibrium concentration of a $10 \%$ by weight mixture. This was chosen so that the mixing times for mixtures whose concentrations are not the same could be compared. The 
final form for concentration displacement was obtained by adding one to the above equation so that at large values of time, the displacement had a value of unity.

There are several implications of utilizing the second order control equation as the mixing model to describe the mixing process. The first is that the loci of the maxima and minima of the model equation, when plotted as a function of time, yield two curves which bound the concentration values that may exist in the mixing vessel. The maxima and minima of the model equation are found by differentiating the local concentration equation and equating to zero. All the possible concentration values lie between these curves. Second, the damped sinusoidal curve may be interpreted as the motion of the zone of maxima concentration in the mixing volume. Third, the concentration displacement must converge to a constant value as time increases, assuming that mixing does not lead to agglomeration or other nonideal effects.

To determine the values for the characteristic time and damping factor, empirical data must be correlated to the model equation. Hoogendoorn and den Hartog [4] found that mixing time and degree of homogeneity could be related by an exponential equation. Following their example an equation of the form

$$
\text { concentration }=a \pm b \exp (-B t)
$$

is correlated to the experimental data. This simple exponential equation contains three parameters. The variable a represents the equilibrium, steady state concentration. The increase in concentration due to solids 
addition is reflected in parameter $b$. The variable $B$ is found by fitting the equation to the data. Plotting the exponential equation as a function of time results with two converging exponential curves.

Ideally if the local concentration is measured continuously, the maxima and minima of the concentration profile are determined and the variable $B$ can be defined. However, because the actual maxima and minima are unknown, Equation 14 should bound all empirical data. Equation 14 should also converge to within a certain percent of the data, this percent being defined by the error associated with the experimental procedure. Therefore, characteristic time and damping factor are specified such that the maxima and minima of the model equation lie on the exponential curves of Equation 14.

The viscosity of the slurry also affects the mixing time; hence, viscosity also must be considered in the mixing model. A function relating viscosity and concentration would be necessary to analyze the viscous effects. At ambient mixing conditions, the mixture was observed to display viscoelastic behavior when the solids content reached approximately $55 \%$ by weight. A material is considered viscoelastic when it possesses characteristics of both a solid and a liquid. It is hypothesized that a more viscous slurry would require a longer mixing time than a less viscous slurry.

Many investigators in the subject of suspension rheology have developed empirical and theoretical correlations for the viscosity behavior of a suspension. Reviews of previous studies can be found in Kamal and 
Mutel [11] and in Metzner [12]. In this work the relation expressing the variation of viscosity with concentration was that due to Hildebrand's modified Batschinski equation [13], [14].

$$
\eta=\frac{V_{0}}{E\left(V-V_{0}\right)}
$$

$V$ is the specific volume of the mixture and $V_{0}$ is the specific volume where the viscosity becomes infinite. The term $\left(V-V_{0}\right)$ represents the "free volume" of the system. Specific volume is defined as the inverse of the molar density. The above equation can be rearranged to give a fluidity expression.

$$
\Phi=\frac{1}{\eta}=\left(\frac{E}{V_{0}}\right) V-E
$$

The values for $V_{0}$ and $E$ are found by plotting the inverse of the viscosity against mixture specific volume. In the system of ammonium sulfate and aerated polybutadiene, the specific volume must be based on masses of solids and fluids and specific gravity terms. Also it was assumed that the concentration of air in the polymer was constant at constant pressure. If this is the case, the viscosity of the mixture with zero concentration solids is the viscosity of the aerated polymer rather than "pure" polymer. Therefore, the value of $\mathrm{V}$ was related to the amounts of polymer and solids and was defined as

$$
V=\frac{1}{\left(x^{*} \text { sp. gr. solids }+(1-x) * s p \cdot g r . \text { polymer }\right)},
$$


where the mass fraction of solids is denoted by $x$. Application of a least squares method to the plotted data yields a slope of $\left(E N_{0}\right)$ and an intercept of (-E). The density of the aerated polymer can be found by weighing a known volume of the material.

With respect to viscosity, dissolved air acts like a solid in slurries. Additions of gas to a slurry will raise the viscosity [15]. Therefore, values for $V_{0}$ would be lower if mixing was performed under vacuum conditions rather than at ambient conditions.

Equation 15 was proposed by Hildebrand as an equation to determine the viscosity of simple liquids. A simple liquid is one which is Newtonian and in which the interactions between solids and between solids and liquid are not present. In the present system, however, many interactions between the polymer chains and between the solids and polymer are present. Except near the blades, the polymer chains are not extended to their full length. The polymer chains are present in many different shapes or configurations because of rotation of the carbon-carbon bond. Chain entanglement therefore causes the polymer to have intermolecular interactions. To account for this nonideality, the Hildebrand/Batschinski equation is modified to

$$
\frac{1}{\eta}=E\left(\frac{V-v_{0}}{v_{0}}\right)^{m} \text {. }
$$

The exponent $m$ would account for nonideality of the system. For simple liquids, the value for $m$ in Equation 19 is one and a plot of fluidity as a 
function of specific volume is linear. Should the plot of fluidity as a function of specific volume not be linear, then the value for $m$ will differ from unity. Taking the logarithm of the equation yields

$$
\ln \left(\frac{1}{\eta}\right)=\ln (E)+m \ln \left(\frac{V-V_{0}}{V_{0}}\right)
$$

By plotting the logarithm of the fluidity as a function of the logarithm of the specific volume terms, the variables $E$ and $m$ can be found by linear regression.

The parameters of the proposed mixing model are examined by varying the particle size and concentration while maintaining constant agitation rate and fluid viscosity. Future experimentation will involve variation of the fluid viscosity, by adding a plasticizer to the polymer, and variation of the agitation rate. With each variation, the other experimental variables are held constant. 


\section{EXPERIMENTAL PROCEDURE}

The experimentation involved preparing mixtures of certain weight percent solids and analyzing samples drawn during the mixing. Size effects were studied by sequential addition of sized ammonium sulfate to increase bulk solids concentration. Batch additions, calculated to increase solids concentration by a specific amount, were made and solids concentration monitored as mixing occurred until uniformity was attained throughout the mixing volume. Batch solids additions were continued until the mixing media became viscoelastic.

There were three stages in the procedure: solids preparation, mixing, and sample analysis. The solids preparation involved separating the ammonium sulfate into size ranges by using a Rotap Sieve shaker and U.S. Standard Sieves. It was discovered that the amount of time for vibration affected the amount of solids collected. Increasing the length of time resulted in the solids degrading and filtering down to the smaller sized sieves. Ammonium sulfate was collected in three size ranges: 180 microns250 microns, 75 microns-150 microns, and particle size less than 75 microns.

The mixing was performed with a vertical mixer (Model 4PU, Baker Perkins). The mixer has two blades which revolved around the tank on a central axis. Simultaneously, each blade revolves on its own axis. One blade revolves at approximately the speed of the central rotation while the 
other blade, having a hole in the blade, revolves at approximately five times the speed of the central rotation. The mixing vessel is a clear Lucite bowl provided by Baker Perkins. Air cylinders raise or lower the mixing vessel. The unit is flanged between the cylindrical straight sides and the head. The head is a stationary housing, above the mixing vessel, with port holes on opposite sides for purpose of charging materials into the vessel and drawing vacuum. The motor, the motor shaft, and the connection to the $\mathrm{DC}$ controller are located above the stationary housing. A DC controller was installed to allow control of the blade speed. The voltage on the DC controller was arbitrarily set at 60 volts. A counter (Model CUB2L8, Red Lion Controls) was installed to monitor the number of revolutions of the motor shaft. By timing the revolutions of the motor shaft a correlation between voltage and shaft revolutions was established. The mixing apparatus is shown on Figure 4.

Mixing was performed with the slower blade rotating at 3.9 revolutions per minute and at ambient conditions (atmospheric pressure and $25^{\circ} \mathrm{C}$ ). The sampling procedure required periodically stopping the mixing and drawing samples for analysis. Sampling was performed by utilizing a syringe mounted on the end of a clutch cable. Three samples of approximately two grams each were drawn from the mix at one time. These samples were taken from the surface, the center, and the bottom of the mixing volume. Drawn samples were placed in labeled beakers and analyzed for their weight percent of ammonium sulfate.

The mass of each sample was determined before being dissolved in 
FIGURE 4

EXPERIMENTAL APPARATUS

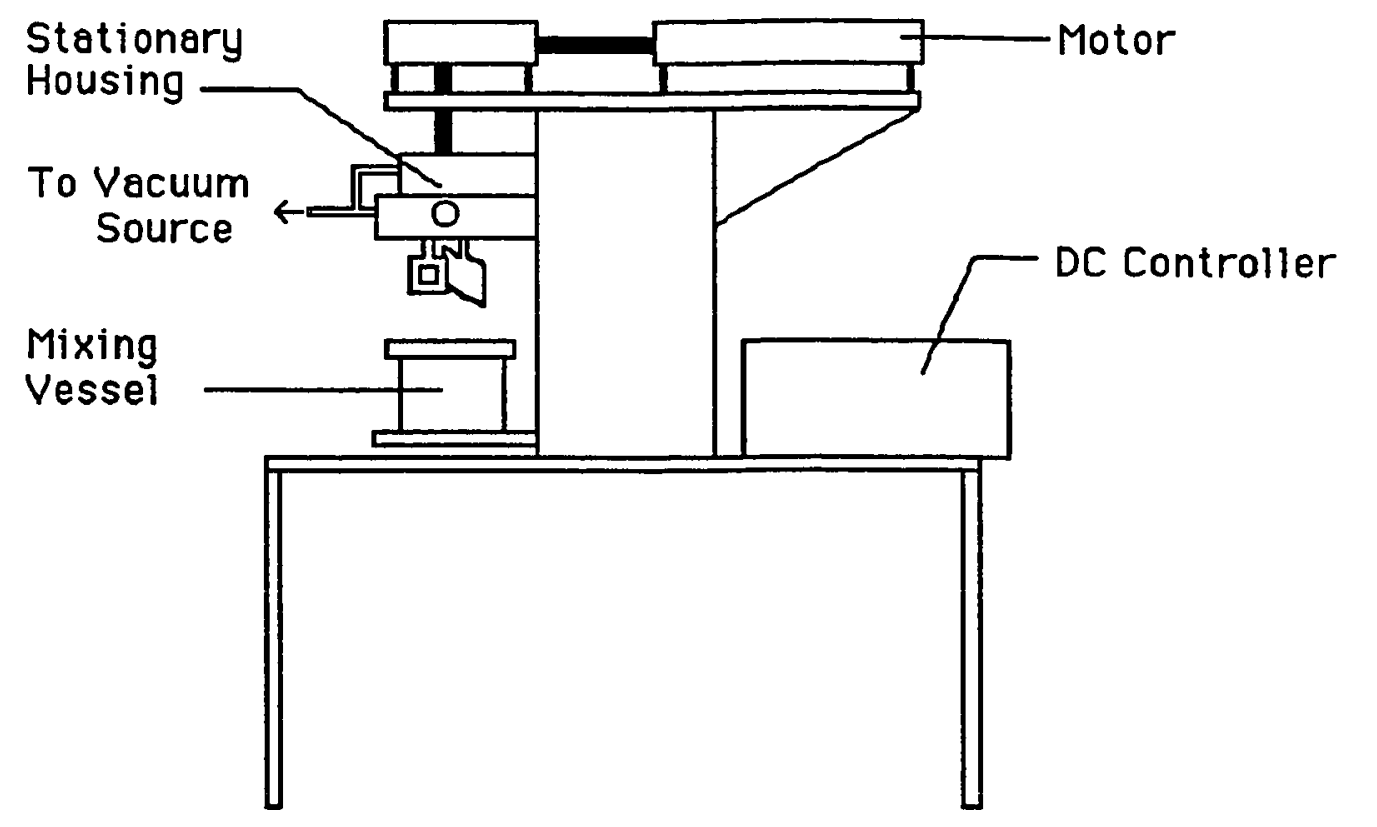


carbon tetrachloride. The dissolved sample was filtered with vacuum through a Büchner funnel containing weighed filter paper. The filter paper was reweighed, and the mass of ammonium sulfate was determined. The weight percent of solids in the sample was calculated by dividing the mass of ammonium sulfate by the mass of the sample. The concentration values were plotted as a function of time. Additional details about the procedure may be found in the appendix.

The samples for viscosity analysis were made by preparing mixtures of various concentrations using particles sized less than 75 microns, 75 microns - 150 microns, and 180 microns - 250 microns. The concentrations ranged from $30 \%$ to $55 \%$ by weight, with increments of $5 \%$ by weight. Approximately 1000 grams of polybutadiene were mixed with the necessary amount of ammonium sulfate for sixty minutes at the operating conditions mentioned. Prior to solids addition a sample of sixty to seventy grams was drawn for viscosity analysis. These samples were tested at ambient conditions for apparent viscosity at six shear rates. The testing was performed by Ed Lee and John Denham with a mechanical spectrometer (Rheometrics Inc., RMS800).

Data were collected for analysis of the effect of system pressure on the presence of viscoelastic behavior in the ammonium sulfate/polybutadiene slurry. Development of the experimental procedure and data collection is credited to Maurino Flora. A mixture of $55 \%$ by weight ammonium sulfate was prepared with deaerated polybutadiene and mixed for approximately 42 minutes at atmospheric pressure. The height of the 
material's deformation was noted. This height was used as a reference to define the attainment of viscoelasticity. Batch additions of ammonium sulfate were added to the mixture. After each addition, the solids were mixed into the mixing media under vacuum $(20 \mathrm{~mm} \mathrm{Hg})$ for approximately 42 minutes. The system pressure was increased and the height of the material's deformation was monitored. When the height of the deformation was equal to the reference height, the material was assumed to be viscoelastic and the pressure noted. Data were also collected by performing the same procedure beginning with a concentrated mixture and making batch additions of polybutadiene to the mixture.

In this work a spot sampling technique was employed. The method has been mentioned in several references [16], [17], [18], [19]. This method involves drawing samples from various areas of the mixed medium and determining their compositions. Analysis associated with this method is time consuming, and numerous samples must be drawn to reflect the entire batch mixing process.

A survey of literature revealed that many other methods have been proposed for use in determining mixing time and mixing hydrodynamics. The majority of investigators have employed one or more of the following techniques:

- conductivity method

- dye addition method

- chemical reaction method

- tracer method

- thermal method 
- Schlieren method

These methods are discussed in Ford, et. al. [20] and Chavan, et. al. [21].

The above methods were considered to be inadequate for the system to be analyzed. The conductivity method involves the observation of a change in electrical conductivity as mixing proceeds. Polybutadiene has a very high resistivity, on the order of $10^{16}$ ohms per meter, which makes this method unsuitable [22]. Dye addition method involves the addition of dye to the bulk fluid. Visual observation is employed in determining the mixing time. Errors in this method arise from the fact that visual observations are subjective. In addition, mixing occurs during the visual analysis and therefore the experimentally determined time may be overestimated. The chemical reaction method is one in which the bulk fluid either loses or changes its initial color due to a chemical reaction with an injected fluid. This method suffers from the same errors as the dye addition method. Also, the initial reactant must be homogeneously mixed with the bulk fluid; otherwise, stagnant zones are not colored and will remain undetected. The thermal method employs a change of temperature as the property to be measured. Heated fluid is injected into the bulk fluid and the fluctuations in temperature are monitored. The change of temperature technique was not considered because it is not practical for suspended solids and because the rheological properties of the system were very temperature sensitive. The tracer method involves the monitoring of radioactive particles in the mix, while the Schlieren method employs the principle that optical inhomogeneities are present in transparent inhomogeneous fluid. Both 
these methods involve intricate equipment. 


\section{RESULTS}

Mixing was performed by making batch additions of solids to the mixture. At ambient conditions the maximum solids concentration attained before viscoelasticity occurred was approximately $55 \%$ by weight.

Viscoelasticity is a state in which the material possesses both liquid and solid characteristics. This state was noticed when the mixing media climbed up the blades during mixing and did not form a smooth layer in the mixing bowl after mixing. Mixing of additional solids to the viscoelastic material resulted in the formation of "packets" of material. These packets were continuously formed and divided by the blades. At this point in the mixing, the solids may not be thoroughly dispersed but localized in the packets of material.

An example of the experimental data collected is shown in Figure 5.

The addition of solids is evidenced by the abrupt increase in the concentrations between the first and second sampling times. The concentrations at the three sampling positions oscillate until the concentrations converge to within a small range of values. Additional experimental data are located in the appendix.

For the purpose of data analysis, the experimental times were reduced by a factor to ten, a step which allowed the investigator to conceptualize the results. This reduced time is called modified time, $t^{\star}$. Following the example of Hoogendoorn and den Hartog [4], an exponential 
FIGURE 5

\section{EXPERIMENTAL DATA, BATCH MIXING}

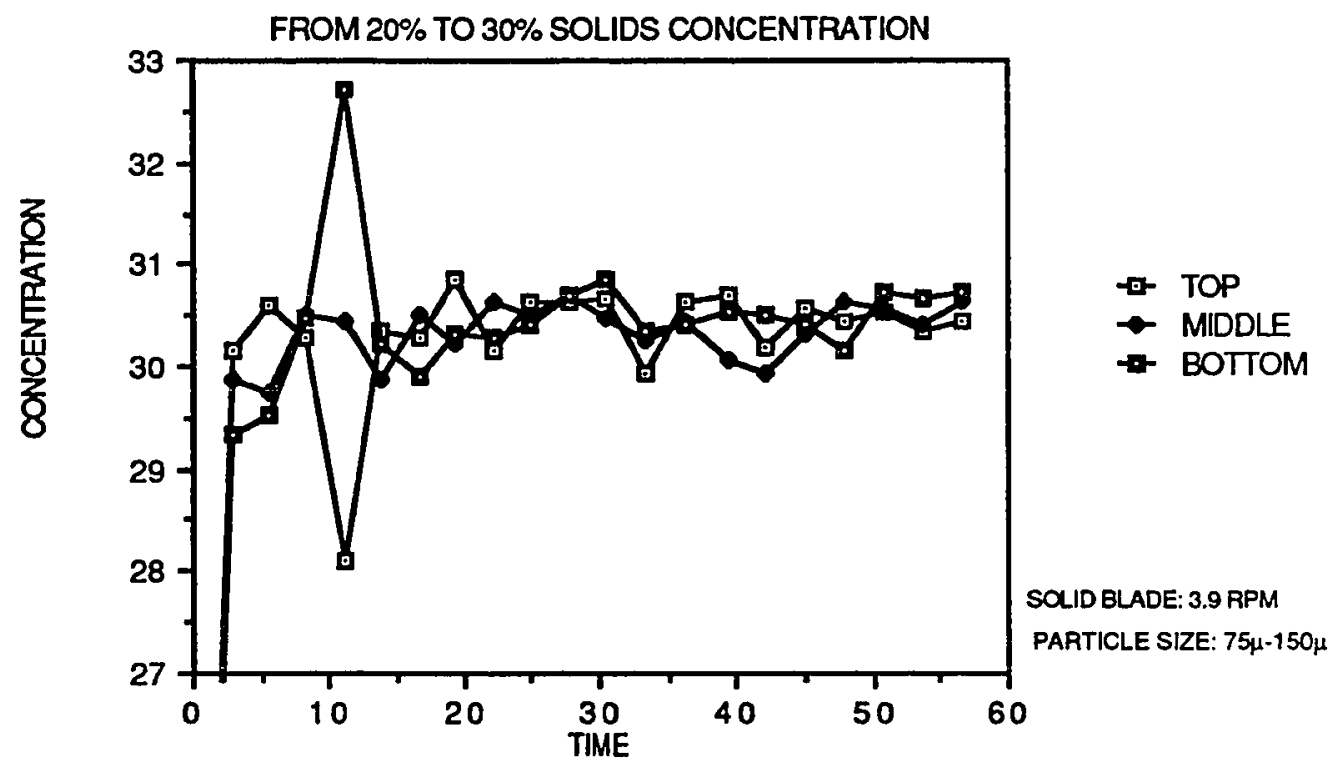


equation of the form:

$$
\text { concentration }=a \pm b \exp \left(-B t^{\star}\right)
$$

was correlated from the data. The variable a represents the equilibrium, steady state concentration and variable b represents the amount of solids added. Variable B was found from the correlation. Figure 6 shows Equation 21 correlated from the experimental data. Table 1 displays the results of correlating Equation 21 to the remaining sets of experimental data.

The experimental data were transformed to express concentration displacement (Equation 10) as a function of time. Figure 7 shows the experimental data and Equation 21 after transformation. The plot shown on Figure 7 is similar to that shown on Figure 6 except for the change in a coordinate. Values for characteristic time and damping factor were correlated so that the loci of maxima and minima of the model equation (Equation 9) lie on the transformed exponential curve (Equation 21). Figure 8 shows a graphical representation of the correlation. The appropriate values for characteristic time and damping factor are such that the differentiated model equation (Equation 9) and the transformed Equation 21 give identical plots. Table 2 displays typical values for the characteristic time and damping factor that represent the highest level of correlation. A trend is not apparent in the table; however, the characteristic time for the majority of the data sets had values that ranged between 0.019 and 0.024 . Other values for characteristic time and damping factors may allow Equation 9 to fit the data, however, may not correlate well with Equation 21. 
FIGURE 6

\section{EQUATION 21 CORRELATED TO EXPERIMENTAL DATA}

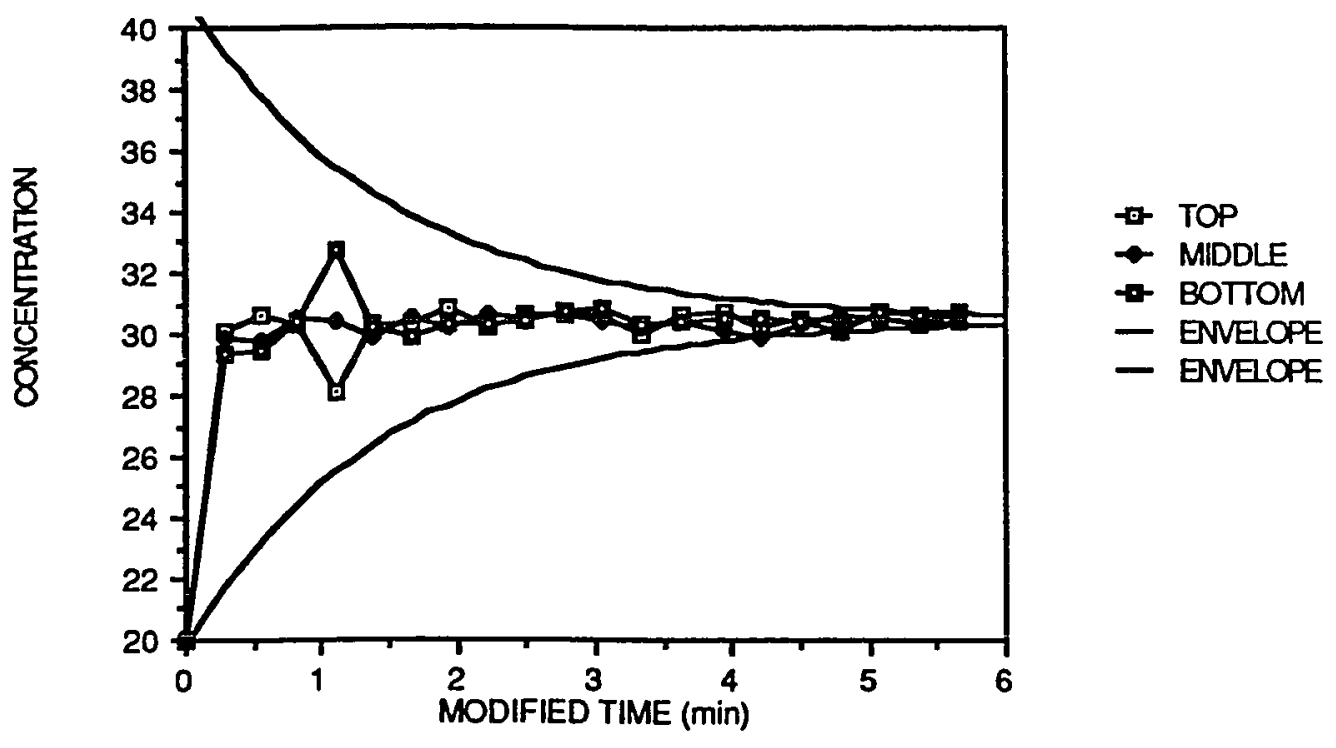




\section{TABLE 1}

\section{EQUATION 21 CORRELATED FROM EXPERIMENTAL DATA}

\section{PARTICLE EXPONENTIAL EXPRESSION}

SIZE

$<75 \mu$

$$
\begin{aligned}
& \text { conc. }=9.41 \pm 9.41 \exp \left(-0.691 \mathrm{t}^{*}\right) \\
& \text { conc. }=19.48 \pm 10.18 \exp \left(-0.555 \mathrm{t}^{*}\right) \\
& \text { conc. }=30.49 \pm 10.89 \exp \left(-0.572 \mathrm{t}^{\circ}\right) \\
& \text { conc. }=41.00 \pm 8.50 \exp \left(-0.554 \mathrm{t}^{*}\right)
\end{aligned}
$$

$75 \mu-150 \mu$

$$
\begin{aligned}
& \text { conc. }=10.16 \pm 10.16 \exp \left(-0.709 \mathrm{t}^{*}\right) \\
& \text { conc. }=20.44 \pm 10.74 \exp \left(-0.627 \mathrm{t}^{\circ}\right) \\
& \text { conc. }=30.49 \pm 10.69 \exp \left(-0.694 \mathrm{t}^{\circ}\right) \\
& \text { conc. }=42.10 \pm 11.50 \exp \left(-0.687 \mathrm{t}^{\circ}\right) \\
& \text { conc. }=47.30 \pm 5.50 \exp \left(-0.427 \mathrm{t}^{*}\right)
\end{aligned}
$$


TABLE 1 (continued)

PARTICLE

SIZE

$180 \mu-250 \mu$

\section{EXPONENTIAL EXPRESSION}

$$
\begin{aligned}
& \text { conc. }=10.49 \pm 10.49 \exp \left(-0.799 t^{*}\right) \\
& \text { conc. }=29.44 \pm 20.54 \exp \left(-0.676 t^{*}\right) \\
& \text { conc. }=40.86 \pm 10.66 \exp \left(-0.848 t^{*}\right) \\
& \text { conc. }=45.90 \pm 6.10 \exp \left(-0.798 t^{*}\right) \\
& \text { conc. }=50.07 \pm 2.87 \exp \left(-0.504 t^{*}\right) \\
& \text { conc. }=53.12 \pm 3.52 \exp \left(-0.792 t^{*}\right)
\end{aligned}
$$

- Solid Blade: 3.9 RPM. 


\section{FIGURE 7}

\section{DISPLACEMENT REPRESENTATION OF EXPERIMENTAL DATA}

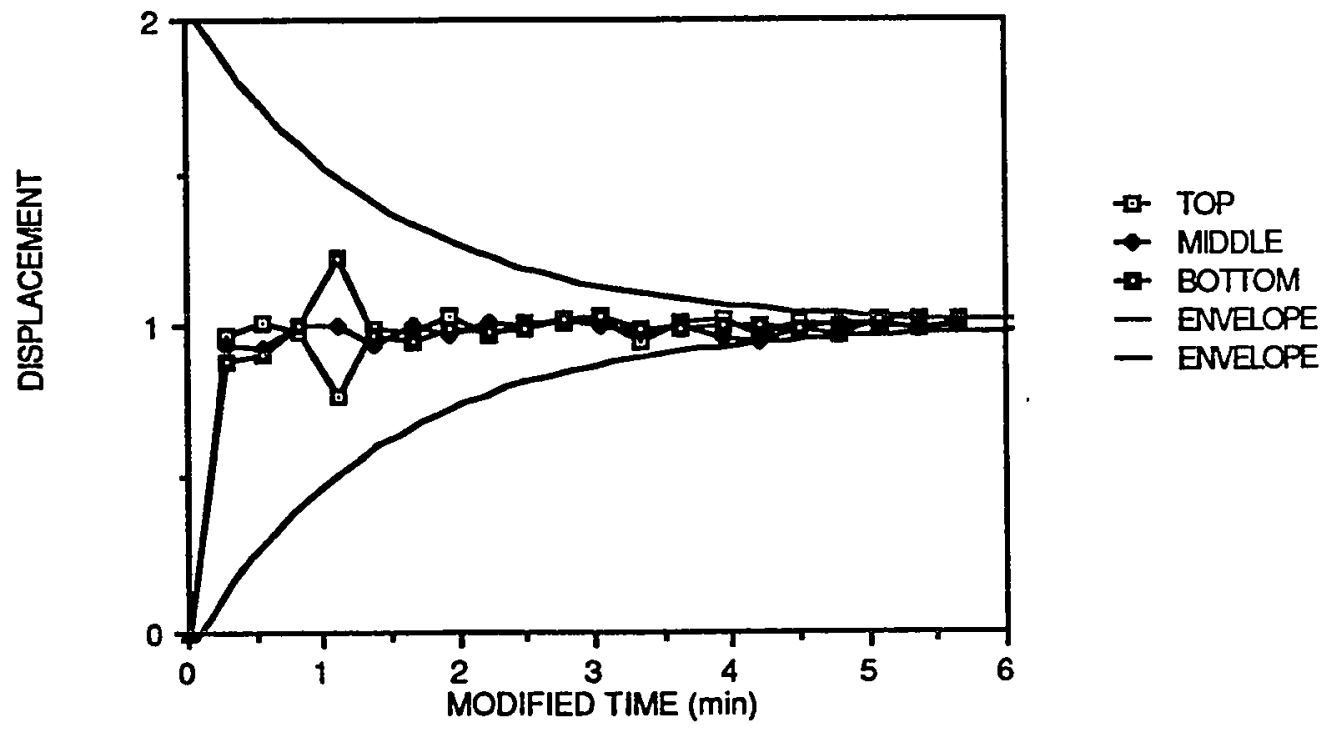


FIGURE 8

\section{GRAPHICAL REPRESENTATION OF CORRELATION}

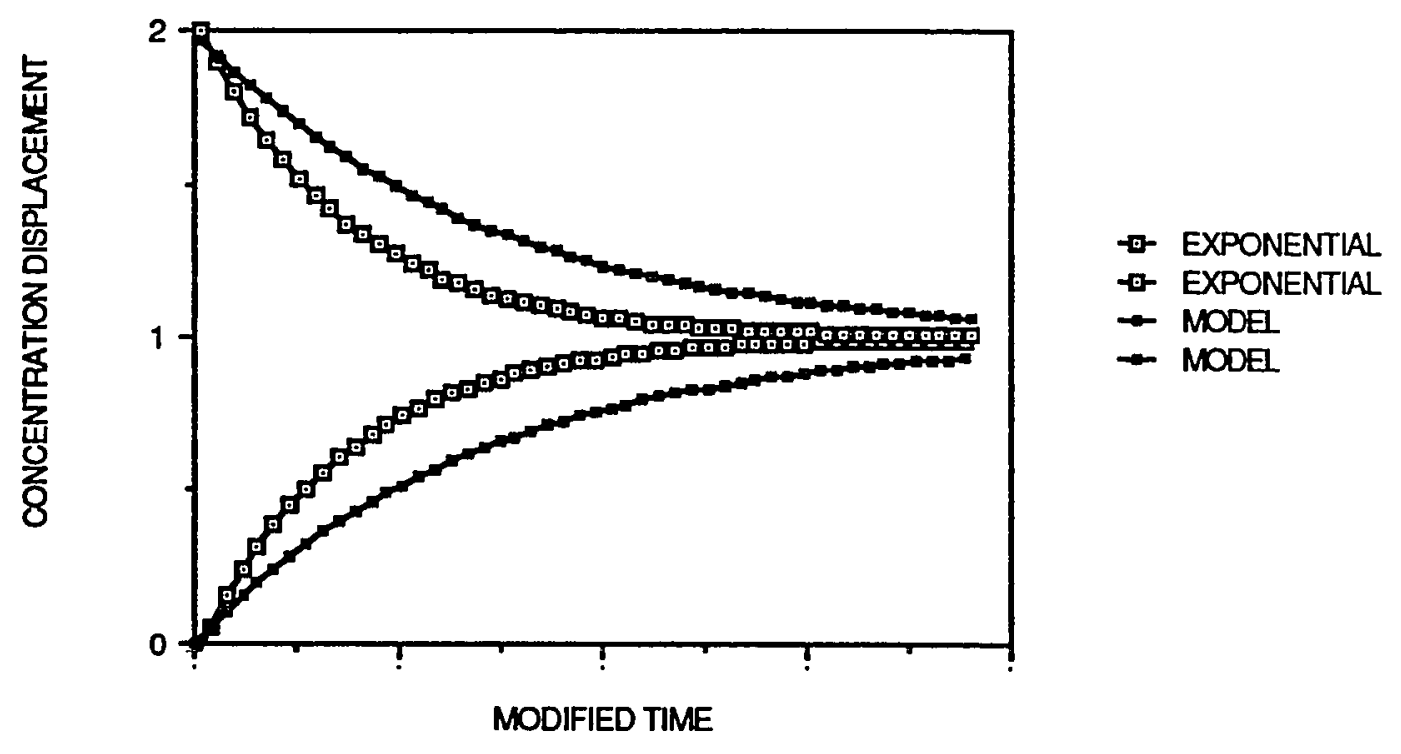


TABLE 2

\section{CHARACTERISTIC TIMES AND DAMPING FACTORS}

\begin{tabular}{|c|c|c|c|c|}
\hline $\begin{array}{l}\text { PARTICLE } \\
\text { SIZE } \\
\text { (micron) }\end{array}$ & $\begin{array}{l}\text { INCREASE } \\
\text { WEIGHT \% }\end{array}$ & $\begin{array}{l}\text { EQUILIBRIUM } \\
\text { WEIGHT \% }\end{array}$ & $\begin{array}{c}T_{C} \\
(\min )\end{array}$ & $\zeta$ \\
\hline \multirow[t]{4}{*}{$<75 \mu$} & 9.41 & 9.41 & 0.022 & 0.015 \\
\hline & 10.18 & 19.48 & 0.027 & 0.014 \\
\hline & 10.89 & 30.49 & 0.019 & 0.010 \\
\hline & 8.50 & 41.00 & 0.020 & 0.012 \\
\hline \multirow[t]{5}{*}{$75 \mu-150 \mu$} & 10.16 & 10.16 & 0.018 & 0.013 \\
\hline & 10.74 & 20.44 & 0.022 & 0.013 \\
\hline & 10.69 & 30.49 & 0.019 & 0.013 \\
\hline & 11.50 & 42.10 & 0.022 & 0.014 \\
\hline & 5.50 & 47.30 & 0.488 & 0.304 \\
\hline \multirow[t]{6}{*}{$180 \mu-250 \mu$} & 10.49 & 10.49 & 0.020 & 0.016 \\
\hline & 20.54 & 29.44 & --- & -.. \\
\hline & 10.66 & 40.86 & 0.021 & 0.017 \\
\hline & 6.10 & 45.90 & 0.531 & 0.920 \\
\hline & 2.87 & 50.07 & --- & -- \\
\hline & 3.52 & 53.12 & -- & -- \\
\hline
\end{tabular}


Characteristic time is assumed to be related to the agitation rate and mixture volume. For a fixed volume and agitation rate, the characteristic time should be constant. Thus, it is hypothesized that the characteristic time variable in Equation 9 is dependent upon the agitation rate since agitation rate is a process variable that can be easily determined. A relationship for characteristic time as a function of agitation rate is

$$
\text { characteristic time }=\left(\text { RPM of solid blade }{ }^{*} 10\right)^{-1} \text {. }
$$

A solid blade speed of 3.9 RPM implied a characteristic time of 0.025 , which is near the range of characteristic time values determined from correlation.

Specifying the characteristic time to be defined as above, Equation 9 contains one undetermined variable, the damping factor. Using the transformed Equation 21 as a basis, the damping factor was determined by performing correlation on the differentiated Equation 9. The results of this correlation are shown on Table 3.

Mixing time required for the concentration fluctuations to fall within one half a percent of the equilibrium concentration was determined from Equation 21. When the concentrations were within a half a percent of the equilibrium concentration, the mixture was assumed to be homogeneous. Table 4 shows the ranges for mixing time as determined from the experimental data. The time indicated should be interpreted as the time required to obtain a homogeneous mixture after an addition of solids to the previous homogeneous mixture. Ranges are given because of the uncertainty in knowing the actual maximum and minimum concentrations at 
TABLE 3

DAMPING FACTORS FOR CONSTANT CHARACTERISTIC TIME

$\begin{array}{crccc}\begin{array}{c}\text { PARTICLE } \\ \text { SIZE } \\ \text { (micron) }\end{array} & \begin{array}{c}\text { INCREASE } \\ \text { WEIGHT \% }\end{array} & \begin{array}{c}\text { EQUILIBRIUM } \\ \text { WEIGHT } \%\end{array} & \begin{array}{c}T_{C} \\ (\mathrm{~min})\end{array} & \zeta \\ <75 \mu & & & & \\ & 9.41 & 9.41 & 0.025 & 0.017 \\ & 10.18 & 19.48 & 0.025 & 0.013 \\ & 10.89 & 30.49 & 0.025 & 0.013 \\ & 8.50 & 41.00 & 0.025 & 0.014 \\ 75 \mu-150 \mu & 10.16 & 10.16 & 0.025 & 0.017 \\ & 10.74 & 20.44 & 0.025 & 0.015 \\ & 10.69 & 30.49 & 0.025 & 0.017 \\ & 11.50 & 42.10 & 0.025 & 0.016 \\ & 5.50 & 47.30 & 0.025 & 0.016 \\ 180 \mu-250 \mu & 10.49 & 10.49 & 0.025 & 0.020 \\ & 20.54 & 29.44 & -- & -- \\ & 10.66 & 40.86 & 0.025 & 0.021 \\ & 6.10 & 45.90 & 0.025 & 0.021 \\ & 2.87 & 50.07 & \cdots & -- \\ & 3.52 & 53.12 & --- & --\end{array}$




\section{TABLE 4}

\begin{tabular}{ccc}
\multicolumn{2}{c}{ EXPERIMENTALLY DETERMINED MIXING TIMES } \\
$\begin{array}{c}\text { PARTICLE } \\
\text { SIZE }\end{array}$ & $\begin{array}{c}\text { INCREASE IN } \\
\text { CONCENTRATION } \\
\text { (micron) }\end{array}$ & TIME \\
& (\% by weight) & (min) \\
$<75 \mu$ & $0->9.41$ & $75-81$ \\
& $9.41->19.48$ & $83-90$ \\
& $19.48->30.49$ & $73-84$ \\
& $30.49 \rightarrow 41.0$ & $66-83$ \\
$75 \mu-150 \mu$ & $0->10.16$ & $74-78$ \\
& $10.16->20.44$ & $73-80$ \\
& $20.44->30.49$ & $60-70$ \\
& $30.49 \rightarrow 42.1$ & $57-68$ \\
& $42.1->47.3$ & $73-86$ \\
$180 \mu-250 \mu$ & & \\
& $0->10.49$ & $64-67$ \\
& $10.49->29.44$ & $72-77$ \\
& $29.44->40.86$ & $46-54$ \\
& $40.86 \rightarrow 45.9$ & $41-52$
\end{tabular}


any time in the mixing vessel. The lower time limit represents the mixing time required as determined from the experimental data. The upper time limit represents the mixing time required if the experimental data were in error by a half a percent.

Figures 9,10 , and 11 display the viscosity behavior for mixtures prepared vititi solids of the three different size ranges. These values for viscosity are based on rheometric analysis, not determined from process variables. The viscosity is plotted as a function of mass fraction of solids. Six shear rates were used to test for slurry viscosity. The general trend in the three plots is that the viscosity increases with increasing mass factions of solids. Viscosity data in tabular form are located in the appendix.

The viscosity data was analyzed using two equations: the Hildebrand/Batschinski equation (Equation 15) and the modified Hildebrand/Batschinski equation (Equation 19). Figure 12 shows an example of the correlation of experimental data with the Hildebrand/Batschinski equation. The upper plot displays the data plotted as specified for this equation. A line representing the result of the linear regression is plotted over the data. The lower plot displays the viscosity as a function of specific volume for both the experimental viscosity data and the viscosity as determined by the Hildebrand/Batschinski equation. In many cases, Equation 15 determined a negative value for viscosity. The negative values indicate that Equation 15 is limited by the value of $\mathrm{V}$. Negative viscosity is calculated if the value for $V$ is less than $V_{0}$. Table 5 presents the values for $E$ and $V_{0}$ as determined from linear regression. 
FIGURE 9

VISCOSITY OF AMMONIUM SULFATE/POLYBUTADIENE SLURRIES:

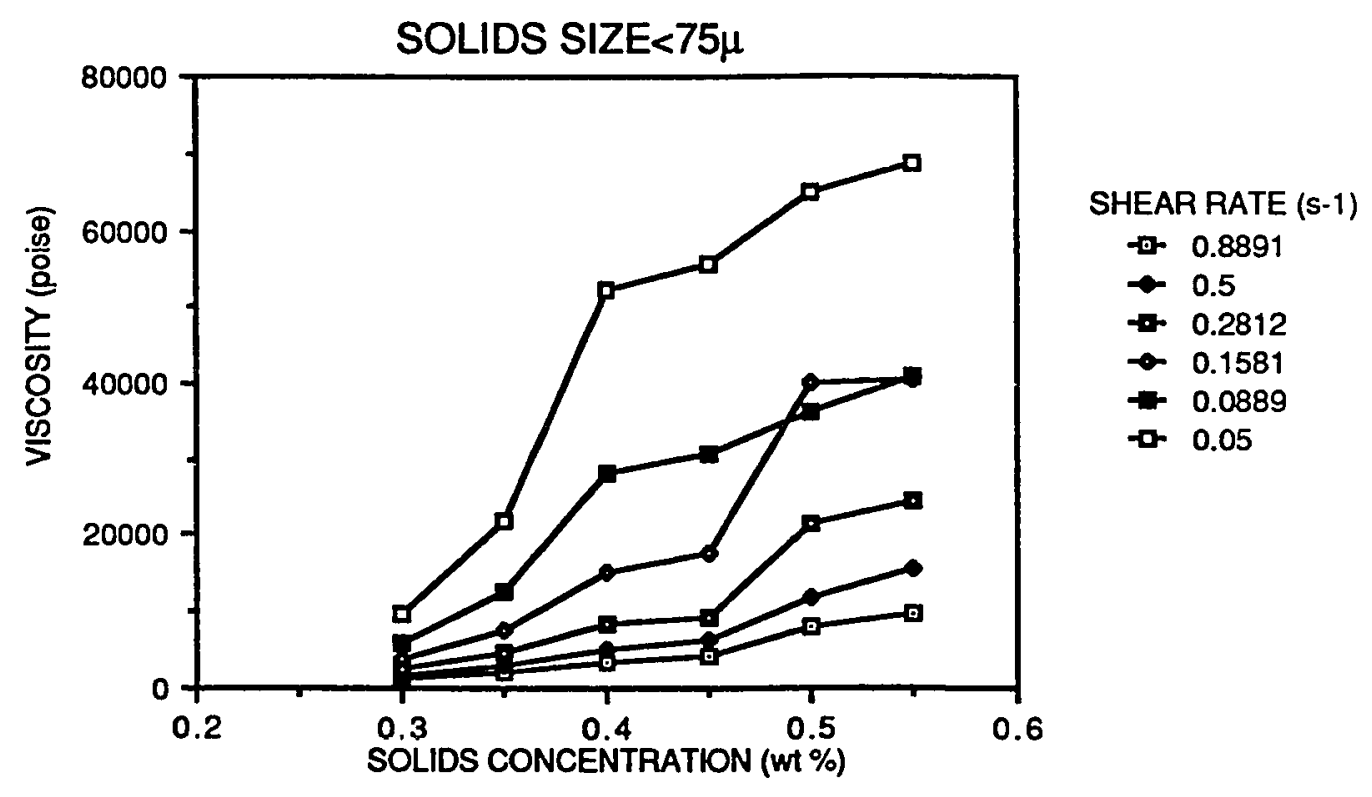

- Data courtesy of United Technologies Chemical Systems. 
FIGURE 10

VISCOSITY OF AMMONIUM SULFATE/POLYBUTADIENE SLURRIES:

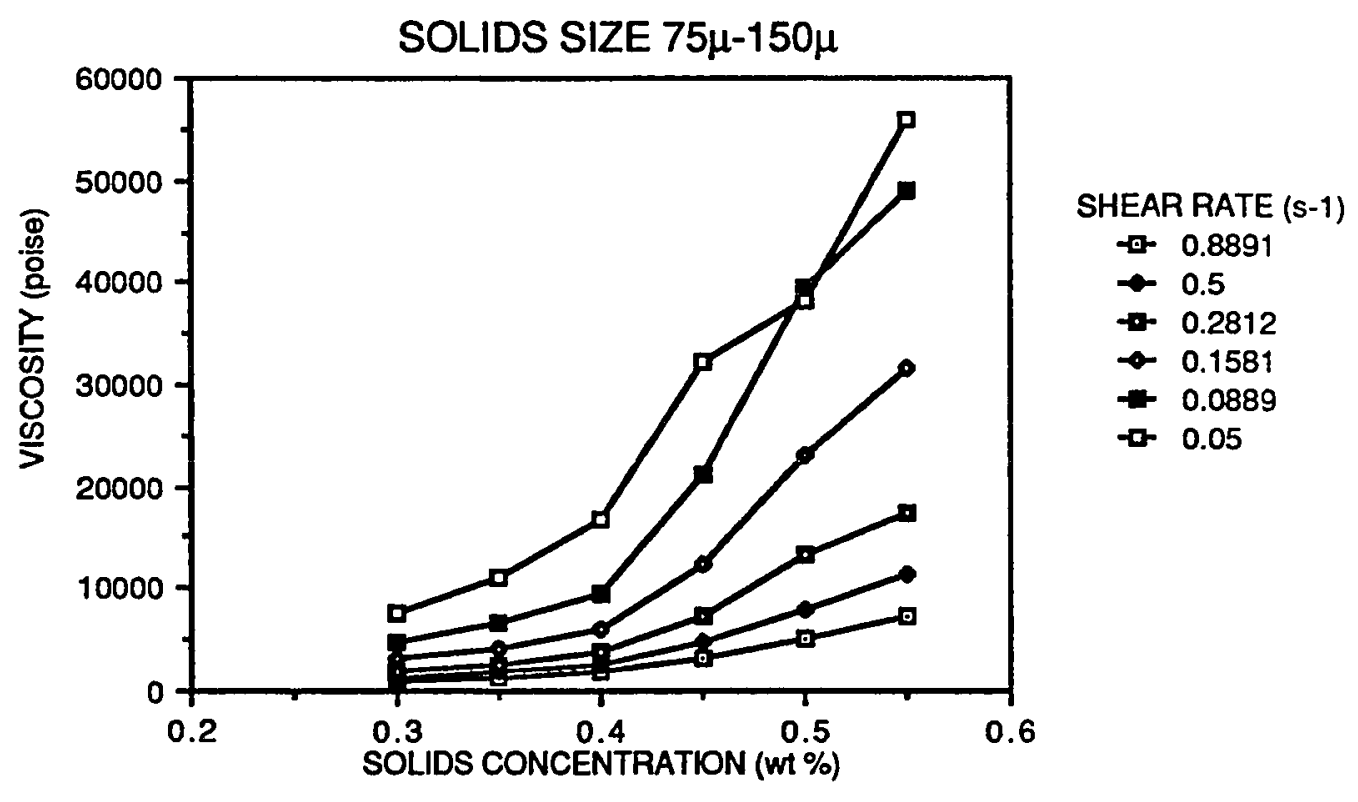

- Data courtesy of United Technologies Chemical Systems. 


\section{FIGURE 11}

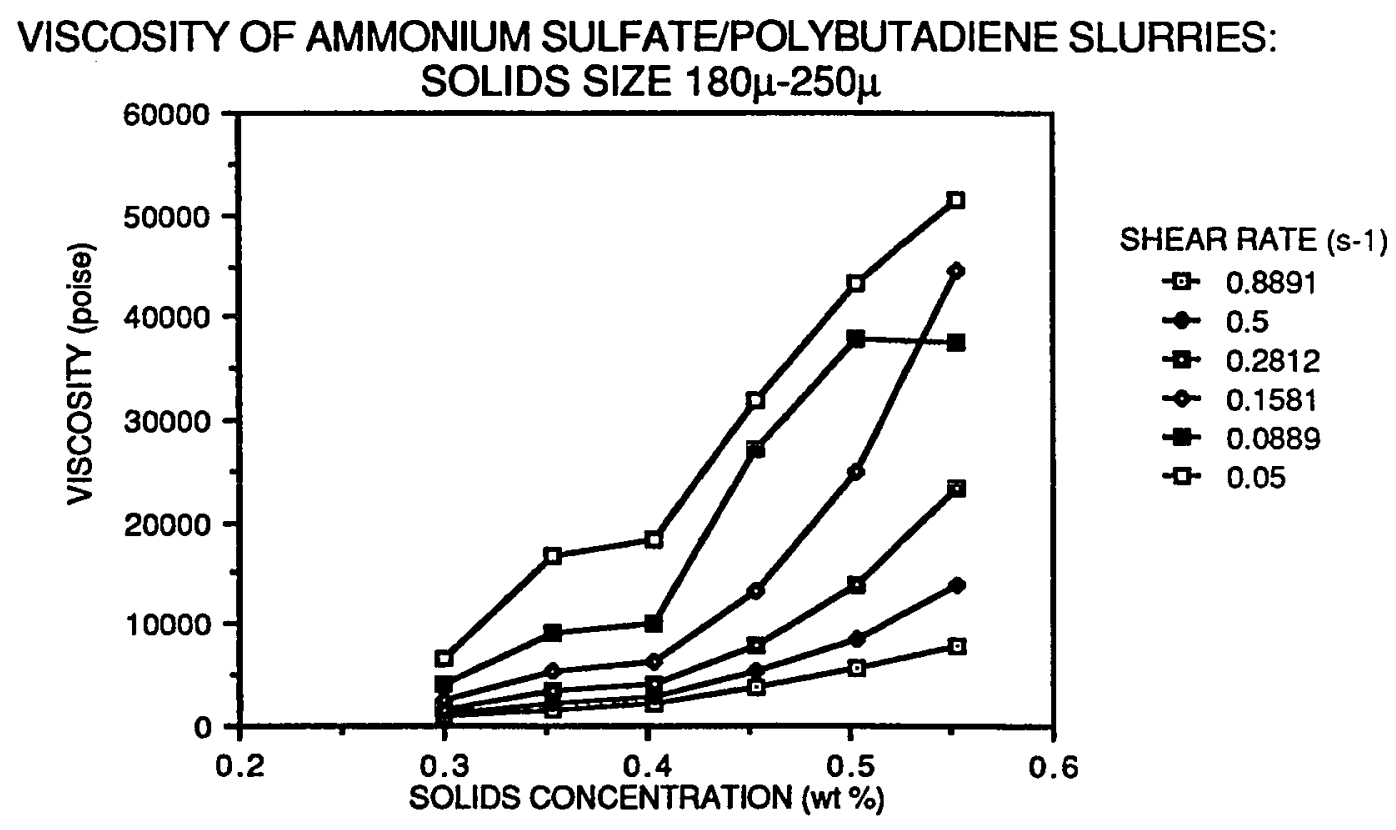

- Data courtesy of United Technologies Chemical Systems. 
FIGURE 12

\section{VISCOSITY ANALYSIS USING HILDEBRAND/BATSCHINSKI EQUATION}

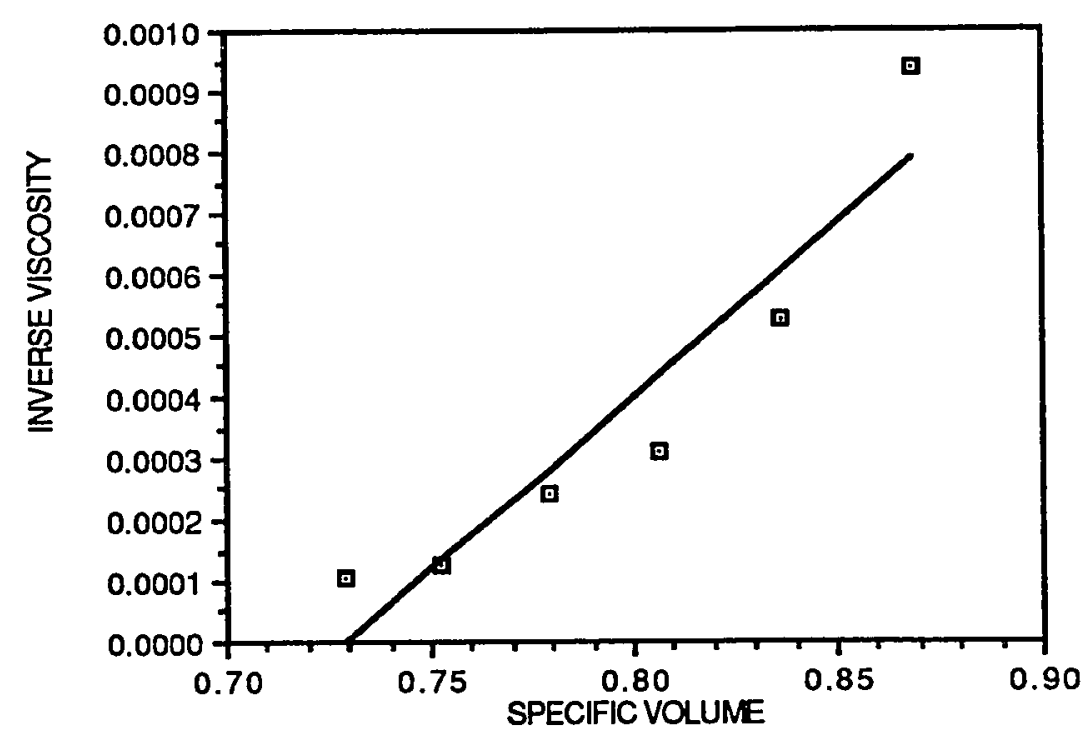

- EXPERIMENTAL

- HILDEBRAND

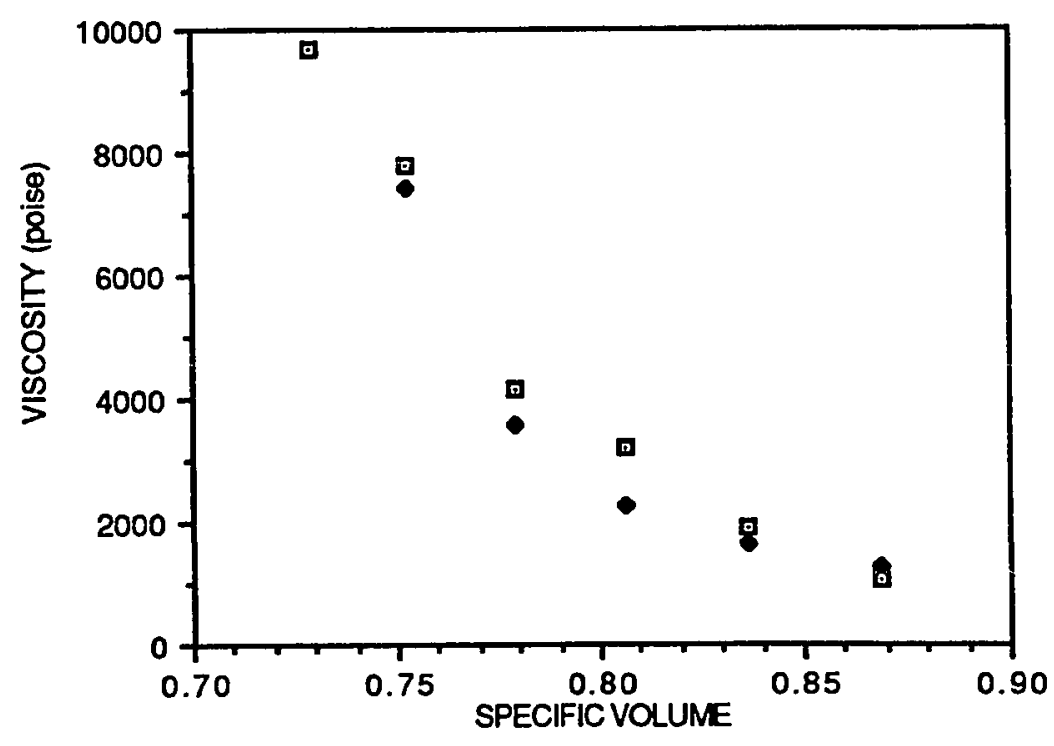

- EXPERIMENTAL

- HILDEBRAND 
TABLE 5

\section{VALUES FOR E AND $V_{0}$ IN THE \\ HILDEBRAND/BATSCHINSKI EQUATION}

\begin{tabular}{clll}
$\begin{array}{c}\text { PARTICLE } \\
\text { SIZE } \\
\text { (micron) }\end{array}$ & $\begin{array}{c}\text { SHEAR } \\
\text { RATE } \\
\left(\mathrm{s}^{-1}\right)\end{array}$ & \multicolumn{1}{c}{$\mathrm{E}$} & $\mathrm{V}_{\mathrm{O}}$ \\
$<75 \mu$ & 0.8891 & 0.0040 & \\
& 0.5 & 0.0028 & 0.722 \\
& 0.2812 & 0.0018 & 0.724 \\
& 0.1581 & 0.0012 & 0.730 \\
& 0.0889 & $6.77 \mathrm{E}-4$ & 0.729 \\
& 0.05 & $6.10 \mathrm{E}-4$ & 0.722 \\
$75 \mu-150 \mu$ & & & 0.734 \\
& 0.8891 & 0.0045 & 0.711 \\
& 0.5 & 0.0034 & 0.715 \\
& 0.2812 & 0.0024 & 0.718 \\
& 0.1581 & 0.0016 & 0.722 \\
& 0.0889 & 0.0010 & 0.723 \\
& 0.05 & $6.05 \mathrm{E}-4$ & 0.717 \\
$180 \mu-250 \mu$ & & & \\
& 0.8891 & 0.0047 & 0.718 \\
& 0.05 & 0.0036 & 0.722 \\
& 0.2812 & 0.0026 & 0.725 \\
& 0.1581 & 0.0017 & 0.728 \\
& 0.0889 & 0.0010 & 0.727 \\
& 0.05 & $6.03 \mathrm{E}-4$ & 0.720
\end{tabular}


$V_{0}$ is the specific volume at which the viscosity is infinite. For any particle size and shear rate the value for $V_{0}$ should be constant. To find $V_{0}$ for the mixer, the values for $V_{0}$ were plotted as a function of shear rate and then extrapolated to zero shear rate. Based on the extrapolations, $V_{0}$ is approximately 0.72 for each of the particle sizes.

This value for $V_{0}$ was inserted into Equation 15 and the viscosity was recalculated. The results are shown on Tables 6,7 , and 8 . By specifying $V_{0}$ to be 0.72 , Equation 15 calculates an infinite viscosity for the mixtures with the smallest specific volume. Equation 15 appears to work best for the mixtures using particles sized 75 microns-150 microns. In most mixtures, Equation 15 determined viscosities that were within twenty percent of the experimental values. For the other particle sizes, the calculated viscosities deviated from the experimental value by percentages as high as sixty percent.

The modified Hildebrand/Batschinski equation (Equation 19) was also used for viscosity data analysis. The value for $V_{0}$ was specified to be 0.72 as determined previously. The values for $E$ and $m$ for each set of data were found by linear regression and are shown on Table 9. Inserting the values for $E$ and $m$ into Equation 19 allows for the computation of viscosity. Tables 10,11, and 12 show the values for the experimental viscosities and the viscosities as calculated by Equation 19. Viscosity is estimated somewhat better with Equation 19. For mixtures using particles sized 75 microns-150 microns, the calculated viscosities are within ten percent of the 


\section{TABLE 6}

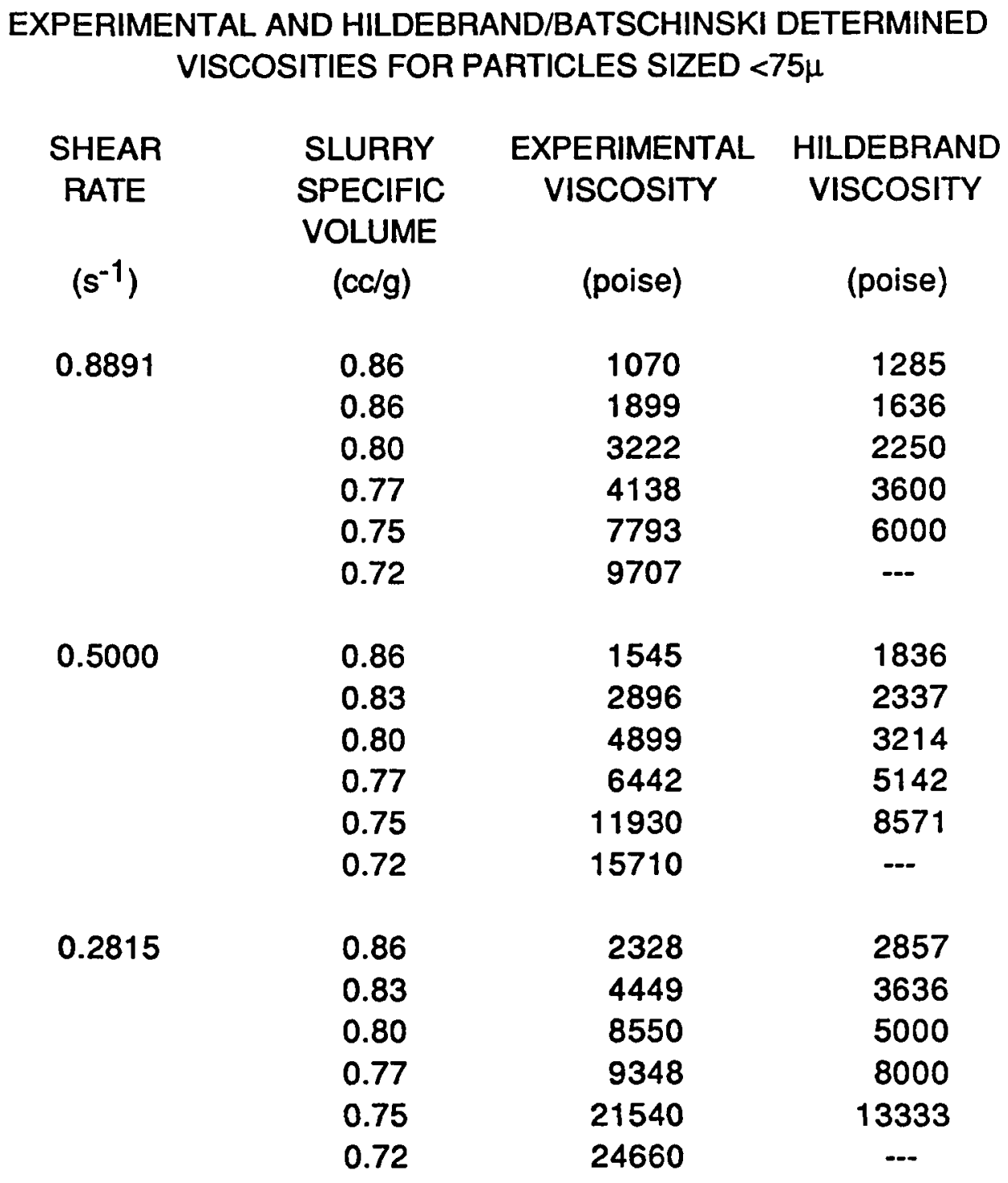


TABLE 6 (continued)

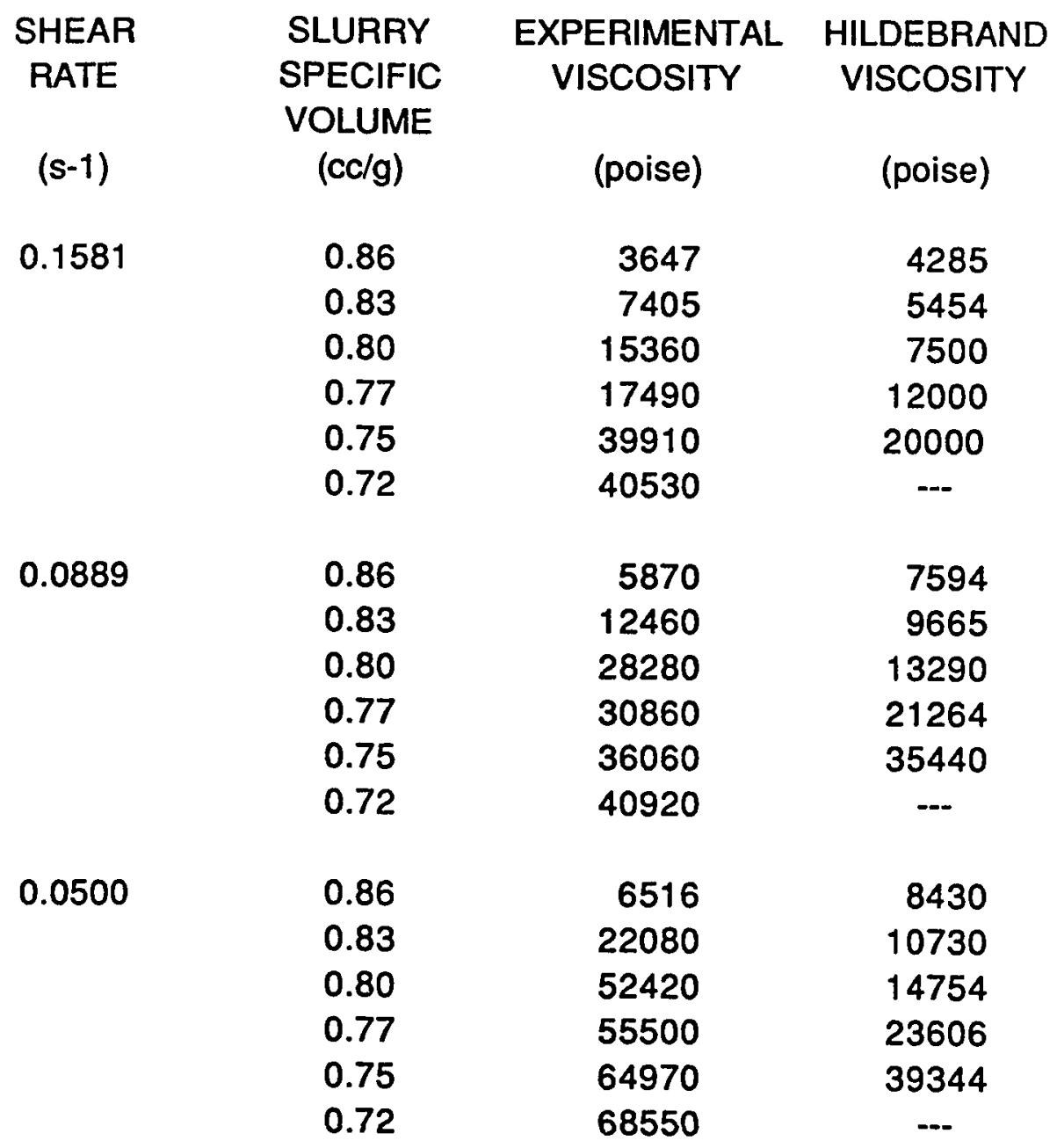




\section{TABLE 7}

EXPERIMENTAL AND HILDEBRAND/BATSCHINSKI DETERMINED VISCOSITIES FOR PARTICLES SIZED $75 \mu-150 \mu$

\begin{tabular}{|c|c|c|c|}
\hline $\begin{array}{l}\text { SHEAR } \\
\text { RATE }\end{array}$ & $\begin{array}{l}\text { SLURRY } \\
\text { SPECIFIC } \\
\text { VOLUME }\end{array}$ & $\begin{array}{l}\text { EXPERIMENTAL } \\
\text { VISCOSITY }\end{array}$ & $\begin{array}{l}\text { HILDEBRAND } \\
\text { VISCOSITY }\end{array}$ \\
\hline$\left(s^{-1}\right)$ & $(\mathrm{cc} / \mathrm{g})$ & (poise) & (poise) \\
\hline \multirow[t]{6}{*}{0.8891} & 0.86 & 1018 & 1142 \\
\hline & 0.83 & 1286 & 1454 \\
\hline & 0.80 & 1799 & 2000 \\
\hline & 0.77 & 3202 & 3000 \\
\hline & 0.75 & 4977 & 5333 \\
\hline & 0.72 & 7407 & --- \\
\hline \multirow[t]{6}{*}{0.5000} & 0.86 & 1388 & 1512 \\
\hline & 0.83 & 1787 & 1925 \\
\hline & 0.80 & 2521 & 2647 \\
\hline & 0.77 & 4758 & 4235 \\
\hline & 0.75 & 7955 & 7058 \\
\hline & 0.72 & 11470 & --- \\
\hline \multirow[t]{6}{*}{0.2812} & 0.86 & 2010 & 2142 \\
\hline & 0.83 & 2641 & 2727 \\
\hline & 0.80 & 3703 & 3750 \\
\hline & 0.77 & 7366 & 6000 \\
\hline & 0.75 & 13380 & 10000 \\
\hline & 0.72 & 17320 & --- \\
\hline
\end{tabular}


TABLE 7 (continued)

\begin{tabular}{|c|c|c|c|}
\hline \multirow{2}{*}{$\begin{array}{c}\text { SHEAR } \\
\text { RATE }\end{array}$} & \multirow{3}{*}{$\begin{array}{l}\text { SLURRY } \\
\text { SPECIFIC } \\
\text { VOLUME }\end{array}$} & \multicolumn{2}{|c|}{ EXPERIMENTAL HILDEBRAND } \\
\hline & & VISCOSITY & VISCOSITY \\
\hline & & & \\
\hline$\left(s^{-1}\right)$ & (cc/g) & (poise) & (poise) \\
\hline \multirow[t]{6}{*}{0.1581} & 0.86 & 3041 & 3214 \\
\hline & 0.83 & 4099 & 4090 \\
\hline & 0.80 & 6027 & 5625 \\
\hline & 0.77 & 12210 & 9000 \\
\hline & 0.75 & 23180 & 15000 \\
\hline & 0.72 & 31520 & --- \\
\hline \multirow[t]{6}{*}{0.0889} & 0.86 & 4745 & 5142 \\
\hline & 0.83 & 6696 & 6545 \\
\hline & 0.80 & 9600 & 9000 \\
\hline & 0.77 & 21210 & 14400 \\
\hline & 0.75 & 39420 & 24000 \\
\hline & 0.72 & 49100 & --- \\
\hline \multirow[t]{6}{*}{0.0500} & 0.86 & 7422 & 8489 \\
\hline & 0.83 & 10900 & 10804 \\
\hline & 0.80 & 16620 & 14856 \\
\hline & 0.77 & 32290 & 23770 \\
\hline & 0.75 & 38350 & 39617 \\
\hline & 0.72 & 55930 & -.- \\
\hline
\end{tabular}


TABLE 8

EXPERIMENTAL AND HILDEBRAND/BATSCHINSKI DETERMINED VISCOSITIES FOR PARTICLE SIZED $180 \mu-250 \mu$

$\begin{array}{cccc}\begin{array}{c}\text { SHEAR } \\ \text { RATE }\end{array} & \begin{array}{c}\text { SLURRY } \\ \text { SPECIFIC } \\ \text { VOLUME } \\ (\mathrm{cc} / \mathrm{g})\end{array} & \begin{array}{c}\text { EXPERIMENTAL } \\ \text { VISCOSITY }\end{array} & \begin{array}{c}\text { HILDEBRAND } \\ \text { VISCOSITY }\end{array} \\ \left(\mathrm{s}^{-1}\right) & & \text { (poise) } & \text { (poise) } \\ 0.8891 & 0.86 & 906 & 1071 \\ & 0.83 & 1654 & 1363 \\ & 0.80 & 2076 & 1875 \\ & 0.77 & 3636 & 3000 \\ & 0.75 & 5768 & 5000 \\ 0.5000 & 0.72 & 7785 & -- \\ & & & \\ & 0.86 & 1215 & 1389 \\ & 0.83 & 2303 & 1769 \\ & 0.80 & 2764 & 2432 \\ & 0.77 & 5357 & 3891 \\ & 0.75 & 8544 & 6486 \\ 0.2812 & 0.72 & 13750 & -.- \\ & & & \\ & 0.86 & 1728 & 1978 \\ & 0.83 & 3367 & 2517 \\ & 0.80 & 3981 & 3461 \\ & 0.77 & 8033 & 5538 \\ & 0.75 & 14050 & 9230 \\ & 0.72 & 23230 & --\end{array}$


TABLE 8 (continued)

$\begin{array}{cccc}\begin{array}{c}\text { SHEAR } \\ \text { RATE }\end{array} & \begin{array}{c}\text { SLURRY } \\ \text { SPECIFIC } \\ \text { VOLUME }\end{array} & \begin{array}{c}\text { EXPERIMENTAL } \\ \text { VISCOSITY }\end{array} & \begin{array}{c}\text { HILDEBRAND } \\ \text { VISCOSITY }\end{array} \\ \left(\mathrm{s}^{-1}\right) & \begin{array}{c}\text { (cc/g) } \\ 0.1581\end{array} & \text { (poise) } & \text { (poise) } \\ & 0.86 & 2590 & 2857 \\ & 0.83 & 5391 & 3636 \\ & 0.80 & 6279 & 5000 \\ & 0.77 & 13180 & 8000 \\ 0.0889 & 0.75 & 25020 & 13333 \\ & 0.72 & 44400 & \cdots \\ & & & \\ & 0.86 & 3994 & 4675 \\ & 0.83 & 9121 & 5950 \\ & 0.80 & 10100 & 8181 \\ & 0.77 & 27150 & 13090 \\ 0.0500 & 0.75 & 37470 & 21818 \\ & 0.72 & 37770 & \cdots \\ & & & \\ & 0.86 & 6536 & 8472 \\ & 0.83 & 16810 & 10783 \\ & 0.80 & 18180 & 14827 \\ & 0.77 & 31780 & 23723 \\ & 0.75 & 43400 & 39538 \\ & 0.72 & 51510 & \cdots\end{array}$


TABLE 9

\section{VALUES FOR E AND $m$ IN THE MODIFIED HILDEBRAND/BATSCHINSKI EQUATION}

\begin{tabular}{clcc}
$\begin{array}{c}\text { PARTICLE } \\
\text { SIZE }\end{array}$ & $\begin{array}{l}\text { SHEAR } \\
\text { RATE }\end{array}$ & \multicolumn{1}{c}{$\mathrm{E}$} & $\mathrm{m}$ \\
$\begin{array}{c}\text { (micron) } \\
\left(\mathrm{s}^{-1}\right)\end{array}$ & $\left(\right.$ poise $\left.{ }^{-1}\right)$ & \\
& & & \\
& 0.8891 & $5.39 \mathrm{E}-3$ & 1.19 \\
& 0.5 & $3.82 \mathrm{E}-3$ & 1.22 \\
& 0.2812 & $2.85 \mathrm{E}-3$ & 1.30 \\
& 0.1581 & $2.10 \mathrm{E}-3$ & 1.40 \\
$75 \mu-150 \mu$ & 0.0889 & $6.50 \mathrm{E}-4$ & 1.08 \\
& 0.05 & $6.52 \mathrm{E}-4$ & 1.29 \\
& 0.8891 & $5.54 \mathrm{E}-3$ & \\
& 0.5 & $4.86 \mathrm{E}-3$ & 1.05 \\
& 0.2812 & $3.96 \mathrm{E}-3$ & 1.15 \\
& 0.1581 & $2.98 \mathrm{E}-3$ & 1.25 \\
& 0.0889 & $2.08 \mathrm{E}-3$ & 1.33 \\
& 0.05 & $7.26 \mathrm{E}-4$ & 1.39 \\
& & & 1.10 \\
$180 \mu-250 \mu$ & 0.8891 & $6.00 \mathrm{E}-3$ & \\
& 0.5 & $5.01 \mathrm{E}-3$ & 1.13 \\
& 0.2812 & $4.09 \mathrm{E}-3$ & 1.20 \\
& 0.1581 & $3.16 \mathrm{E}-3$ & 1.29 \\
& 0.0889 & $1.99 \mathrm{E}-3$ & 1.38 \\
& 0.05 & $6.46 \mathrm{E}-4$ & 1.40 \\
& & & 1.09
\end{tabular}


TABLE 10

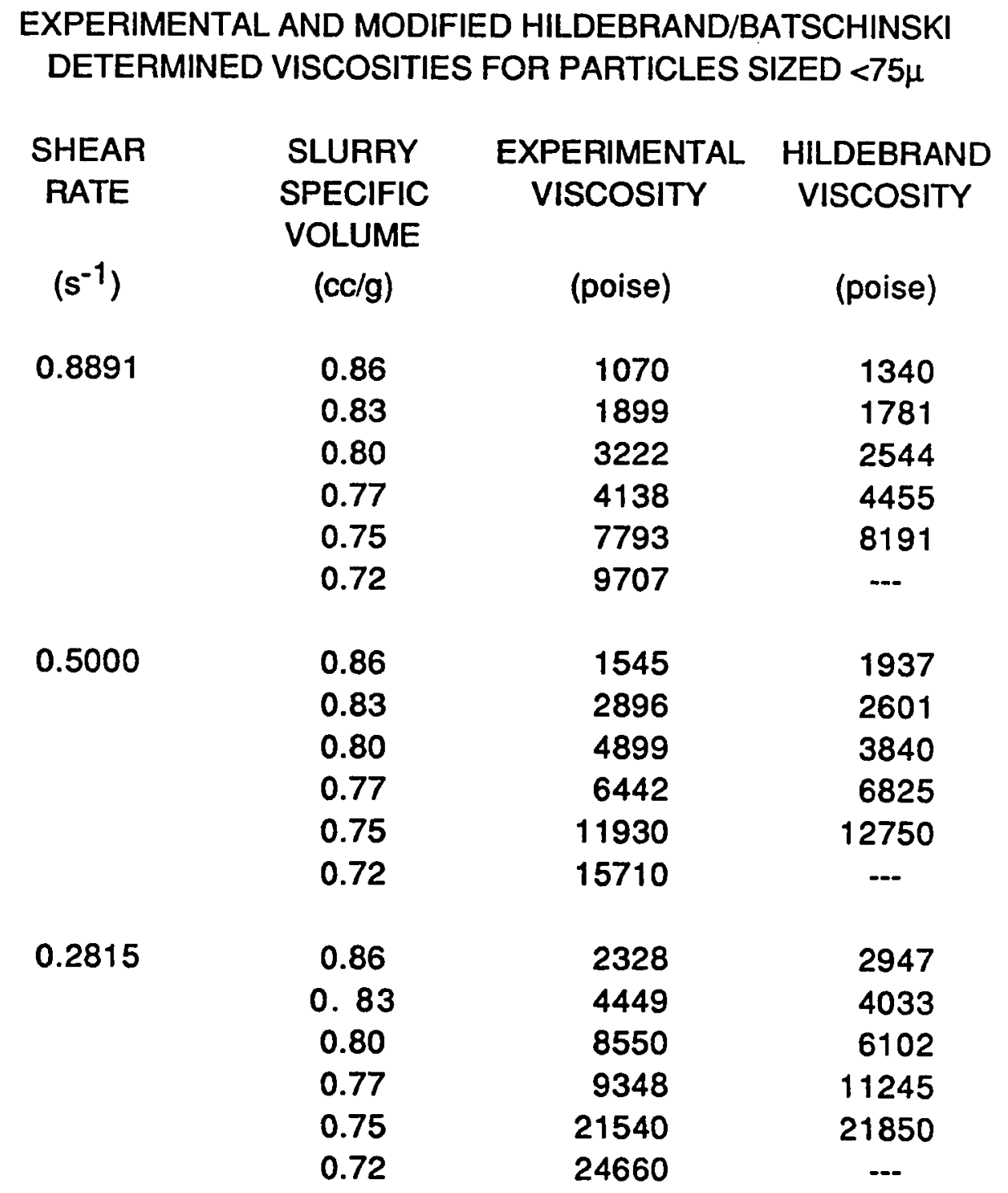


TABLE 10 (continued)

\begin{tabular}{|c|c|c|c|}
\hline $\begin{array}{l}\text { SHEAR } \\
\text { RATE }\end{array}$ & $\begin{array}{l}\text { SLURRY } \\
\text { SPECIFIC } \\
\text { VOLUME }\end{array}$ & $\begin{array}{l}\text { EXPERIMENTAL } \\
\text { VISCOSITY }\end{array}$ & $\begin{array}{l}\text { HILDEBRAND } \\
\text { VISCOSITY }\end{array}$ \\
\hline$\left(s^{-1}\right)$ & $(\mathrm{cc} / \mathrm{g})$ & (poise) & (poise) \\
\hline \multirow[t]{6}{*}{0.1581} & 0.86 & 3647 & 4783 \\
\hline & 0.83 & 7405 & 6719 \\
\hline & 0.80 & 15360 & 10525 \\
\hline & 0.77 & 17490 & 20411 \\
\hline & 0.75 & 39910 & 41925 \\
\hline & 0.72 & 40530 & --- \\
\hline \multirow[t]{6}{*}{0.0889} & 0.86 & 5870 & 9032 \\
\hline & 0.83 & 12460 & 11723 \\
\hline & 0.80 & 28280 & 16543 \\
\hline & 0.77 & 30860 & 27499 \\
\hline & 0.75 & 36060 & 47777 \\
\hline & 0.72 & 40920 & --- \\
\hline \multirow[t]{6}{*}{0.0500} & 0.86 & 6516 & 12801 \\
\hline & 0.83 & 22080 & 17501 \\
\hline & 0.80 & 52420 & 26447 \\
\hline & 0.77 & 55500 & 48646 \\
\hline & 0.75 & 64970 & 94342 \\
\hline & 0.72 & 68550 & $\cdots$ \\
\hline
\end{tabular}




\section{TABLE 11}

EXPERIMENTAL AND MODIFIED HILDEBRAND/BATSCHINSKI DETERMINED VISCOSITIES FOR PARTICLES SIZED $75 \mu-150 \mu$

$\begin{array}{cccc}\begin{array}{c}\text { SHEAR } \\ \text { RATE }\end{array} & \begin{array}{c}\text { SLURRY } \\ \text { SPECIFIC } \\ \text { VOLUME }\end{array} & \begin{array}{c}\text { EXPERIMENTAL } \\ \text { VISCOSITY }\end{array} & \begin{array}{c}\text { HILDEBRAND } \\ \text { VISCOSITY }\end{array} \\ \left(\mathrm{s}^{-1}\right) & (\mathrm{cc} / \mathrm{g}) & (\text { poise) } & \text { (poise) } \\ 0.8891 & 0.86 & 1018 & 1014 \\ & 0.83 & 1286 & 1307 \\ & 0.80 & 1799 & 1829 \\ & 0.77 & 3202 & 3003 \\ & 0.75 & 4977 & 5148 \\ 0.5000 & 0.72 & 7407 & \cdots \\ & & & \\ & 0.86 & 1388 & 1367 \\ & 0.83 & 1787 & 1808 \\ & 0.80 & 2521 & 2613 \\ & 0.77 & 4758 & 4502 \\ & 0.75 & 7955 & 8131 \\ 0.2812 & 0.72 & 11470 & --- \\ & & & \\ & 0.86 & 2010 & 1955 \\ & 0.83 & 2641 & 2644 \\ & 0.80 & 3703 & 3937 \\ & 0.77 & 7366 & 7087 \\ & 0.75 & 13380 & 13424 \\ & 0.72 & 17320 & --- \\ & & & \end{array}$


TABLE 11 (continued)

$\begin{array}{cccc}\begin{array}{c}\text { SHEAR } \\ \text { RATE }\end{array} & \begin{array}{c}\text { SLURRY } \\ \text { SPECIFIC } \\ \text { VOLUME }\end{array} & \begin{array}{c}\text { EXPERIMENTAL } \\ \text { VISCOSITY }\end{array} & \begin{array}{c}\text { HILDEBRAND } \\ \text { VISCOSITY }\end{array} \\ \left(\mathrm{s}^{-1}\right) & \begin{array}{c}\text { (cc/g) } \\ \text { (poise) }\end{array} & \text { (poise) } \\ 0.1581 & 0.86 & 3041 & 2981 \\ & 0.83 & 4099 & 4114 \\ & 0.80 & 6027 & 6296 \\ & 0.77 & 12210 & 11795 \\ & 0.75 & 23180 & 23334 \\ 0.0889 & 0.72 & 31520 & -- \\ & & & \\ & 0.86 & 4745 & 4709 \\ & 0.83 & 6696 & 6592 \\ & 0.80 & 9600 & 10278 \\ & 0.77 & 21210 & 19797 \\ & 0.75 & 39420 & 40365 \\ 0.0500 & 0.72 & 49100 & -- \\ & & & \\ & 0.86 & 7422 & 8354 \\ & 0.83 & 10900 & 10895 \\ & 0.80 & 16620 & 15470 \\ & 0.77 & 32290 & 25956 \\ & 0.75 & 38350 & 45549 \\ & 0.72 & 55930 & --\end{array}$




\section{TABLE 12}

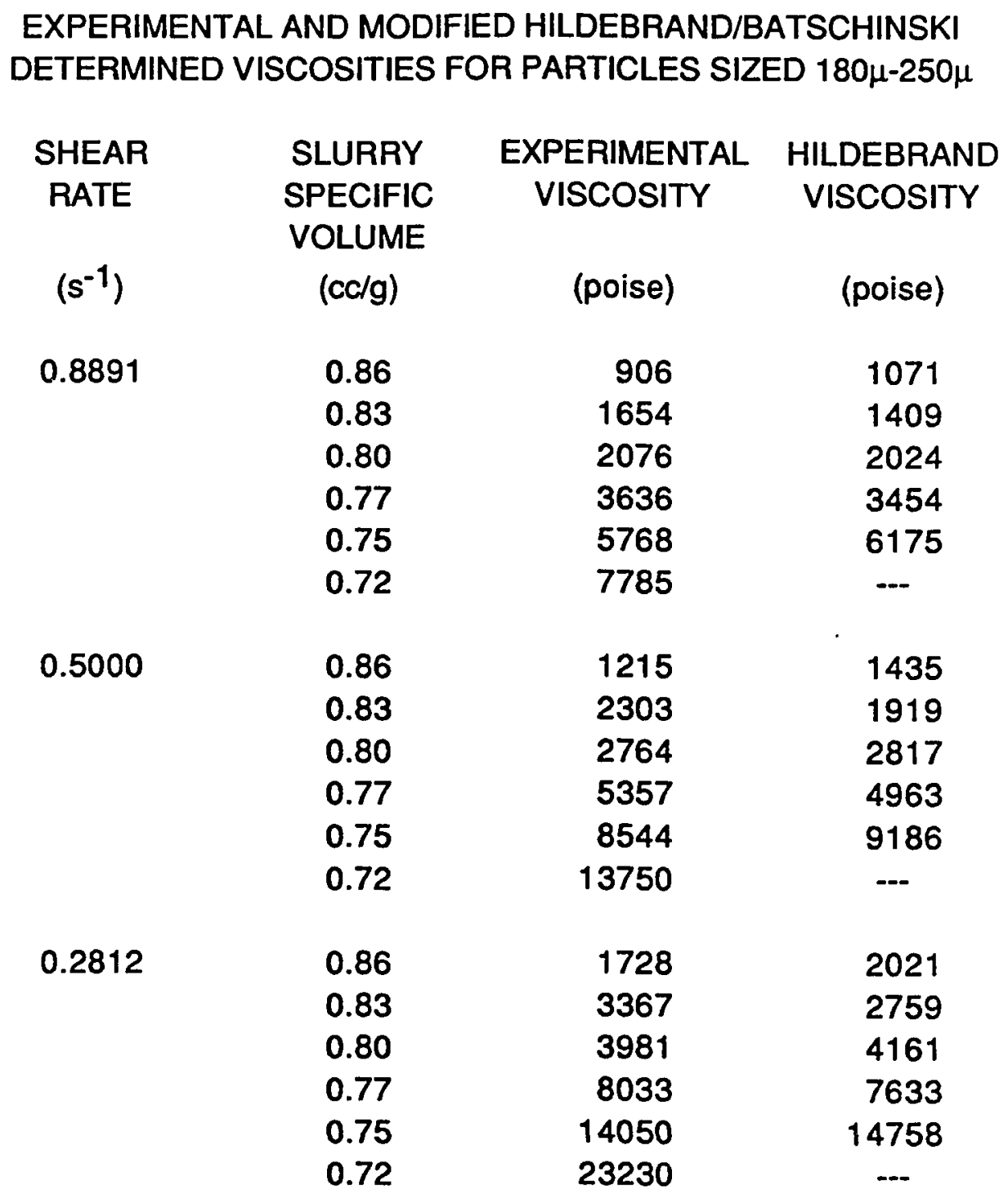


TABLE 12 (continued)

\begin{tabular}{|c|c|c|c|}
\hline $\begin{array}{l}\text { SHEAR } \\
\text { RATE }\end{array}$ & $\begin{array}{l}\text { SLURRY } \\
\text { SPECIFIC } \\
\text { VOLUME }\end{array}$ & $\begin{array}{l}\text { EXPERIMENTAL } \\
\text { VISCOSITY }\end{array}$ & $\begin{array}{l}\text { HILDEBRAND } \\
\text { VISCOSITY }\end{array}$ \\
\hline$\left(s^{-1}\right)$ & $(\mathrm{cc} / \mathrm{g})$ & (poise) & (poise) \\
\hline \multirow[t]{6}{*}{0.1581} & 0.86 & 2590 & 3063 \\
\hline & 0.83 & 5391 & 4280 \\
\hline & 0.80 & 6279 & 6656 \\
\hline & 0.77 & 13180 & 12772 \\
\hline & 0.75 & 25020 & 25935 \\
\hline & 0.72 & 44400 & --- \\
\hline \multirow[t]{6}{*}{0.0889} & 0.86 & 3994 & 5039 \\
\hline & 0.83 & 9121 & 7077 \\
\hline & 0.80 & 10100 & 11081 \\
\hline & 0.77 & 27150 & 21477 \\
\hline & 0.75 & 37470 & 44088 \\
\hline & 0.72 & 37770 & --- \\
\hline \multirow[t]{6}{*}{0.0500} & 0.86 & 6536 & 9283 \\
\hline & 0.83 & 16810 & 12086 \\
\hline & 0.80 & 18180 & 17123 \\
\hline & 0.77 & 31780 & 28635 \\
\hline & 0.75 & 43400 & 50073 \\
\hline & 0.72 & 51510 & --- \\
\hline
\end{tabular}


experimental values. The calculated viscosities for mixtures using 180 microns-250 microns are within twenty percent of the experimental values. This can be compared to the viscosities that were determined by Equation 15. Equation 15 calculated viscosities that were within forty percent of the experimental values. Viscosity calculations are also improved by using Equation 19 for mixtures using particles sized less than 75 microns. In most mixtures, the calculated viscosity was within thirty percent of the experimental values.

Mixing of ammonium sulfate and deaerated polybutadiene was performed at ambient conditions (atmospheric pressure and $25^{\circ} \mathrm{C}$ ). Preliminary studies of the effect of the system pressure on the presence of viscoelasticity in the mixture are shown on Figures 13 and 14 . The data are also presented in the appendix in tabular form. One study involved the addition of solids to the mixture while the second study involved the dilution of a highly concentrated slurry with deaerated polybutadiene. The data points represent the highest system pressure in the mixing vessel at which the material with that solid content just becomes viscoelastic. At pressures greater than the highest system pressure, the material is viscoelastic while at pressures less than the maximum system pressure the material is still fluidlike. A solid line over the data represents a curve fit to the data and the equation is shown on the figure. 
FIGURE 13

SYSTEM PRESSURE FOR INITIAL VISCOELASTIC BEHAVIOR IN AMMONIUM SULFATE/POLYBUTADIENE SLURRY AS A FUNCTION OF CONCENTRATION: SOLIDS ADDITION

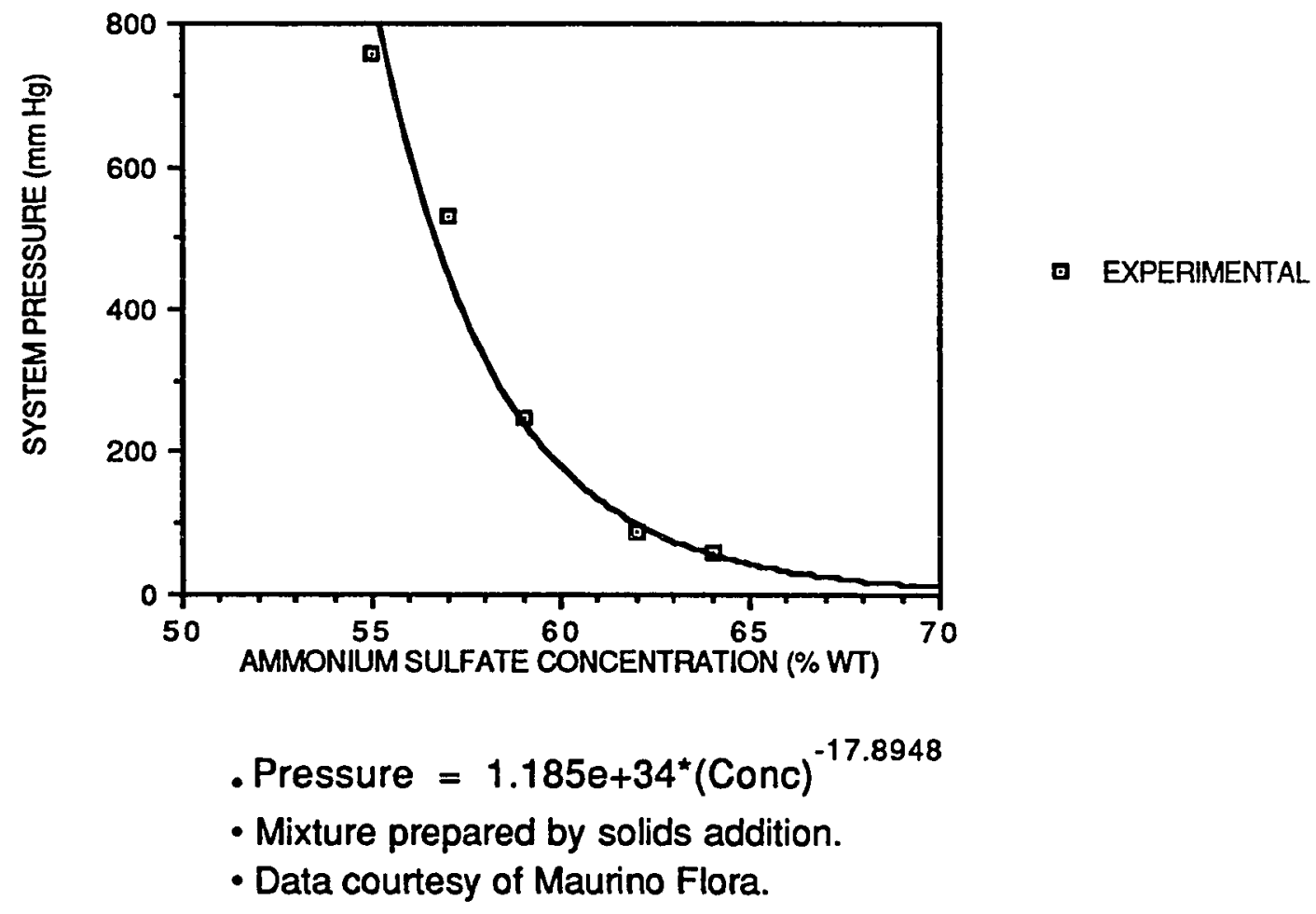




\section{FIGURE 14}

SYSTEM PRESSURE FOR INITIAL VISCOELASTIC BEHAVIOR IN AMMONIUM SULFATE/POLYBUTADIENE SLURRY AS A FUNCTION OF CONCENTRATION: POLYMER ADDITION

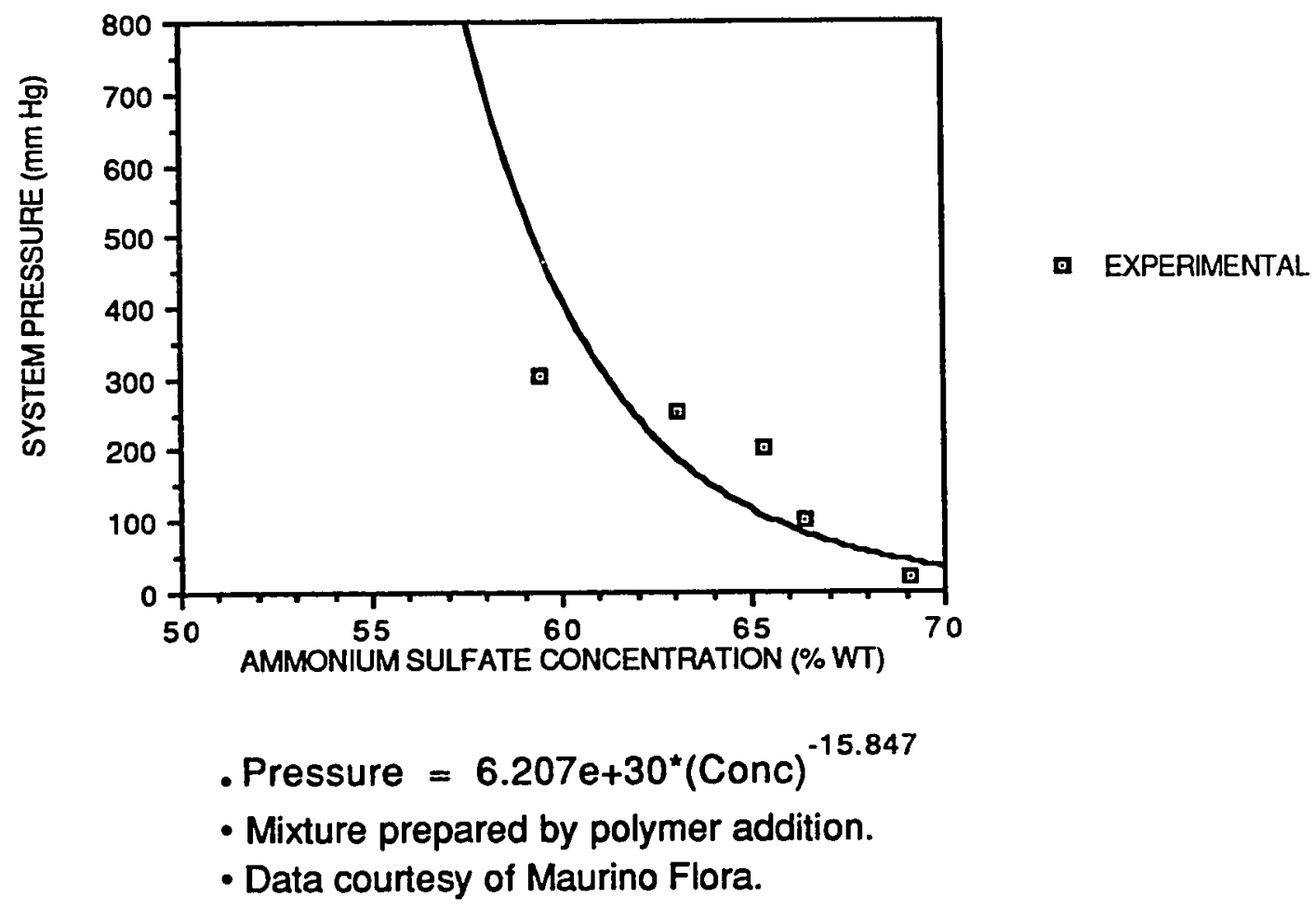




\section{ANALYSIS}

The mixing time required to attain homogeneity in the system of ammonium sulfate and aerated polybutadiene was studied by preparing mixtures and analyzing samples, drawn from the mix, for solids content. The mixture was assumed to be homogeneous if the sample concentrations were within a half a percent of the equilibrium concentration. After all the samples used to determine the concentration profile as a function of time were collected, an additional nine samples were drawn for error analysis. Statistical analysis using the nine samples indicated that the error associated with the experimental method can determine the concentration to within a half of a percent of the true equilibrium value. The small error percentage also indicates that the data represents the behavior of the actual system and is not influenced greatly by the choice of analysis method.

A comparison of mixing times between the different solids sizes shows that mixing with the largest particle size results in the shortest mixing times and that mixing with the smallest particle size results in the longest mixing times. These results may be reasoned from fluid dynamics. The particle is accelerated through the mixing volume by the fluid flow as the blade moves. The momentum imparted to the particle is proportional to the volume and diameter of the particle. Thus, for a given blade speed, the particle with the larger diameter will have the larger momentum. The smaller particle, with the least momentum, will tend to follow the streamline unless 
acted upon by forces due to other particles. The larger sized particle, having a larger momentum, can more easily deviate from the streamline and disperse more rapidly. A streamline is a curve in the fluid flow which at any instant of time is tangent to the velocity vectors of the fluid particles.

For a given particle size, the trend is decreasing mixing time with increasing concentration. This conclusion may also be explained by analyzing particle momentum. At lower concentrations, the momentum of the particle is dissipated by the viscous forces of the fluid, and the particle is relocated to another equilibrium position in the mixing volume. At higher concentration, the momentum of the particle is dissipated by other particles in addition to the fluid forces. Interactions between particles allow the transfer of momentum, and, as a result, many more particles are relocated to other equilibrium positions.

In order to analyze the viscous effects, a function relating viscosity and concentration would be necessary. Two functions were proposed: the Hildebrand/Batschinski equation (Equation 15) and the modified Hildebrand/Batschinski equation (Equation 19). Hildebrand modified Batschinski's equation for use in describing simple fluids. Thus, Equation 15 may not be applicable for the ammonium sulfate/aerated polybutadiene system. Equation 15 was modified by raising the specific volume term to a power $m$ which would account for the nonideality of the system. The power $m$ was found to vary with the particle size and shear rate. For a particular particle size, independent of the shear rate, the values for $m$ varied within 
fifteen percent of the calculated average value for $m$. However, for shear rates ranging between $0.8891 \mathrm{~s}^{-1}$ and $0.1581 \mathrm{~s}^{-1}$, the values varied within six percent of the calculated average value, independent of particle size. For the remaining two shear rates, the values varied within sixteen percent of the average value for $m$. This conclusion indicates that $m$ is perhaps more influenced by the particle size and low shear rates rather than by the high shear rates. Studies need to be performed in order to define the relationship between $m$ and particle size and shear rate.

Preliminary studies on the effect of system pressure on the presence of viscoelasticity in the mixing media indicated that the solids content may be increased if deaerated polybutadiene was used and mixing occurred at vacuum conditions. Dissolved air in the polymer acts like solids in slurries, with respect to viscosity. Thus, the removal of the dissolved air allows the increase in the solids content. 


\section{CONCLUSIONS}

A semi-empirical model is proposed for the mixing time of ammonium sulfate in aerated polybutadiene as a function of agitation rate, fluid viscosity, and particle size and concentration. The model has the form

$$
c\left(t^{*}\right)=K\left\{1-\frac{\exp \left(\frac{-\zeta t^{*}}{T_{c}}\right)}{\sqrt{1-\zeta^{2}}} \sin \left(\sqrt{1-\zeta^{2}} \frac{t^{*}}{T_{c}}+\cos ^{-1}(\zeta)\right)\right\}
$$

where $t^{*}$ is the modified time, actual time divided by ten. The three parameters in the model are the gain, $K$, the characteristic time, $T_{C}$, and the damping factor, $\zeta$. A mixing model based on the above equation may be valid for two reasons. The model qualitatively describes the behavior of the concentration gradient at any position in the mixing vessel as a function of time. The parameters can be explained in terms of the mixing phenomenon. The gain is inherently unity for a batch mixing. The decay function represents the tendency of the system towards homogeneity, and the damping function represents the resistance to dispersion of the solids. The characteristic time $T_{C}$ is hypothesized to be dependent on the agitation rate and has the form

$$
\text { characteristic time }=\left(\text { RPM of solid blade }{ }^{*} 10\right)^{-1} .
$$

The effects of agitation rate and fluid viscosity on the mixing time and their representation in the model equation will be found by further experimentation. This experimentation involves varying either agitation rate 
or fluid viscosity, holding the other process variables constant and repeating the experimental procedure.

The effect of particle size and concentration on the mixing of ammonium sulfate and polybutadiene was studied. The time required for homogeneity was found to decrease with increasing particle size and, for a certain particle size, with increasing concentration. These observations may be explained by particle momentum. The larger sized particle will have greater momemtum than a smaller sized particle. For a fixed blade speed, the smaller particle will have the least momentum and will tend to follow the streamline. The larger particle, having greater momentum can deviate from the streamline and disperse more rapidly than smaller particles. In high concentrated mixtures, the transfer of momentum between particles results in the relocation of many particles. This is compared to the low concentrated mixtures, where the transfer of momentum is either between particle and fluid or between few particles.

Two correlations were tested for the possible relationship between viscosity and concentration. The first correlation was the Hildebrand/Batschinski equation.

$$
\eta=\frac{V_{0}}{E\left(V-V_{0}\right)}
$$

This relation predicted viscosities within twenty percent of the experimental value for most mixtures of particle size 75 microns-150 microns. For mixtures of particles less than 75 microns and 180 microns-250 microns, the 
calculated viscosities deviated much more than twenty percent. Negative values for viscosity were also determined by this equation. This was possible if $V$, the specific volume of the mixture, was less than $V_{0}$, the specific volume of the mixture at infinite viscosity.

The second equation was a modification of the Hildebrand/Batschinski equation.

$$
\frac{1}{\eta}=E\left(\frac{V-V_{0}}{V_{0}}\right)^{m}
$$

This relation predicted viscosities that were within ten percent of the experimental values for most mixtures of particle size 75 microns -150 microns, within twenty percent for mixtures of particle size 180 microns-250 microns, and within thirty percent for mixture of particle size less than 75 microns. By specifying $V_{0}$ to be the specific volume of a $55 \%$ concentrated mixture, when viscoelasticity was visually noted, negative values for viscosity were avoided.

The effect of particle size and concentration was one facet of the larger project: the development of a comprehensive mixing model for ammonium sulfate and polybutadiene. Other aspects to be considered are the effects of variable agitation rate and variable fluid viscosity. These aspects can be considered by varying one and maintaining the other process variable constant while repeating the experimental procedures outlined in this work. 


\section{APPENDICES}


NOMENCLATURE

\begin{tabular}{|c|c|}
\hline a & constant in exponential equation \\
\hline$a^{\prime}$ & empirical constant in Moo-Young equation \\
\hline$A^{\prime}$ & empirical constant in Moo-Young equation \\
\hline b & constant in exponential equation \\
\hline B & width of baffle \\
\hline $\mathrm{C}_{\mathrm{H}}$ & constant in Hoogendoorn/den Hartog equation \\
\hline c(base) & base concentration \\
\hline$c(t)$ & concentration at time $t$ \\
\hline$c(10 \%)$ & concentration of $10 \%$ by weight mixture \\
\hline$c(\infty)$ & concentration at time $t=\infty$ \\
\hline$\hat{c}$ & constant in Brennan/Lehrer equation \\
\hline C & distance \\
\hline$C_{D}$ & drag force \\
\hline d & impeller diameter \\
\hline D & diameter of vessel \\
\hline $\mathrm{D}_{\mathrm{ABM}}$ & diffusivity of mass due to molecular diffusion \\
\hline $\mathbf{E}$ & constant in Hildebrand/Batschinski equation \\
\hline$f$ & fluid flow behavior index \\
\hline g & conversion constant \\
\hline $\mathbf{F}$ & driving force \\
\hline $\mathrm{H}$ & height of liquid surface above vessel base at vessel axis \\
\hline J & fluid consistency coefficient \\
\hline k & Hooke's constant \\
\hline K & gain \\
\hline m & $\begin{array}{l}\text { index to represent nonideality in Hildebrand/Batschinski } \\
\text { equation }\end{array}$ \\
\hline $\mathbf{n}$ & stirring rate \\
\hline N & impeller rotational speed \\
\hline$p$ & degree of homogeneity \\
\hline$P$ & viscous damping coefficient \\
\hline $\operatorname{Re}$ & generalized Reynolds number \\
\hline & \\
\hline
\end{tabular}




\begin{tabular}{|c|c|}
\hline$t^{*}$ & modified time \\
\hline$t_{p}$ & mixing time in which $p \%$ of vessel volume is mixed \\
\hline$\vec{v}$ & $\begin{array}{l}\text { volume of liquid in vessel } \\
\text { specific volume }\end{array}$ \\
\hline$v_{0}$ & specific volume at infinite viscosity \\
\hline w & impeller blade width \\
\hline W & weight \\
\hline$x$ & mass fraction of solids \\
\hline $\mathbf{z}$ & diffusion distance \\
\hline B & constant in exponential equation \\
\hline$\zeta$ & damping factor \\
\hline$\eta$ & viscosity \\
\hline$\theta$ & mixing time \\
\hline$\theta_{M}$ & mixing time due to molecular diffusion \\
\hline$\theta_{p}$ & batch mixing time for $p$ \\
\hline$\theta_{T}$ & mixing time due to turbulent motion \\
\hline $\mathbf{v}$ & velocity \\
\hline$\rho$ & density \\
\hline$\phi$ & power number \\
\hline$\Psi$ & velocity factor \\
\hline
\end{tabular}




\section{REFERENCES}

[1] Kubota, Naminosuke. "Survey of Rocket Propellants and Their Combustion Characteristics." In Fundamentals of SolidPropellant Combustion. Ed. Kenneth K. Kuo and Martin Summerfield. New York: American Institute of Aeronautics and Astronautics, 1984, pp. 1-52

[2] Klager, K. and J. M. Wrightson. "Recent Advances in Solid Propellant Binder Chemistry." In Solid Propellant Technology. Ed. Francis A. Warren. New York: American Institute of Aeronautics and Astronautics, 1970, pp. 37-64

[3] Private Communication

[4] C. J. Hoogendoorn and A. P. den Hartog, Chem. Eng. Sci, 22, 1689 (1967)

[5] S. Nagata, M. Nishikawa, T. Katsube, and K. Takaish, Int. Chem. Engrs., 12:1, 175 (1972)

[6] D. J. Brennan and I. H. Lehrer, Trans. Instn. Chem. Engrs., 54, 139 (1976)

[7] M. Moo-Young, K. Tichar, and F. A. L. Dullien, A.LCh.E. L., 18:1, 178 (1972)

[8] J. G. van de Vusse, Chem. Eng. Sci., 4, 178 (1955)

[9] D. R. Coughanowr and L. B. Koppel, Process Systems Analysis and Control, McGraw-Hill, New York, 1965, pp. 82-86 
[10] R. Byron Bird, Warren E. Stewart, and Edwin N. Lightfoot, Transport Phenomena, Wiley, New York, 1960, pp. 56-59

[11] M. R. Kamal and A. Mutel, L Polym. Eng, 5:4, 293 (1985)

[12] A. B. Metzner, L. Bheol, 29:6, 739 (1985)

[13] J. H. Hildebrand, Viscosity and Diffusivity, Wiley-Interscience, New York, 1977, pp. 15-28

[14] A. J. Batschinski, Z. Physik. Chim., 84, 643 (1913)

[15] Krieger, Irvin M. "Rheology of Emulsions and Dispersions." In Physical Properties of Foods. Ed. Micha Peleg and Edward B. Bagley. Westport, CT: AVI Publishers, 1983, pp. 351-398

[16] H. B. Ries, Int. Chem. Engrs., 18:3, 426 (1978)

[17] A. S. Michaels and Y. Puzinaukas, Chem. Eng. Prog., 50:12, 604 (1954)

[18] J. W. Hiby, Int Chem. Engrs, 21:2, 197 (1981)

[19] H. Blasinski, Int Chem. Engrs., 12:1, 24 (1972)

[20] D. E. Ford, R. A. Mashelkar, and J. Ulbrecht, Process Technology

Intern., 17:10, 803 (1972)

[21] V. V. Chavan, D. E. Ford, and J. Arumugam, Can. J. Chem. Eng., 53, 628 (1975)

[22] Private Communication 


\section{EXPERIMENTAL DETAILS}

There were three stages in the procedure: solids preparation, mixing, and sample analysis. The solids preparation involved separating the ammonium sulfate into size ranges by using a Rotap sieve shaker and U.S. Standard Sieves. It was discovered that the amount of time for vibration affected the amount of solids collected. Increasing the length of time resulted in the solids degrading and filtering down to the smaller sized sieves. Ammonium sulfate was collected in three size ranges: 180 microns 250 microns, 75 microns - 150 microns, and particle size less than 75 microns.

The mixing was performed with a vertical mixer (Model 4PU, Baker Perkins). The mixing vessel was a clear Lucite bowl provided by Baker Perkins. The mixing bowl was raised or lowered by air cylinders. Above the mixing bowl was the stationary housing which had on opposite sides port holes for charging materials into the bowl. The steel agitators dropped beneath the stationary housing. These agitators operated at different speeds with double planetary motion. Above the stationary housing was located the motor, the motor shaft and the connection to a DC controller. The DC controller was installed to allow variation in the blade speed. The voltage on the $\mathrm{DC}$ controller was arbitrarily set at sixty volts. A counter (Model CUB2L8, Red Lion Controls) was installed to monitor the number of revolutions of the motor shaft. By timing the revolutions of the motor shaft a 
correlation between time and shaft revolutions was established.

Initially approximately $\mathbf{2 0 0 0}$ grams of polybutadiene was poured into the mixing vessel. An amount of ammonium sulfate, sufficient to give a ten weigh percent solids mixture, was evenly distributed onto the surface. The bowl was raised and the mixer turned on. The speed of the slower blade was arbitrarily set at 3.9 revolutions per minute. Periodically the mixing was stopped and samples were drawn for analysis. Samples were drawn in three minute intervals during a total mixing time of approximately sixty minutes. The sampling instrument was a syringe on the end of a clutch cable. The clutch cable was fitted with an aluminum amount to hold the syringe. The syringe was lowered through one of the port holes and samples were drawn by pulling on the clutch cable. Three samples of approximately two grams were drawn from the surface, the center, and the bottom of the mixing volume. The drawn samples were placed in weighed, labeled glass jars.

The samples were analyzed for their solids content. Each sample was reweighed and the sample's mass was determined. After many tests it was found that carbon tetrachloride was the most suitable solvent for this work. The solvent dissolved the polymer but not the ammonium sulfate. The dissolved sample was filtered by vacuum into a Büchner funnel containing weighed filter paper. The dissolved sample was poured into the funnel and the sample bottle rinsed with carbon tetrachloride. The rinse solvent was also poured into the funnel. Approximately $50 \mathrm{ml}$ of the solvent was used to 
rinse the filter paper. The filter was removed from the funnel and allowed to dry overnight at ambient conditions. The filter was reweighed and the mass of collected solids determined.

After the last samples were drawn from the mixture, the mixture was agitated for approximately twenty minutes. Nine samples were drawn, three samples from each position. The concentration of these samples were used for error analysis. It was assumed that after twenty minutes of continuous mixing, in addition to the sixty minutes of noncontinuous mixing, the mixture would be homogeneous and the concentration of these nine samples would be uniform. The standard deviation was calculated using the concentration values of these nine samples, and this deviation was assumed to be the error due to the experimental method chosen and not due to the mixing process.

The amounts of ammonium sulfate and polybutadiene were determined and taken into account when solids were added to the mixture. In most cases, the amount of solids added was calculated so that the increase in concentration was approximately ten percent. The desired increase was usually not met because of either loss of material due to sampling (material on the outer surfaces of the sampling instrument) or addition of excess solids. 


\section{EXPERIMENTAL DATA}

The mixing occurred at ambient conditions and at an agitation rate of 3.9 RPM. A plasticizer was not added to the aerated polybutadiene prior to mixing. Mixing was performed with three particle sizes: less than 75 microns, 75 microns-150 microns, and 180 microns-250 microns. Figures $15,16,17$, and 18 display the experimental data for mixture using particles less than 75 microns in diameter. Data for the 75 microns-150 microns particles are shown on Figures 19, 20, 21, 22, and 23 . Figures 24, 25, 26, 27,28 , and 29 present the data for particles sized 180 microns-250 microns. The viscosity data collected by Ed Lee and John Denham are presented in tabular form on Tables 13,14, and 15. Table 16 displays the data collected by Maurino Flora. 
FIGURE 15

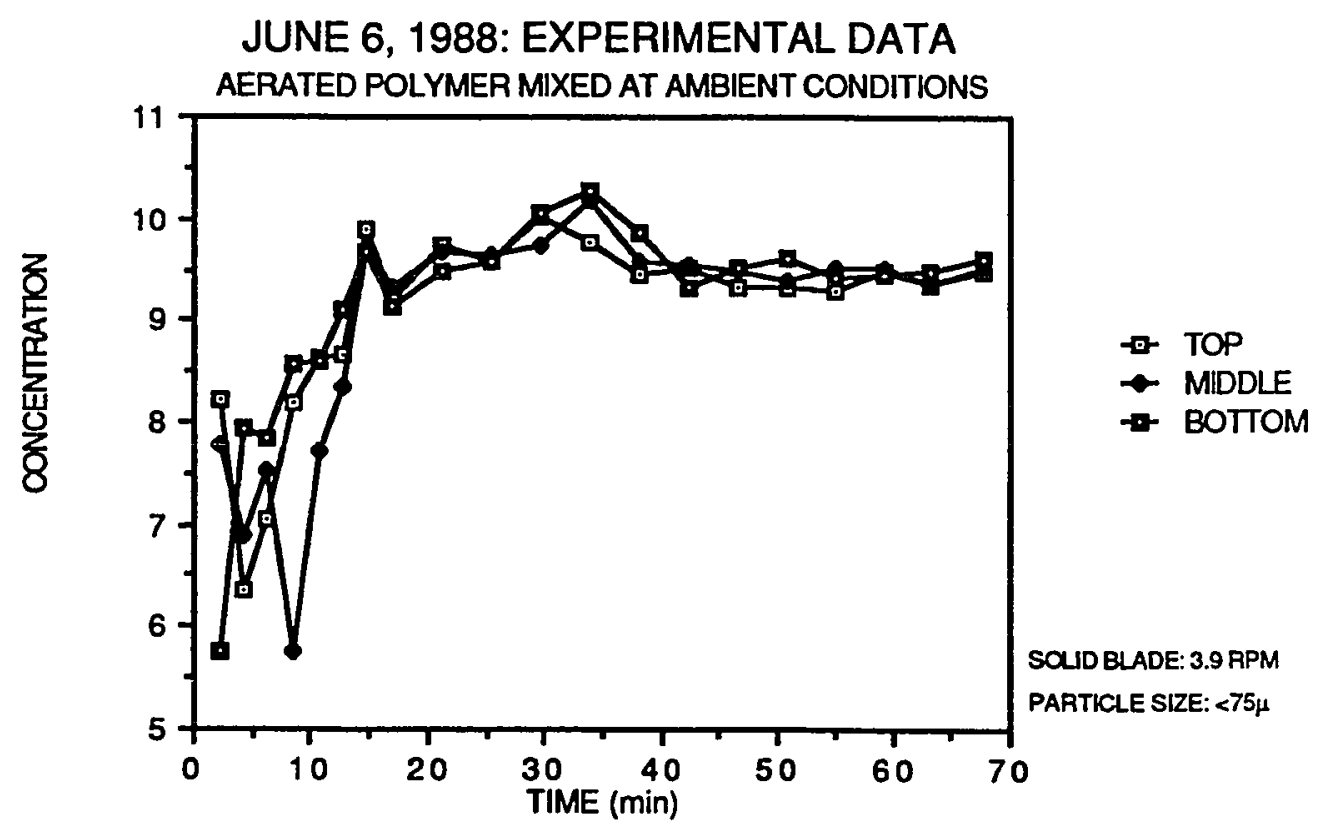


FIGURE 16

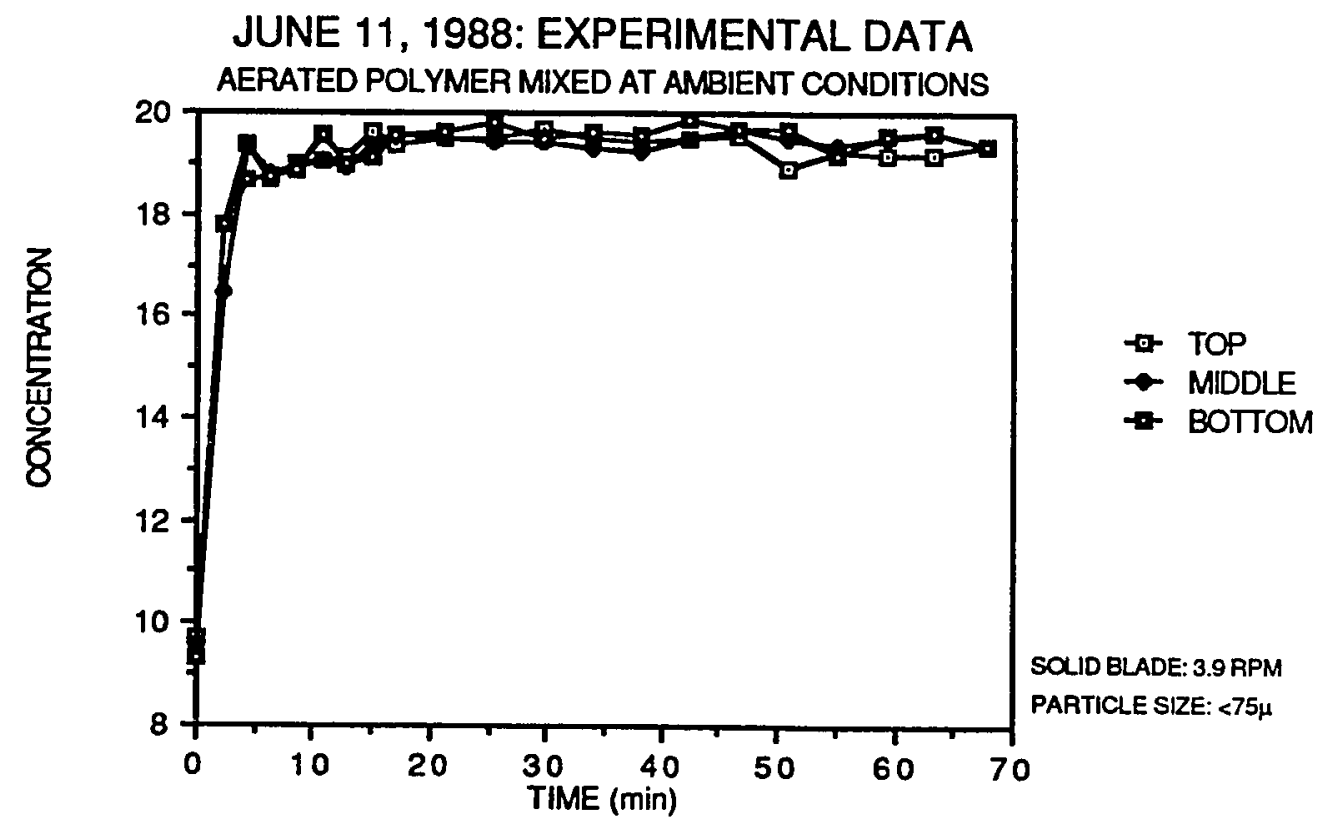


FIGURE 17

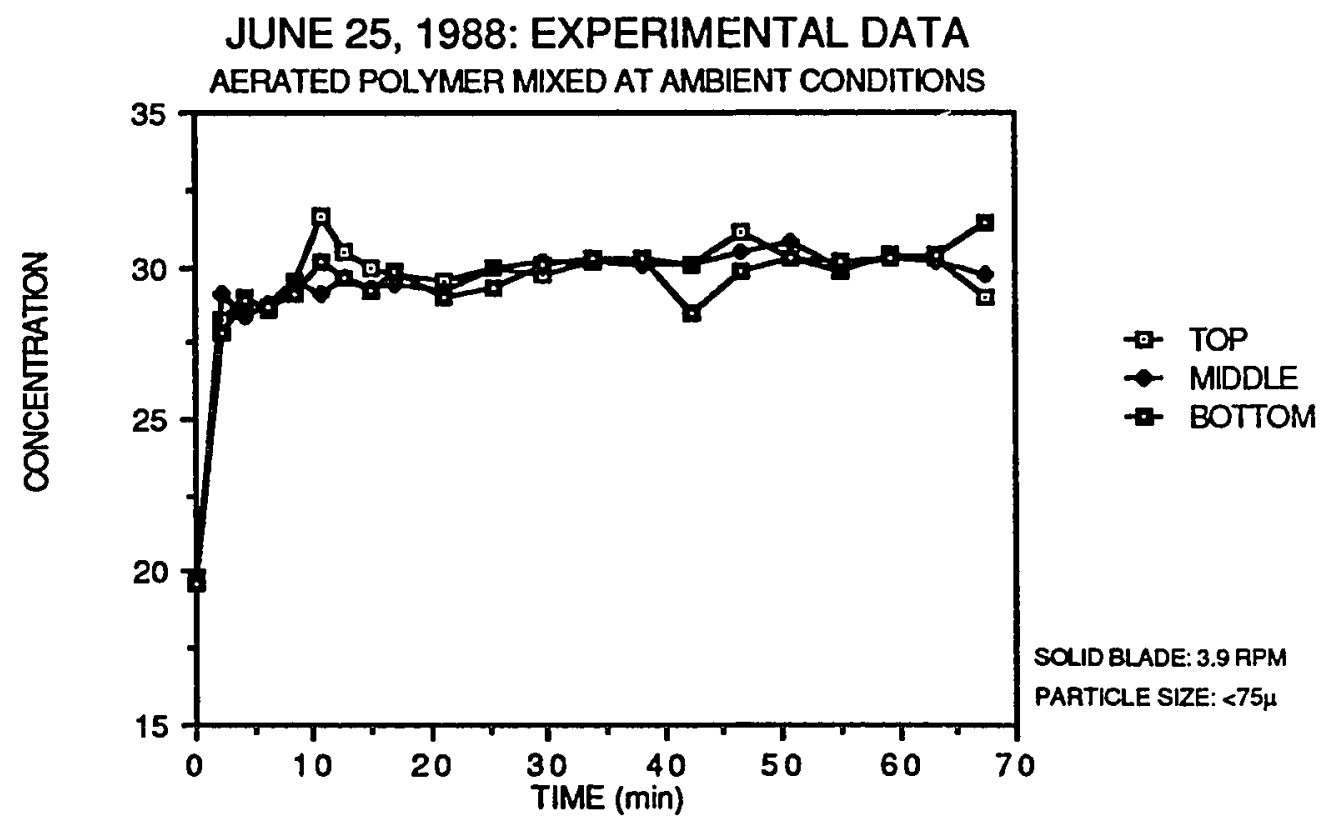


FIGURE 18

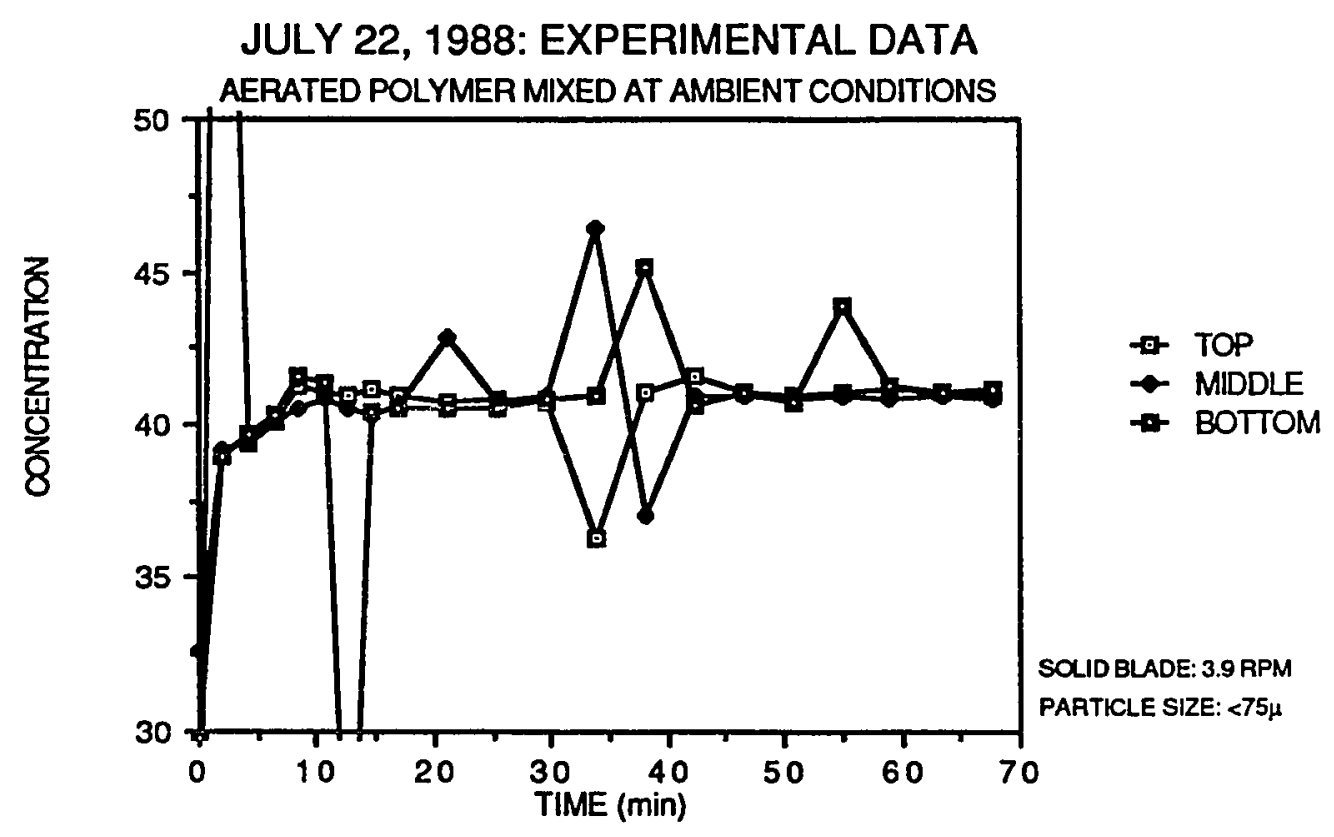


FIGURE 19

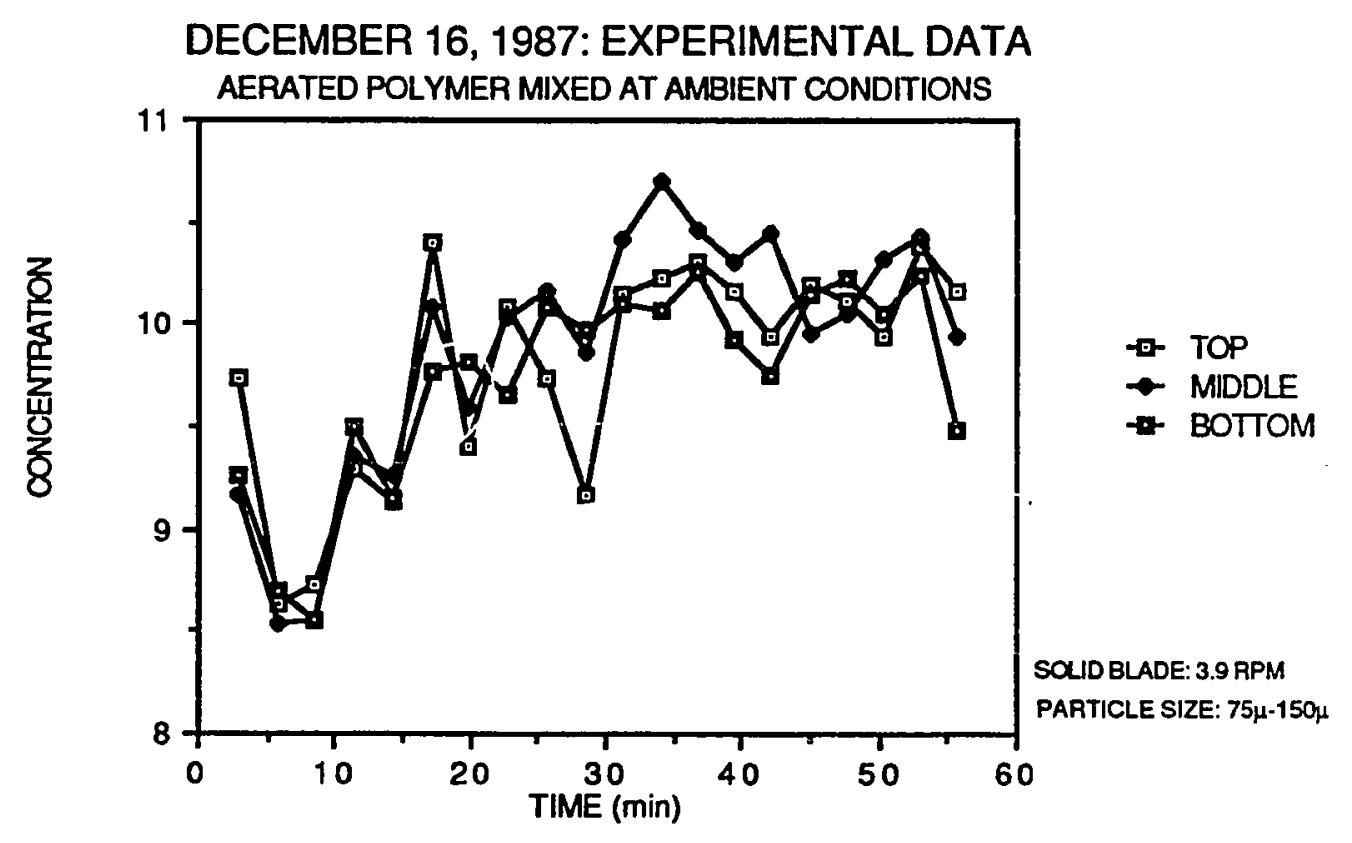


FIGURE 20

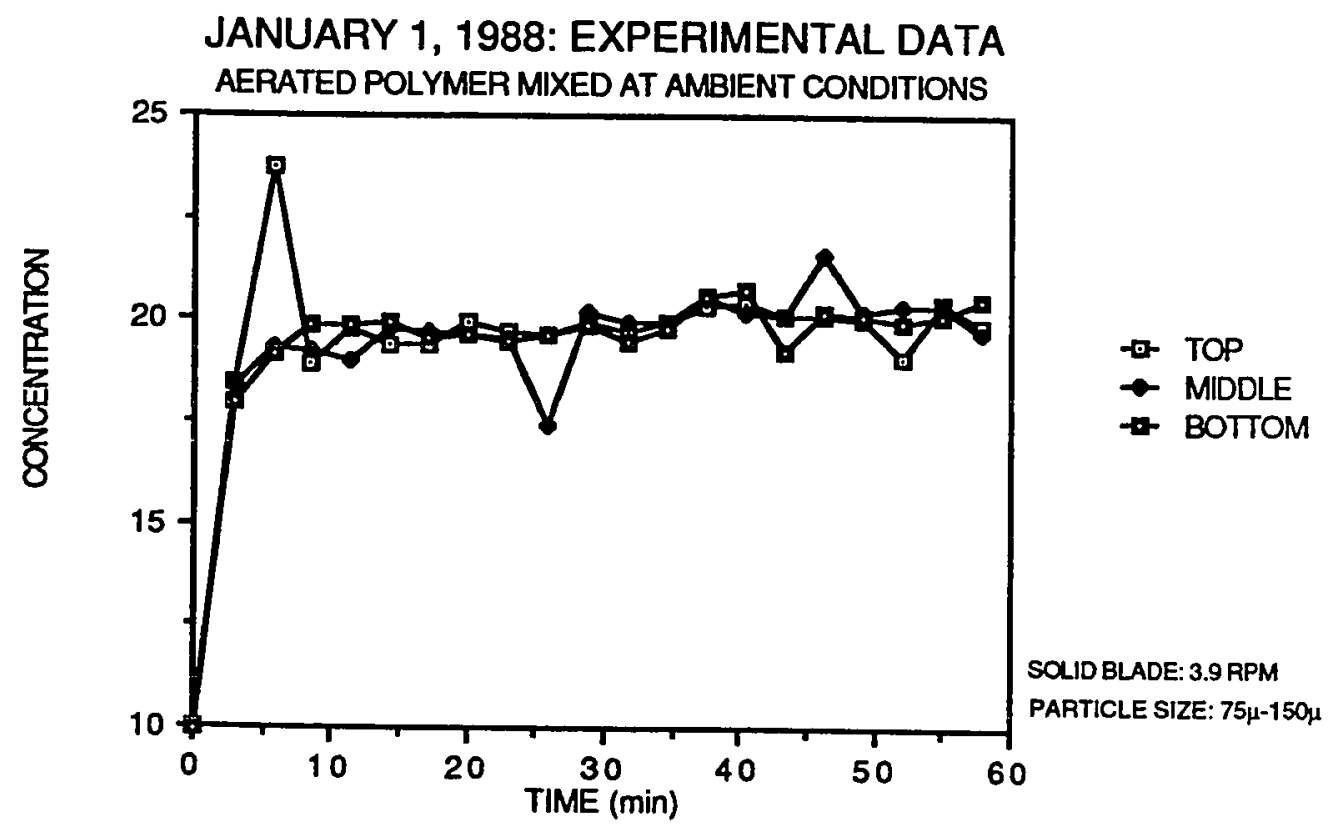


FIGURE 21

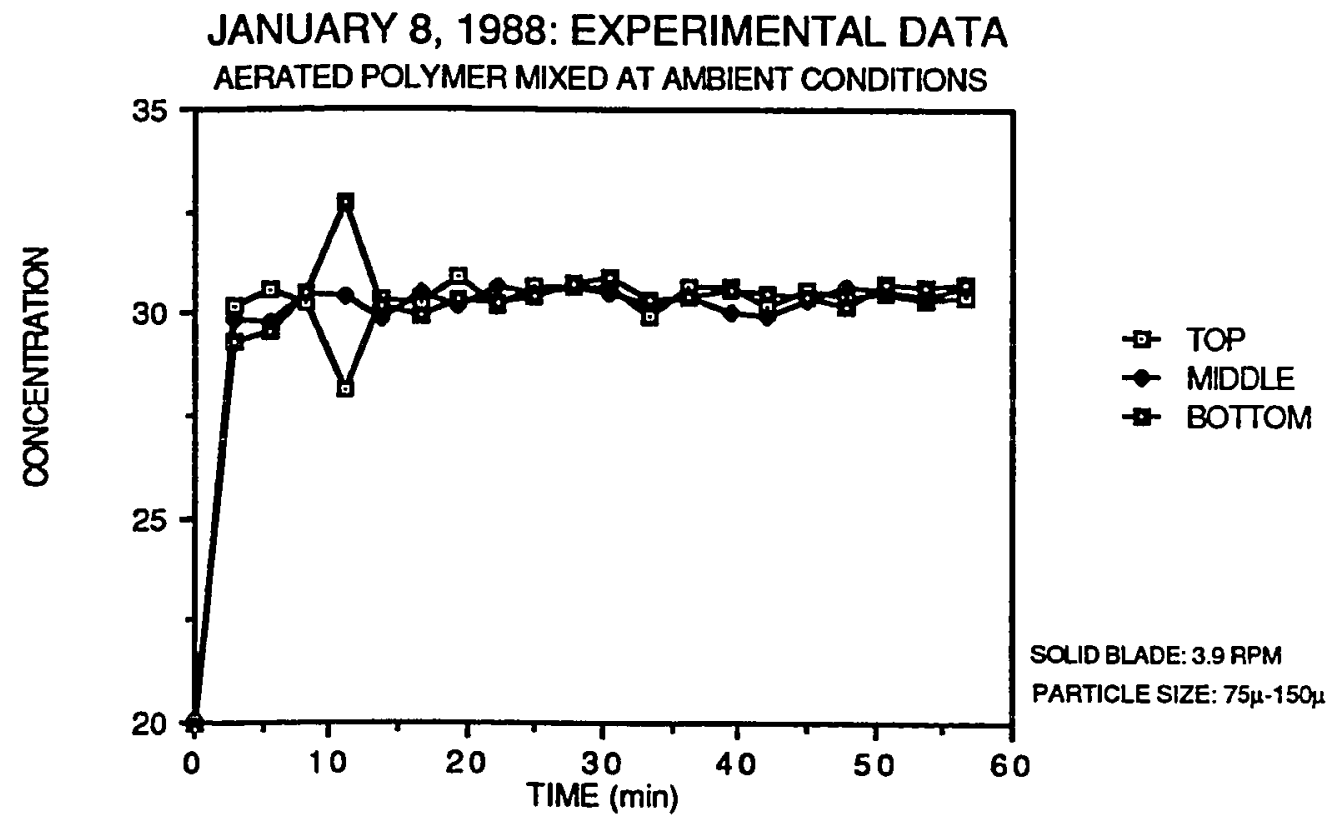


FIGURE 22

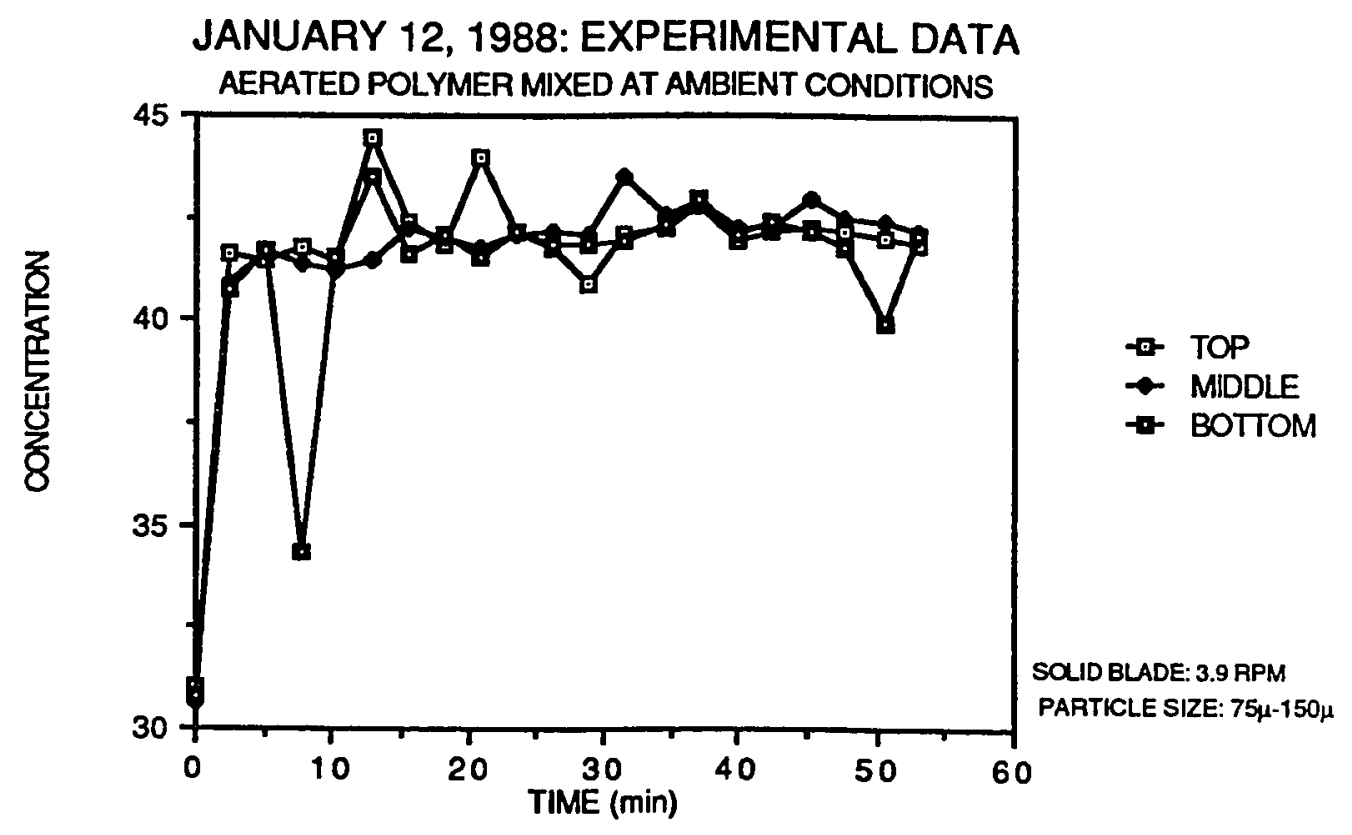




\section{FIGURE 23}

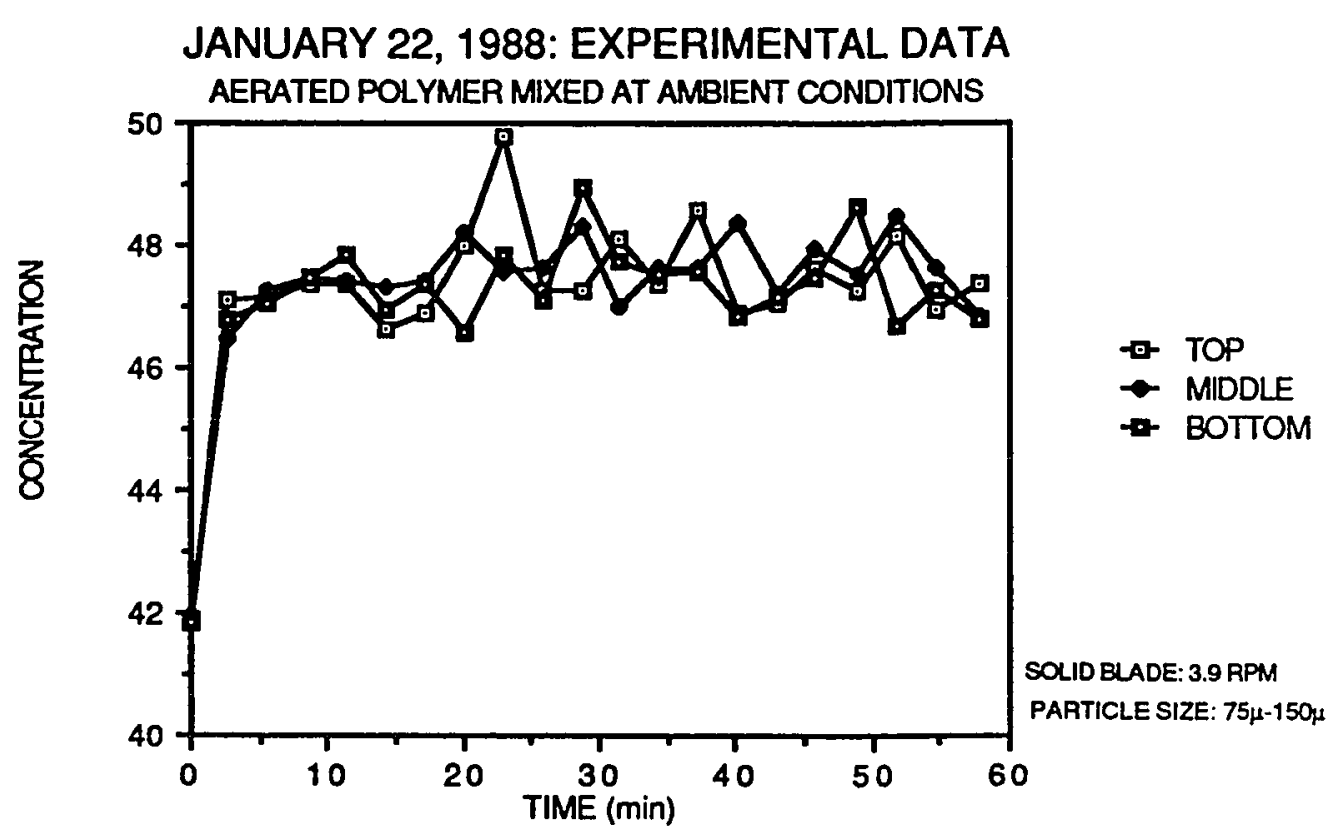


FIGURE 24

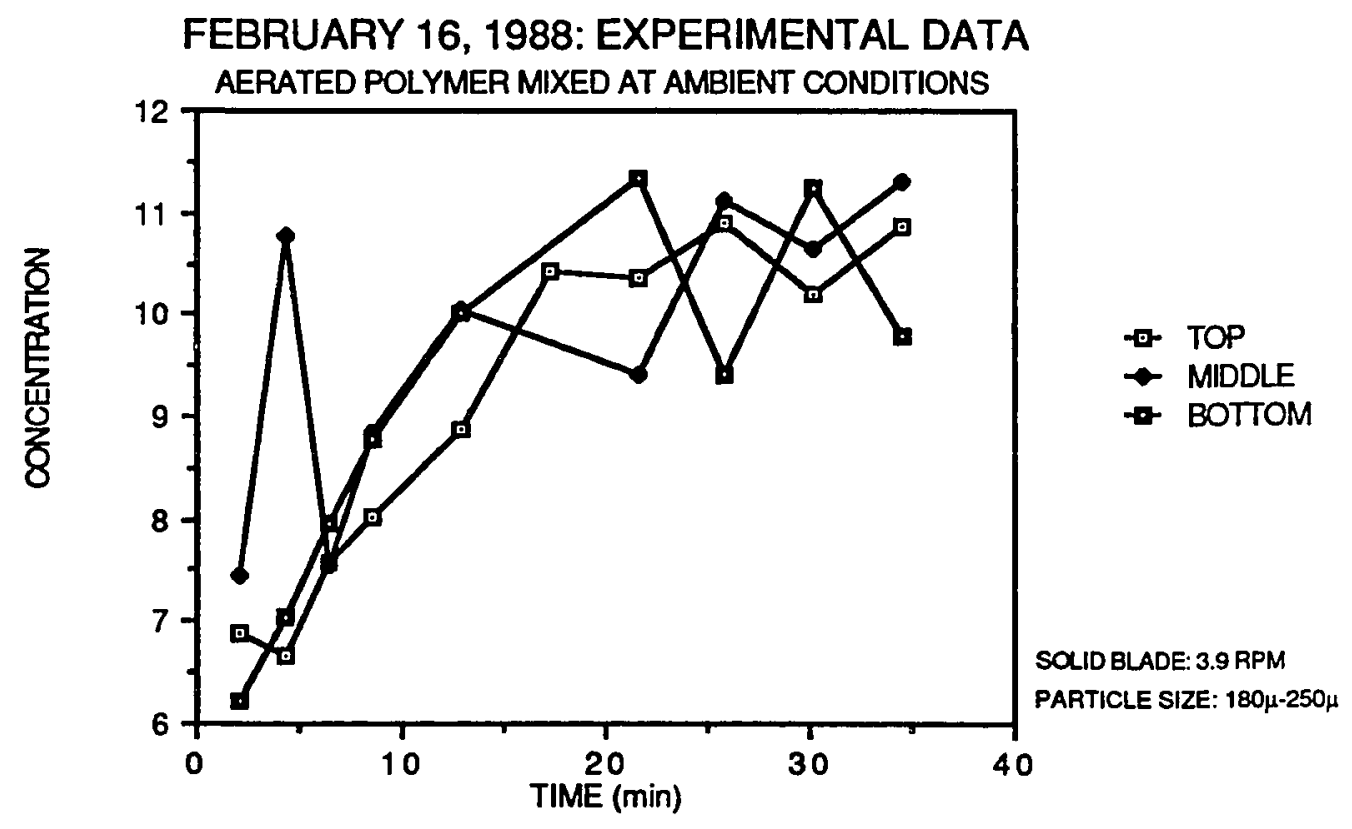


FIGURE 25

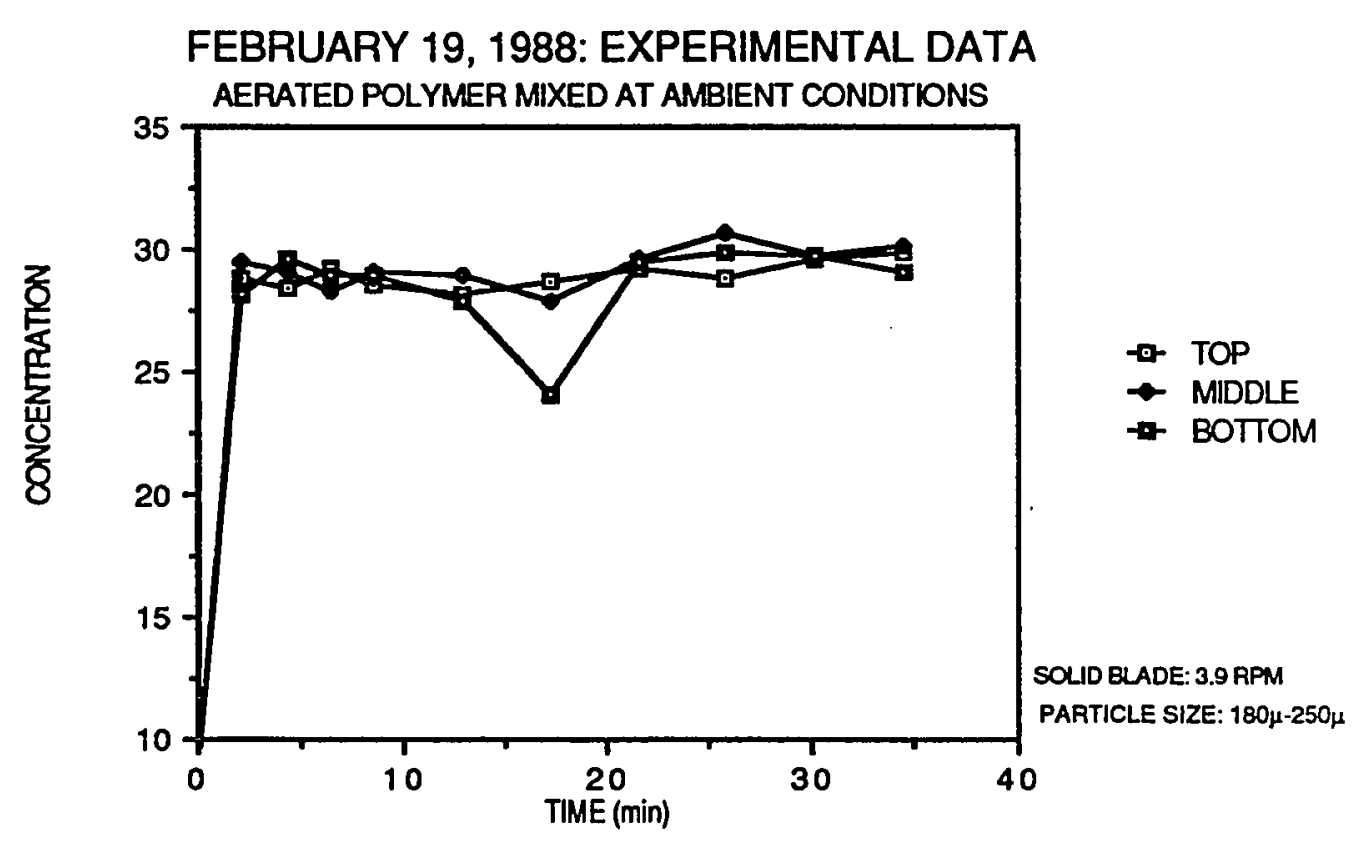


FIGURE 26

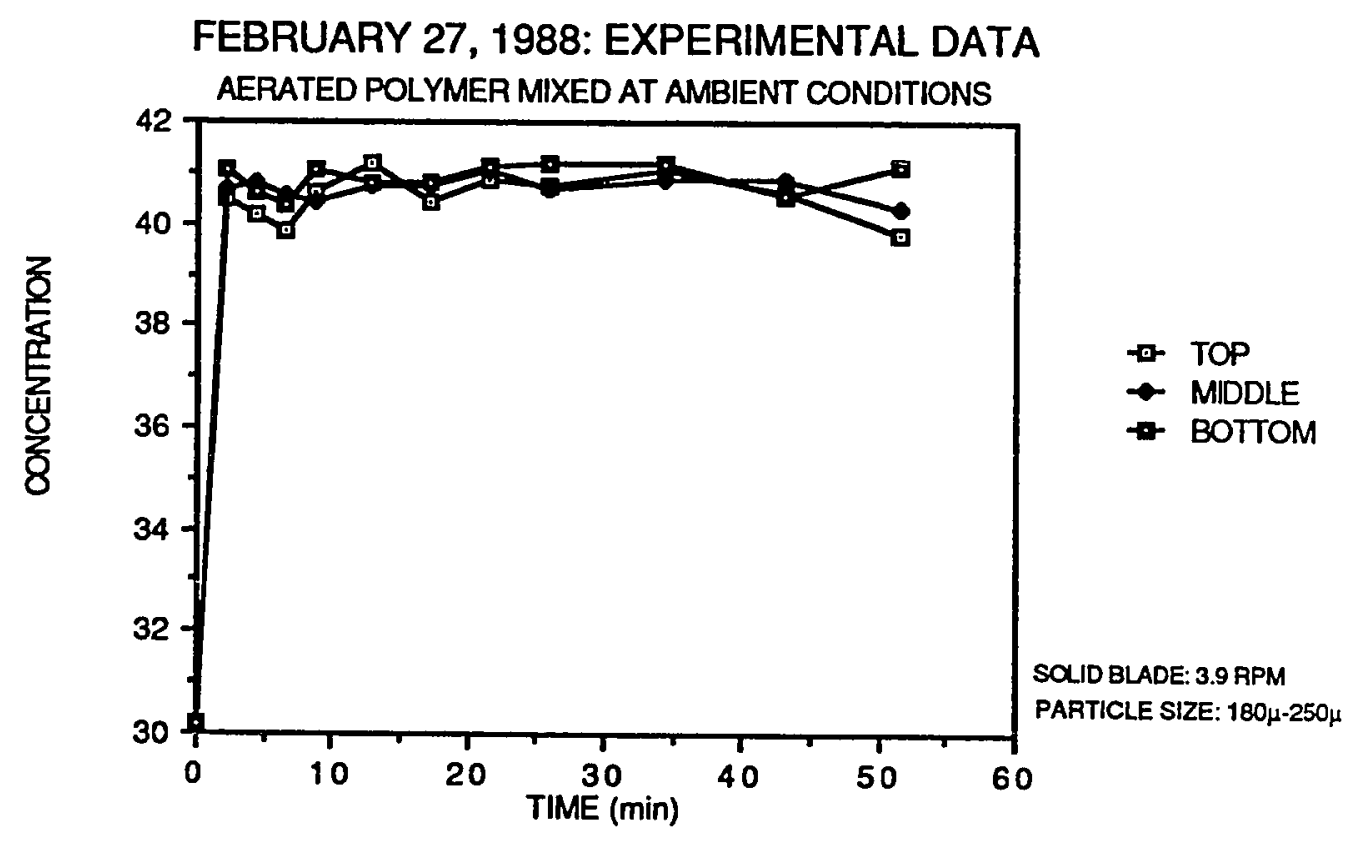


FIGURE 27

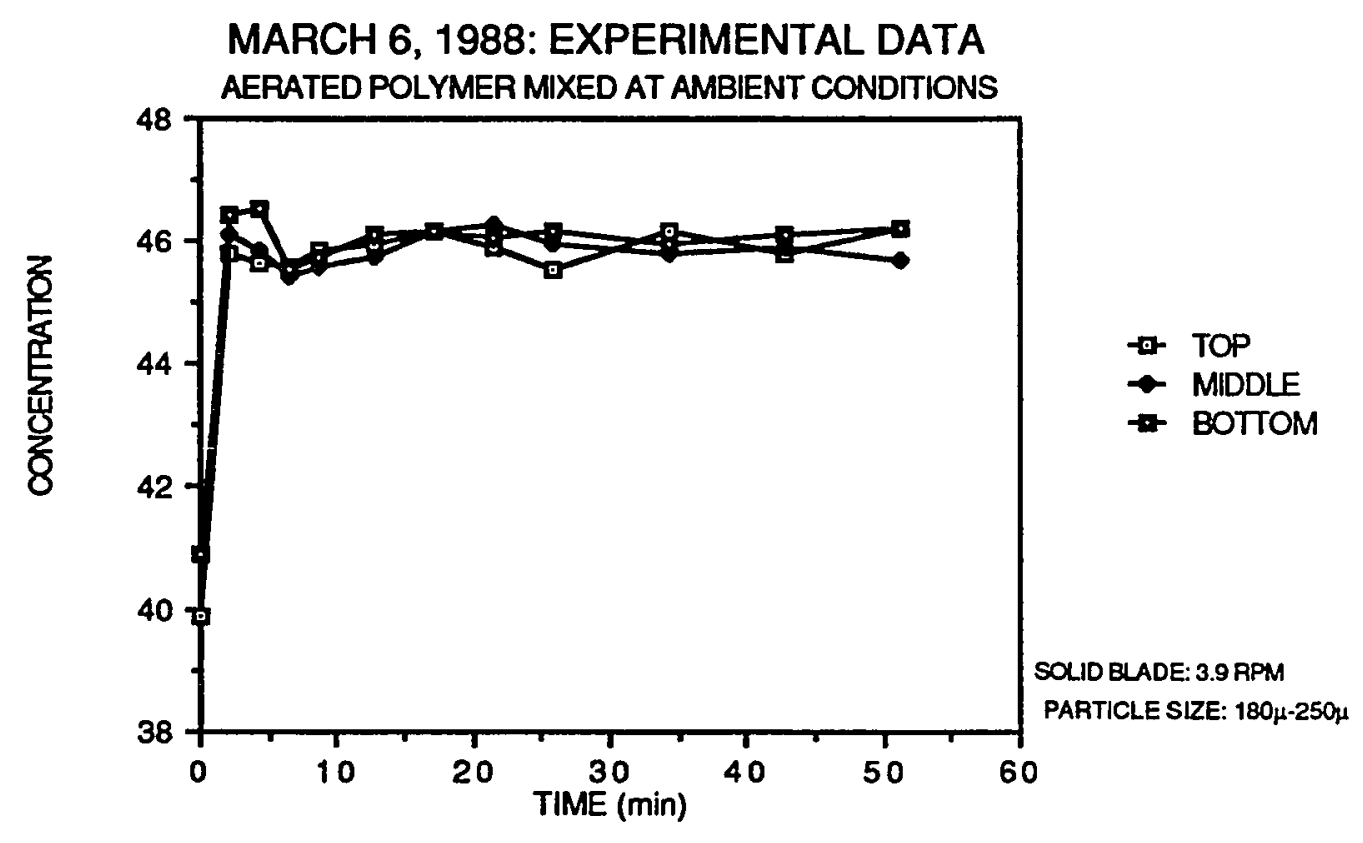


FIGURE 28

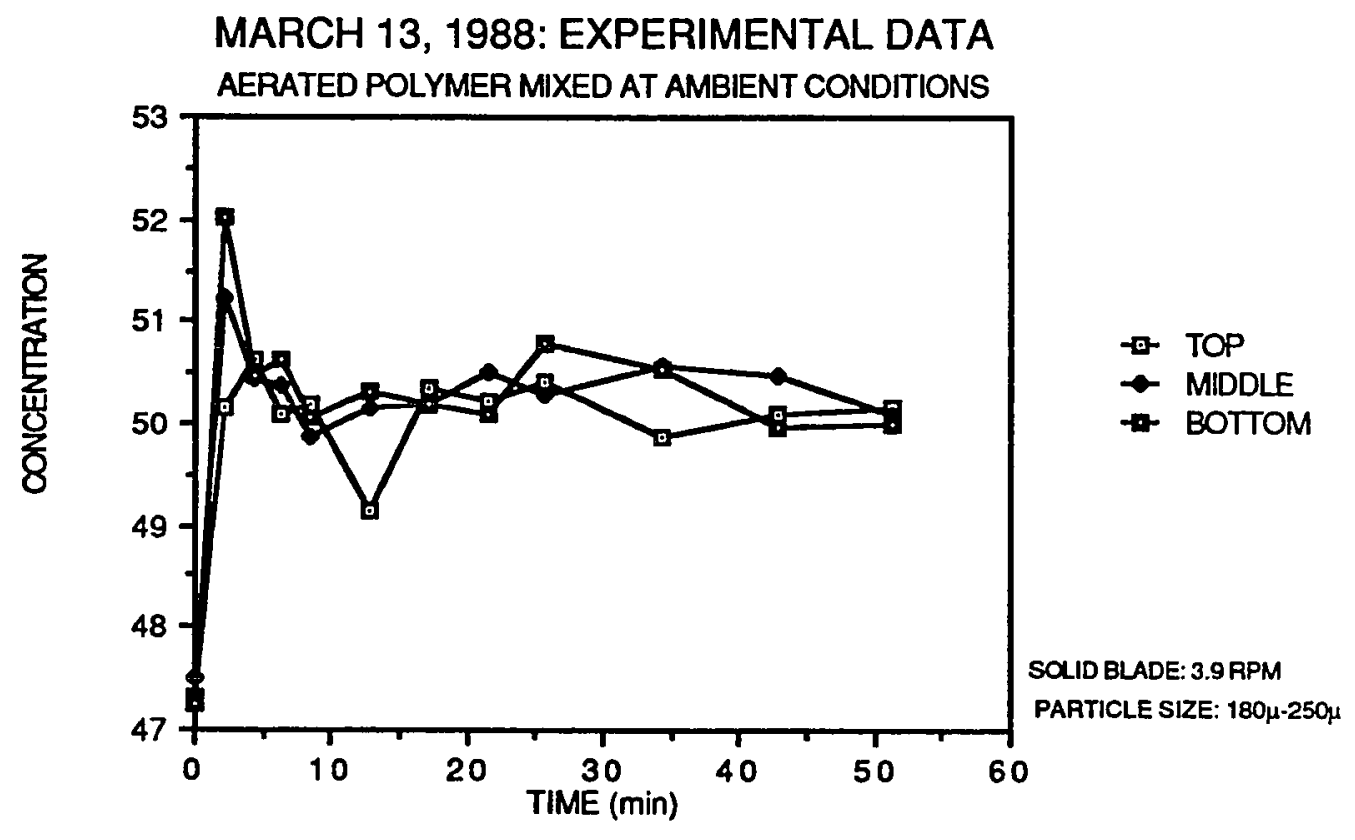




\section{FIGURE 29}

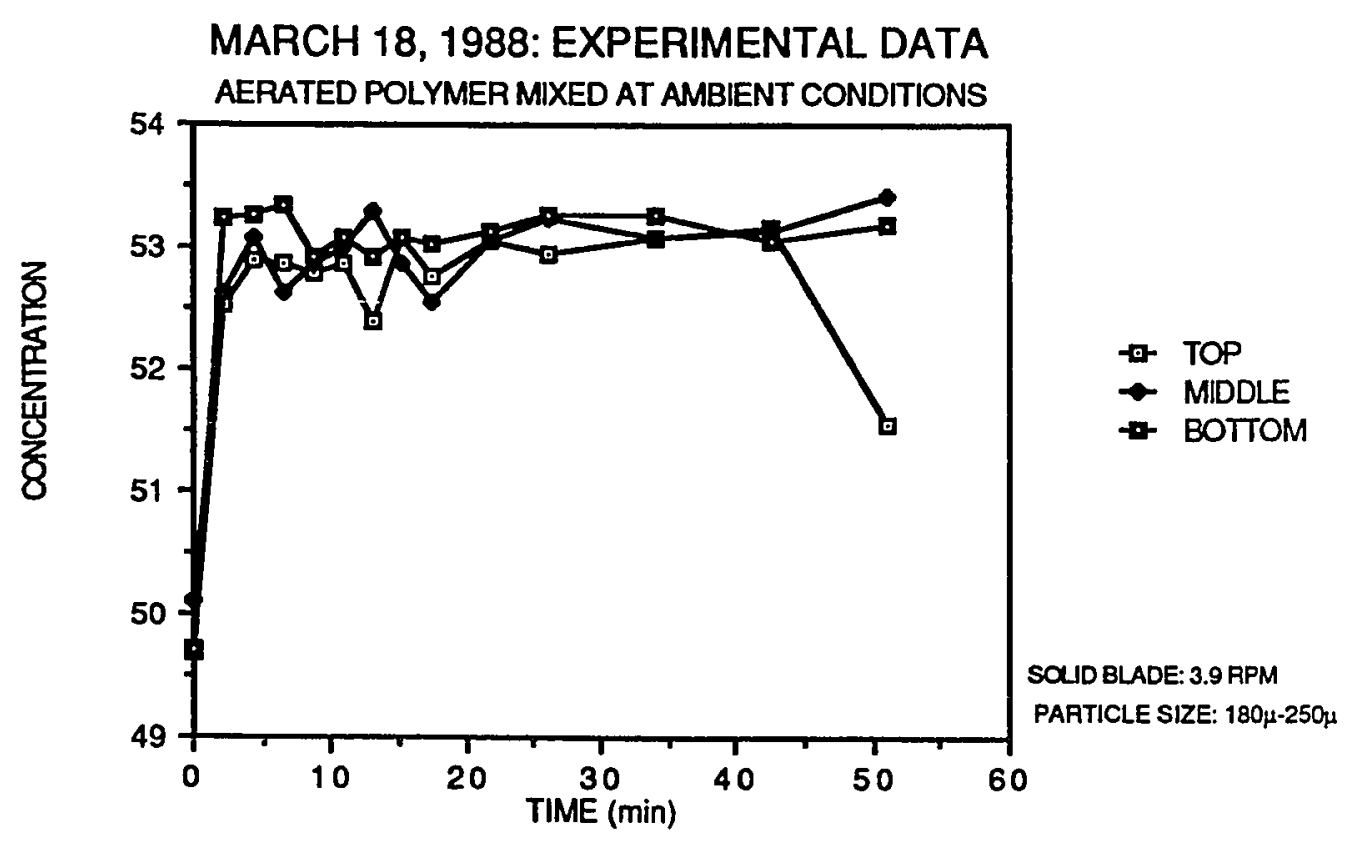


TABLE 13

VISCOSITY OF MIXTURES OF POLYBUTADIENE AND AMMONIUM SULFATE (SIZE $<75$ MICRONS)

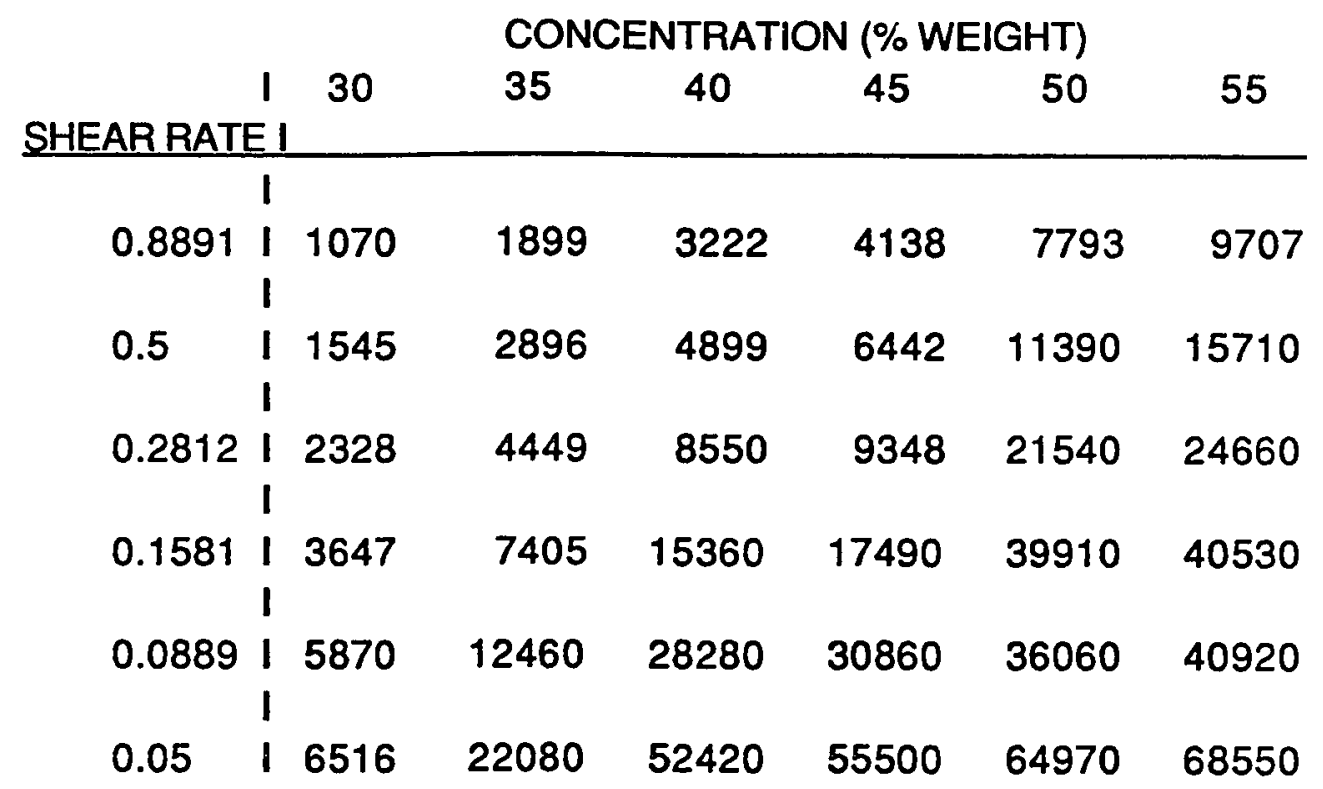

- Viscosity in units of poise.

- Viscosity analysis courtesy of United Technologies Chemical Systems.

- Testing performed with a mechanical spectrometer (Rheometrics Inc., RMS800) at ambient conditions. 
TABLE 14

VISCOSITY OF MIXTURES OF POLYBUTADIENE AND

AMMONIUM SULFATE (75 MICRONS-150 MICRONS)

\begin{tabular}{|c|c|c|c|c|c|c|c|}
\hline & & & CON & ENTRATI & N (\% WE & GHT) & \\
\hline SHEAR RATE & $\begin{array}{l}1 \\
=1\end{array}$ & 30 & 35 & 40 & 45 & 50 & 55 \\
\hline & I & & & & & & \\
\hline 0.8891 & $\begin{array}{l}1 \\
1\end{array}$ & 1018 & 1286 & 1799 & 3202 & 4977 & 7407 \\
\hline 0.5 & $\begin{array}{l}1 \\
1\end{array}$ & 1388 & 1787 & 2521 & 4758 & 7955 & 11470 \\
\hline 0.2812 & $\begin{array}{l}1 \\
1\end{array}$ & 2010 & 2641 & 3703 & 7366 & 13380 & 17320 \\
\hline 0.1581 & I & 3041 & 4099 & 6027 & 12210 & 23180 & 31520 \\
\hline 0.0889 & I & 4745 & 6696 & 9600 & 21210 & 39420 & 49100 \\
\hline 0.05 & I & 7422 & 10900 & 16620 & 32290 & 38350 & 55930 \\
\hline
\end{tabular}

- Viscosity in units of poise.

- Viscosity analysis courtesy of United Technologies Chemical Systems.

- Testing performed with a mechanical spectrometer (Rheometrics Inc., RMS800) at ambient conditions. 
TABLE 15

VISCOSITY OF MIXTURES OF POLYBUTADIENE AND AMMONIUM SULFATE (180 MICRONS-250 MICRONS)

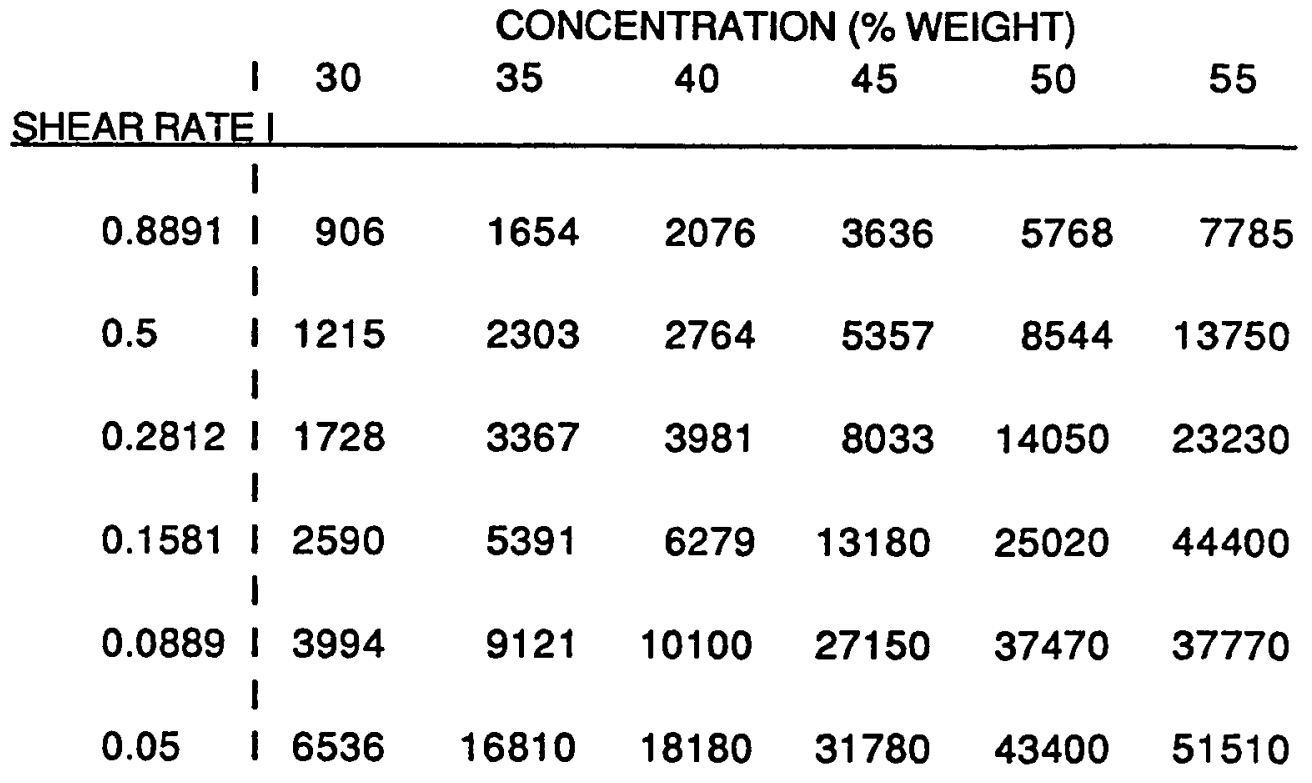

- Viscosity in units of poise.

- Viscosity analysis courtesy of United Technologies Chemical Systems.

- Testing performed with a mechanical spectrometer (Rheometrics Inc., RMS800) at ambient conditions. 
TABLE 16

CONCENTRATIONS AND PRESSURES FOR VISCOELASTICITY

$\begin{array}{cc}\begin{array}{c}\text { BY SOLIDS ADDITION } \\ \text { SOLIDS } \\ \begin{array}{c}\text { SONCENTRATION } \\ \text { (WEIGHT \%) }\end{array}\end{array} & \begin{array}{c}\text { SYSTEM } \\ \text { PRESSURE } \\ (\mathrm{mm} \mathrm{Hg})\end{array} \\ 55 & \\ 57 & 760 \\ 59 & 531 \\ 62 & 247 \\ 64 & 89\end{array}$

\begin{tabular}{cc}
\multicolumn{2}{c}{ BY POLYMER ADDITION } \\
SOLIDS & SYSTEM \\
CONCENTRATION & PRESSURE \\
(WEIGHT \%) & $(\mathrm{mm} \mathrm{Hg})$
\end{tabular}

59.4

303

63.1

252

65.3

201

66.4

99

69.1

23

- Data courtesy of Maurino Flora. 